\title{
Making Connections 3D printing, Libraries and augmenting their reality.
}







\title{
Making Connections
}

\author{
By Dylan John Hughes-Ward
}

A 90 point thesis submitted to the Schools of Architecture \& Design, Victoria University of Wellington. In fulfilment of the requirements for the degree of Master of Design innovation.

2016 
Acknowledgements 
I would like to extend thanks to my supervisors Simon Fraser and Tim Miller for their continued support and for allowing creation of oddball ideas. Your advice along the way was invaluable.

To The National Library of New Zealand Te Puna Mātauranga o Aotearoa for its continued support of this research and providing an excellent context to it, especially Peter Rowlands and his team for their insight on collections and assistance in nurturing creativity.

To Jan Farr and Pamela Allen, thank you for allowing the use of your great book as a case study for this research project. Jan, thank you for taking the time to visit and for your involvement in the process. Without your support this thesis could not have taken the path it did.

To my parents Alun and Gilli, your confidence in me and visits have been a great support that I'm very thankful for. Alison, thank you for listening to all my studio day stories and helping pull me away from the stress.

To my studio colleagues, it has been great working with you, I wish you all the best in the future. Lastly, thank you to all my friends for your support along the way. 
Abstract 
Digital technologies have initiated a global shift in the way we conceive, configure, and exchange information. This shift is occurring on many levels and is impacting the way many organisations operate; including Libraries. "Individuals and organizations now have many sources alternative to those provided by libraries, which would suggest that the role of libraries is shrinking. However, libraries are expanding to include a wider array of services, such as providing digital libraries and support for distance learning" (Borgman, 2003, p. 653). As they continue to re-examining their role, many libraries are currently exploring 3D printing in the form of "makerspaces" in an attempt to engage people in the library environment. Doing this raises the question "But why exactly is it appropriate for a library service to provide 3D printing?” (Rundle, 2013).

In response to the question, this thesis explores the role that $3 \mathrm{D}$ printing may take in making connections between collections and people in new and interesting ways, beyond the typical application as a "makerspace" (Cavalcanti, 2013). In doing so it acknowledges that $3 \mathrm{D}$ printing does not exist in isolation and that its real potential to enhance both content and collections might best be realised in combination with the many other forms of $3 \mathrm{D}$ and $4 \mathrm{D}$ digital media and systems that are emerging at an exponential rate. This thesis speculates on what that potential may be, through a series of design scenarios that simulate future possibilities of $3 \mathrm{D}$ printing and Augmented Reality.

The National Library of New Zealand Te Puna Mātauranga o Aotearoa provides the context for this exploration and the opportunity to demonstrate how revisiting their collections with reference to these new technologies can empower its mandate to "collect, connect and co-create knowledge to power New Zealand" (National Library of New Zealand, 2015). 
Table of contents 
Table of Contents $\quad X$

Introduction

Context Analysis

Libraries

Technology

4

5

(a) $3 D$ printing 6

(b) Augmented Reality 7

Smart Object

9

Methodology

14

Smart Object Reviews

22

Maaike Roozenburg $\quad 26$

Dundee central library $\quad 28$

Quiver 30

LEGO catalogue $\quad 32$

Smart object Case Analysis 39

Initial Designs

44

Storyboard 1

Storyboard $2 \quad 50$

Storyboard 3

Storyboard 4

Storyboard key insight $\quad 56$

Collections analysis 60

Areas of interest 61

Specific areas 67

Scenario development $\quad 72$

Scenario 1

Scenario 2

Scenario 3

Conclusion 88

Figures List $\quad 92$

Reference List $\quad 94$

Appendix 102

Appendix (a) 3D modelling $\quad 103$

Appendix (b) Cases 120 



\section{"Without Libraries, what do we have? We have no past and no future." Ray Bradbury}


Introduction 
Over a university break I was lucky to gain a summer scholarship with two classmates, to work with the National Library of New Zealand hereafter referred to as "the Library" (Department of Internal Affairs, 2016). We were tasked to "explore the potential of 3 D printing to create enhanced information experiences for visitors."

Over the Summer Scholarship we discovered how 3D media is more effective in a library when it is used to aid learning, enhance narratives, and encourage interactive engagement with existing collections. We found that the most successful interactions with 3D printers were those that connect the user with other forms of digital media. These include augmented reality, gesture interaction, and other user interactive media that enable visitors to engage playfully within the library space while discovering and learning. We explored four scenarios that demonstrated how these technologies facilitated interactions with the Library's collections (National Library of New Zealand, The digital archive of the future $\mid$ Blog).

During the Summer Scholarship it also became evident that 3D printing and "makerspaces" are a polarising topic within libraries (Colegrove, 2013), and so was worthy of further investigation. This encouraged me to consider a more specific and in-depth investigation into the core of Library's business, questioning how 3D printing, related technologies and media can be used to better connect people and collections.

This project started by exploring and cataloguing the current use of $3 \mathrm{D}$ printing and other relevant media technologies in libraries. It included the many digital technologies that have developed alongside $3 \mathrm{D}$ printing that make the technology more accessible, such as $3 \mathrm{D}$ scanning, computer aided design (CAD) software, as well as the online platforms, networks, and service providers that facilitate its uptake. The research also expanded on the other forms of 3D and 4D digital media such as Augmented Reality (AR), Virtual reality (VR) and 
sensing technologies, often in the form of smart objects and replicas, which are becoming more evident in library practice.

An important consideration in parallel to this research was identifying items or data from the Library that lend themselves to interpretation as $3 \mathrm{D}$ prints. This formed the basis for developing scenarios of use: to demonstrate how 3D printing might be connected to archival data and, in doing so, how it might be used in turn to enhance the data, and thereby open up the Library for new and more engaging forms of interaction. 



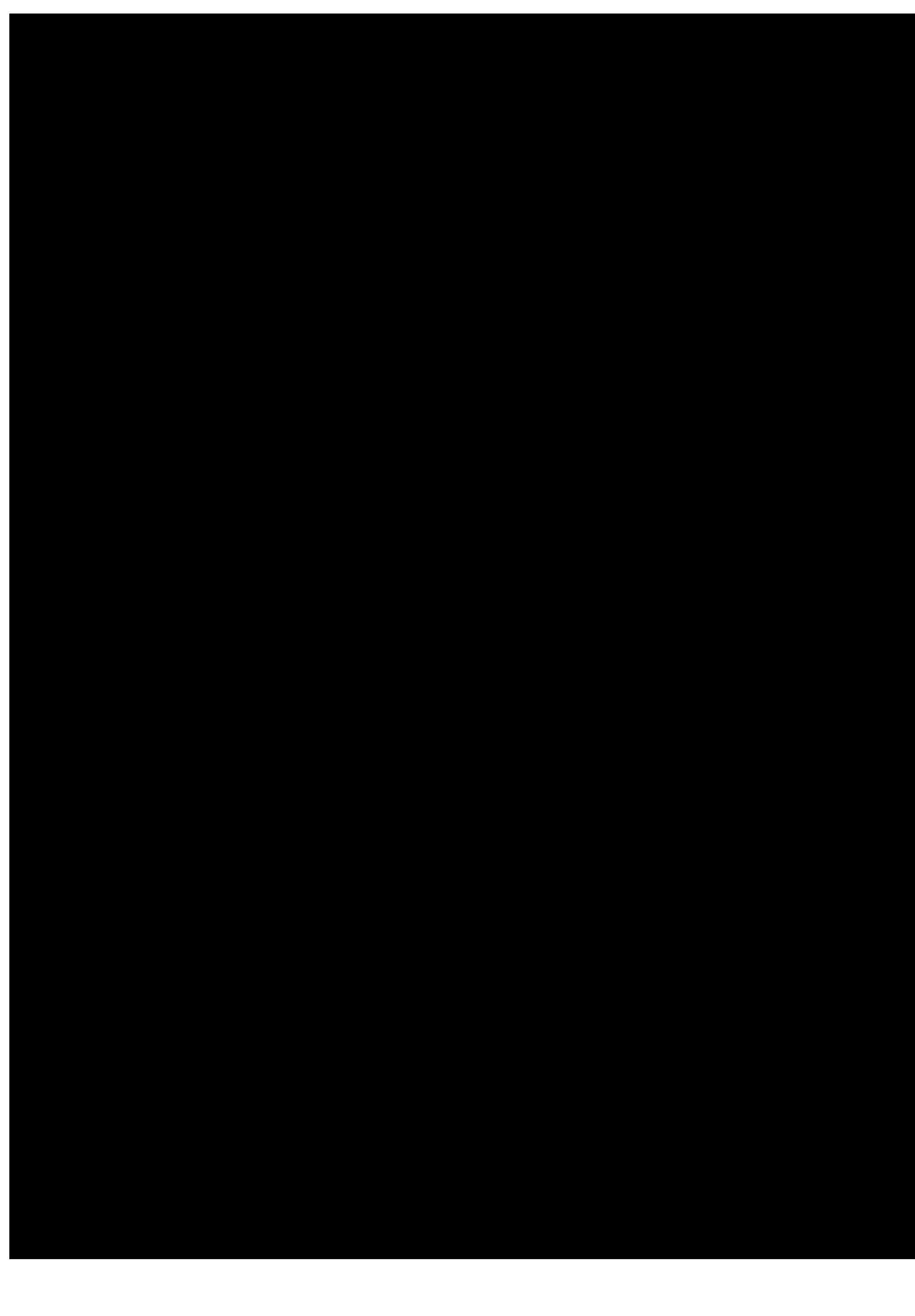




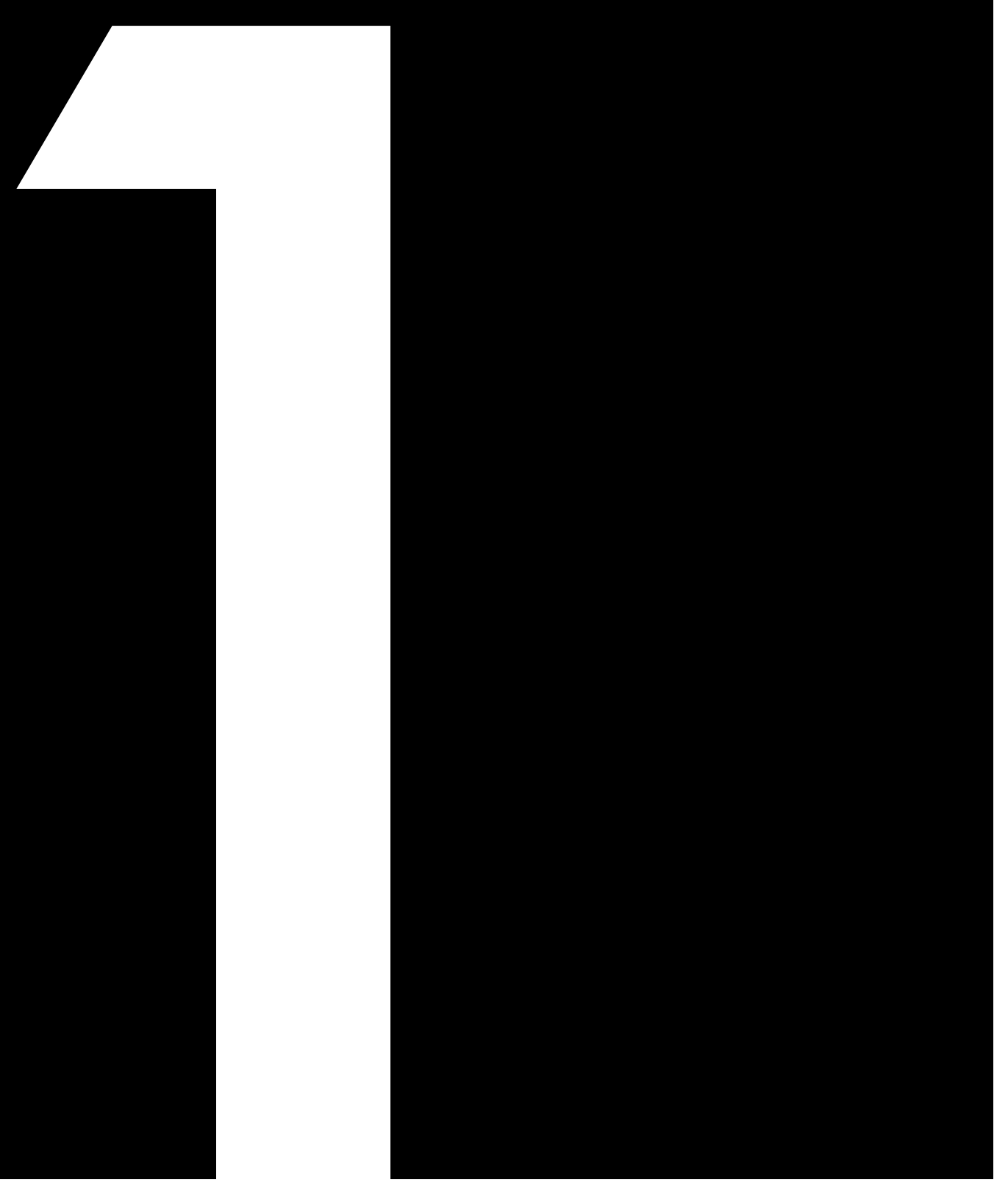


Context Analysis 
This context analysis explores three key aspects in reference to the research question: Libraries (more specifically The National Library of New Zealand), technology, and smart objects.

\section{Libraries}

Libraries' roles are changing because of the shift in information communication (Lougee, 2002). This can be seen in the shifting definition of libraries, from organisations defined "largely by the functions of collection development and management." (Lougee, 2002, p. 5), to organisations that "provide resources for not only consuming information, but also for generating new information and research.” (Pryor, 2014, p. 2).

This shift places the modern library as a service provider of knowledge to create new knowledge, rather than an information collection. As service providers, most libraries give public access to books, computers, the internet, and printing. However, contention surrounds including new technologies within their services. Libraries are adopting a view that there is no business case for the inclusion of new technologies; some are even dismissing these new technologies, specifically 3D printing, as simply "technolust" (Rundle, 2013). Counter to this, R. David Lankes of Syracuse University's School of Information Studies states in his blog post Beyond the Bullet Points: Missing the Point and $3 \mathrm{D}$ Printing, that at the core of the library is idea creation and knowledge generation and that a $3 \mathrm{D}$ printer is simply another tool, just like the computer, to allow creation (Lankes, 2013).

With the Library providing the context for this research, it is important to understand libraries' role within New Zealand. The Library's job is "to collect, connect, and co-create knowledge to power New Zealand. Collect: New Zealand's documentary taonga in words, sounds, and pictures are collected, protected, and accessible. Connect: New Zealanders can easily access national and international resources through knowledge networks. Co-create: New Zealanders working together to turn knowledge into value" (National Library of New 
Zealand, 2015). This statement shows how the Library's role compares to the traditional definition of a library, with three keywords as part of its mandate, "Collect, Connect, and Co-Create." This mandate captures the Library's goal of co-creation and how it relates to the shifting definition of libraries, putting the Library into the domain of Pryor's definition as a resource for consuming and also generating new knowledge. This is an interesting place to be situated contextually, as it gives the Library a strategic basis from which to venture into new areas to fulfil its mandate.

One of these new areas of technology is $3 \mathrm{D}$ printing, a service being offered by more and more libraries around the world. Auckland Central City Library, University College of London's Petrie Museum, Dundee Central Library in Scotland, Southern Illinois University Edwardsville's Lovejoy Library, and The New Zealand National Library are just a handful of the libraries offering 3D printing. These libraries experimenting with 3D printing are using it in different ways, from makerspaces (Maloney, 2014), to 3D printing children's book characters (The Courier Reporter, 2014). Currently the Library is exploring giving the public access to $3 \mathrm{D}$ printing with three UP! 3D printers (National Library of New Zealand, n.d. 2016).

\section{Technology}

(a) 3D printing

Far from being a new technology, 3D printing technology has been around for 30 years (Warnier, Verbruggen, Ehmann, \& Klanten, 2014) and initially made its way into mainstream manufacturing in the form of rapid prototyping. 3D printing comes in a range of forms that are often referred to as additive manufacturing. This refers to a process where material is slowly built up layer by layer as defined by a digital computer aided design (CAD) file to reveal the desired form (Warnier et al., 2014). 3D printing is to some "the Holy Grail of the rapid-prototyping (RP) industry." (Ashley, 1997, p. 82) as there is minimal waste from only building up the form you want, as opposed 
to traditional subtractive manufacturing where material is removed to reveal the desired form.

The most common 3D printers are fused deposition modelling (FDM) printers, which use a variety of coloured plastics that are heated and extruded in layers to form the object. Recently FDM printers have attracted popular attention, with companies such as MakerBot and 3D systems (3DS) making low-cost 3D printers - the Makerbot replicator and UP! Printer respectively. Both these printers are commercially available for around NZ\$2000 (PB Tech, 2016). However, much more advanced $3 \mathrm{D}$ printers are also in use, which allow highly detailed full colour 3D models to be printed. The range of materials being used for 3D printing is developing quickly (Lipson \& Kurman, 2013, p. 264), with different materials such as metals and ceramics as well as a large variety of plastics now on offer. The advent of low-cost printers would not have whetted public appetite for $3 \mathrm{D}$ printing without the availability of the many associated technologies. Advances in CAD, 3D scanning, and online 3D printing services have created the platform on which $3 \mathrm{D}$ printing could flourish. The many options available for these technologies (Solidworks, Rhino, 3DS, Maya, Zbrush, Sketch up, 123D, Blender, TinkerCAD, FreeCAD, Meshmixer, 123D design and Onshape, 3D scanning, 3D Systems' iSense 3D Scanner, Artec Eva 3D Scanner, MakerBot Digitizer 3D Scanner, Dynascan M250) have all played a significant role in breaking down barriers to 3D printing. This reduced threshold for entry and the advent of the makerspace has encouraged a slew of libraries, all seeking new ways of engaging with their public, to engage in $3 \mathrm{D}$ printing.

(b) Augmented Reality

Augmented Reality (AR) is a technology used to overlay digital content onto physical reality (Azuma et al., 2001). AR uses image tracking, a display unit, scripts, and a software engine to create a 3D representation of a digital model within the physical world (Billinghurst, Clark, \& Lee, 2015). AR uses a reader to track a 2D 
printed marker such as a Quick Response code $(\mathrm{QR})$ or other unique identifier that the engine has been trained to recognise (Billinghurst et al., 2015). The marker, through the engine database, is linked to a digital 3D model that is shown over the marker on a digital display as it would appear in the 3D digital space. From there this model can be interacted with on the display and navigated around in the $3 \mathrm{D}$ digital world.

Like 3D printing, augmented reality devices are not new technology and have existed in some form since the 1960s (Azuma et al., 2001) originally as dedicated devices for reading and displaying AR, usually attached to a computer that runs the AR engine. There has been much exploration into AR and possible applications since the 1960s (Billinghurst et al., 2015). It now holds an interesting place in culture, with mainstream applications of AR in sports such as sailing (Honey, Milnes, 2013) to display information live while races are occurring. With the development of smart phones the technology once reliant on dedicated reading devices rapidly became pocket sized and smart phones are now a viable option for AR (Wagner, Schmalstieg, 2009) with the reader, display and engine all in one. This advancement initiated the development of mobile apps that utilise this compact reader and display in one, such as Layar, Google Translate live, Crayola Color Alive, IKEA catalogue and the Lego Catalogue.

AR offers opportunities for interaction and content exploration through a digital interface. AR is a way for people to connect with digital content in the physical world, beginning to integrate the digital into physical (Azuma et al., 2001). Exploring digital content in a physical world through digital representation is something worth investigating for libraries and museums with ever-expanding collections of digital content. Applications of augmented reality are becoming increasingly popular in libraries and museums (Pence, 2010) and offering the opportunity to "connect" the digital and physical supports the mandate of the Library. 


\section{Smart Object}

"A Smart Object is able to acquire, to receive and to distribute information in a near or distant environment, and is able to carry out diverse actions on its own initiative or request help from others objects" (Bajic, 2009, p. 37). The concept of smart objects has existed for some time, from ubiquitous computing in 1993 by Mark Weiser, to more recently with the popularisation of the term smart object. These terms refer to the connection of multiple devices to a network to generate information and allow the devices to adapt over time to the context (Goumopoulos, Kameas, 2009).

Like many technologies, the smart object is becoming ubiquitous and expanding increasingly into new areas (Vasseur, Dunkels, 2010). The adaptive nature of smart objects is evident in their uptake into everyday life, as can be seen from the onslaught of smart fridges, smart washing machines, smart TVs, smart shoes, and smart phones. Smart object use has expanded to the point where it must be asked, why the proliferation and what do they offer? This question is answered in part by research into the potential of smart objects in different areas $(\mathrm{Hsu}$, 2011; Kimura, Nakajima, 2009; Praca, Barral, 2001; Roozenburg, 2013; Sinha, Couderc, 2013). A growing number of smart objects are also demonstrating commercial success such as Hue, Sonos, WeMo, Nike +, fitbit, nest, smart TV, Withings Body Scale, and Koubachi.

Smart objects have also been used to facilitate tracking and provide easy access to information. The first documented smart object dates back to 1982, when engineering students at Carnegie Mellon University connected a vending machine to the internet to check the availability of cold drinks (Madakam, 2015).

This led to the development of interconnected devices to gather information and generate data, and from this the internet of things (IOT) emerged. The IOT is defined as an open network of intelligent objects that can share information and react to situations or changes in 
their environment (Madakam, 2015).

Many different technologies are utilised in the development of smart objects and the IOT, such as Bluetooth low energy (BLE), Radio Frequency Identification (RFID), Near Field Communication (NFC), Global Positioning Systems (GPS) and wireless. As a result, the use of smart objects and the IOT has blossomed. Its impact is made visible though sites such as https://thingful.net/. However, the role of smart objects in libraries is still new territory. Becker (2012) discusses this in Get Smart: Raising the Intelligence of DIY Library Smart Objects, where he investigates libraries' potential to be a space where people are introduced to smart objects. This evolving use of smart objects encourages further exploration to provide new experiences and interactions. 



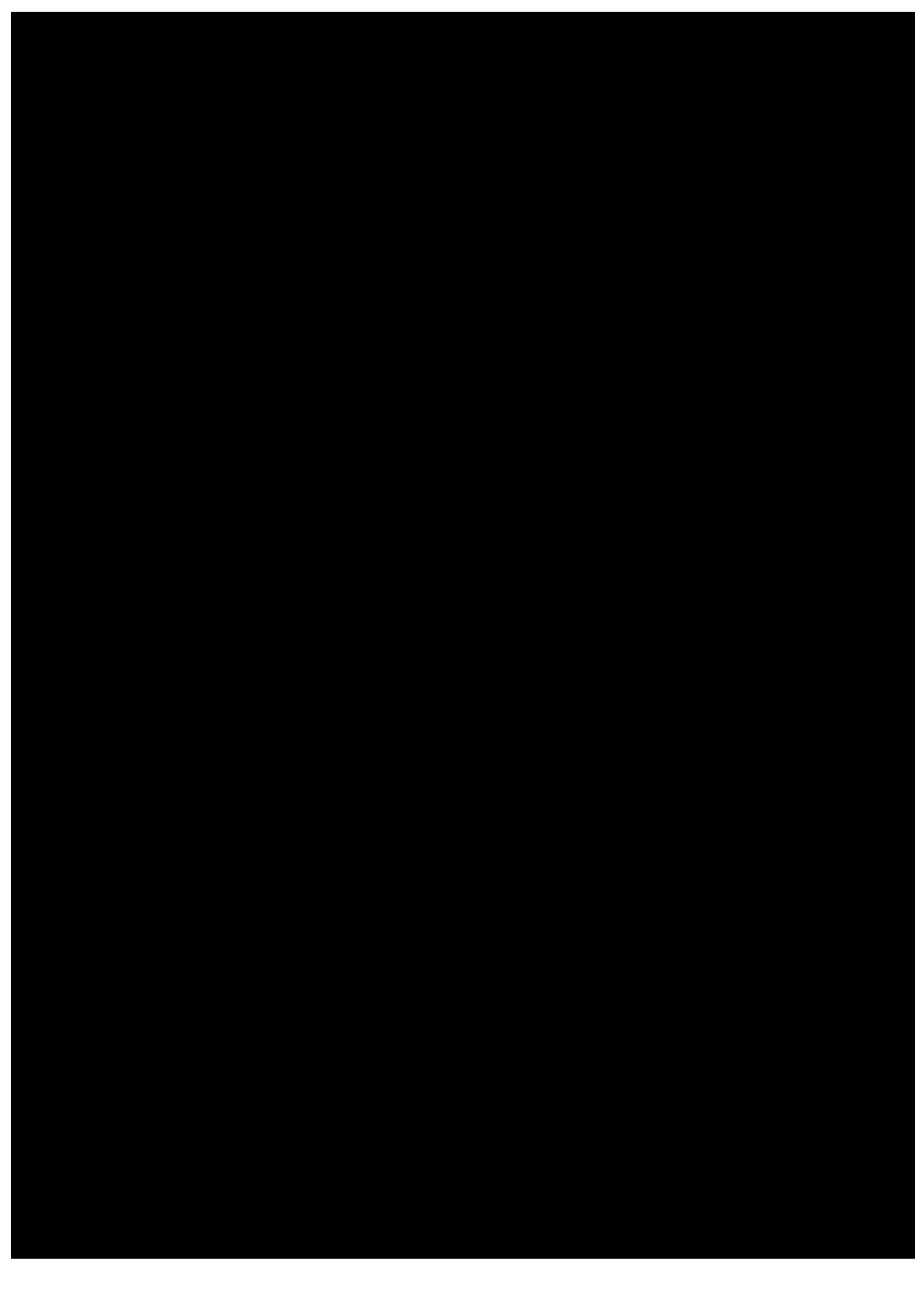




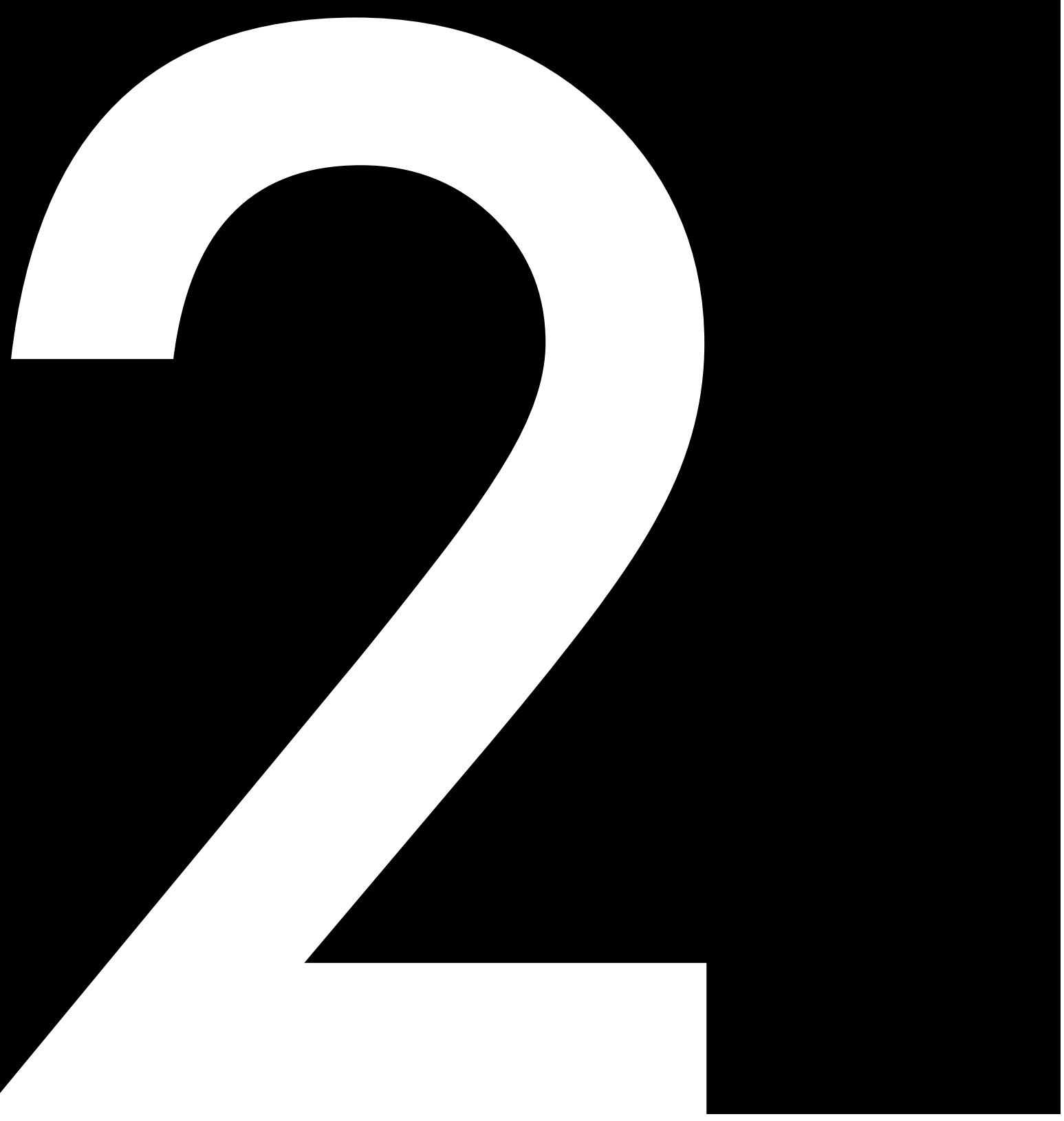


Methodology 
"Research in a design context breaks with the determinisms of the past; it continually challenges, provokes and disrupts the status quo." Milton, Rodgers. 
This chapter provides an overview of the methodologies used in the thesis to investigate the topic. More detailed documentation of the research process and outputs is captured elsewhere in this document under the respective chapter headings.

\section{Chapter 1: Context analysis}

The use of literature reviews and background research was key in developing the scope of the research. A clear contextual understanding surrounding libraries revealed both issues and opportunities and helped to focus the research topic.

The literature review initially looked into the operating context for libraries: how information technologies are precipitating change and how libraries are responding to their changing circumstances. It also introduced the technologies that libraries are adopting in order to meet the challenge. The literature review revealed that although 3D printing is a topical technology, augmented reality and smart objects are also finding increasing importance in providing access to information.

\section{Chapter 3: Smart Object Analysis}

In response to the initial literature review, smart objects and other relevant technologies were evaluated in greater depth using Artefact Analysis "to discover interactive and aesthetic elements of current design precedents" (Collier \& Collier, 1986). Similar to the background research it gave a clear but more detailed understanding of the current landscape of smart objects, AR technology, and 3D printing. The artefact analysis exposed the key aspects of each item and offered insights as to how these technologies might be connected.

\section{Chapter 4: Storyboards}

Storyboarding was used to generate and showcase initial ideas. It was used to develop, recontextualise, and connect ideas revealed during the literature review and artefact analysis. Storyboarding opens up opportunities to challenge current uses and generate ideas at a rapid pace. 
Four storyboards were used to illustrate speculative connections between contextual and technical consideration, and potential users to spark ideas for further development. Storyboarding addresses broad concepts and avoids the constraints imposed by detail. Therefore, it is a useful method for initial concepts; however, it lacks the clarity to create fully resolved ideas, thus limiting its use to the first phase of the research.

\section{Chapter 5: Content selection}

The Library's collection consists of over 30,000,000 unique items. Therefore, analysis of the collections for suitability was conducted through content analysis, in which a matrix of all collections was generated to identify the content of the main collections. This matrix was used to discover areas of content that are potentially best suited to $3 \mathrm{D}$ treatment, including photos, images, and drawings. Limiting this exploration to collections with these items reduced the exploration to a manageable area.

\section{Chapter 6: Design Scenarios}

Scenarios were used to develop the initial storyboards into realistic situations or systems of making. However, the scenarios are presented as speculative propositions that are nevertheless informed by the research into applicable technologies. In this respect, they are feasible but have not been implemented as functioning systems. This will require cross-disciplinary development of AR systems, apps, and content management systems along with implementing new connections to $3 \mathrm{D}$ printing. Testing would result in valuable feedback of how the designs would be used and interacted with; however, the scope of this research seeks to simulate feasible rather than functioning scenarios for the use of 3D printing as reference points for future development, rather than a fully resolved and functioning system.

Integral to scenario development was a final design phase iterative making in the form of $\mathrm{CAD}$ or parametric modelling. 3D prototyping 
was used to generate the final physical outputs. Variations of these methods were used to create a range of $3 \mathrm{D}$ printed artefacts in response to the selected content from the Library and the proposed scenarios in a tangible way. The physical outputs are intended to demonstrate how $3 \mathrm{D}$ printing can be used to expand on the original narrative in unexpected ways.

\section{Chapter 7: Analysis}

Analysis and critical reflection is used in the discussion and conclusion of this thesis to reflect on the process and outputs of this thesis. Assessing the strengths, weaknesses, limitations, and potential future development that could occur beyond this research includes reflection on the impact this research could have within the Library as well as the implications for a wider context. 



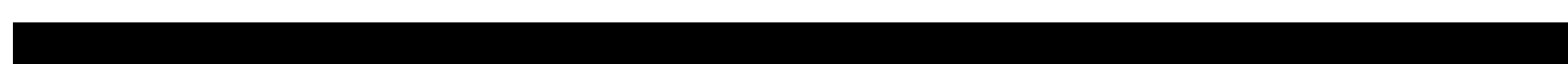




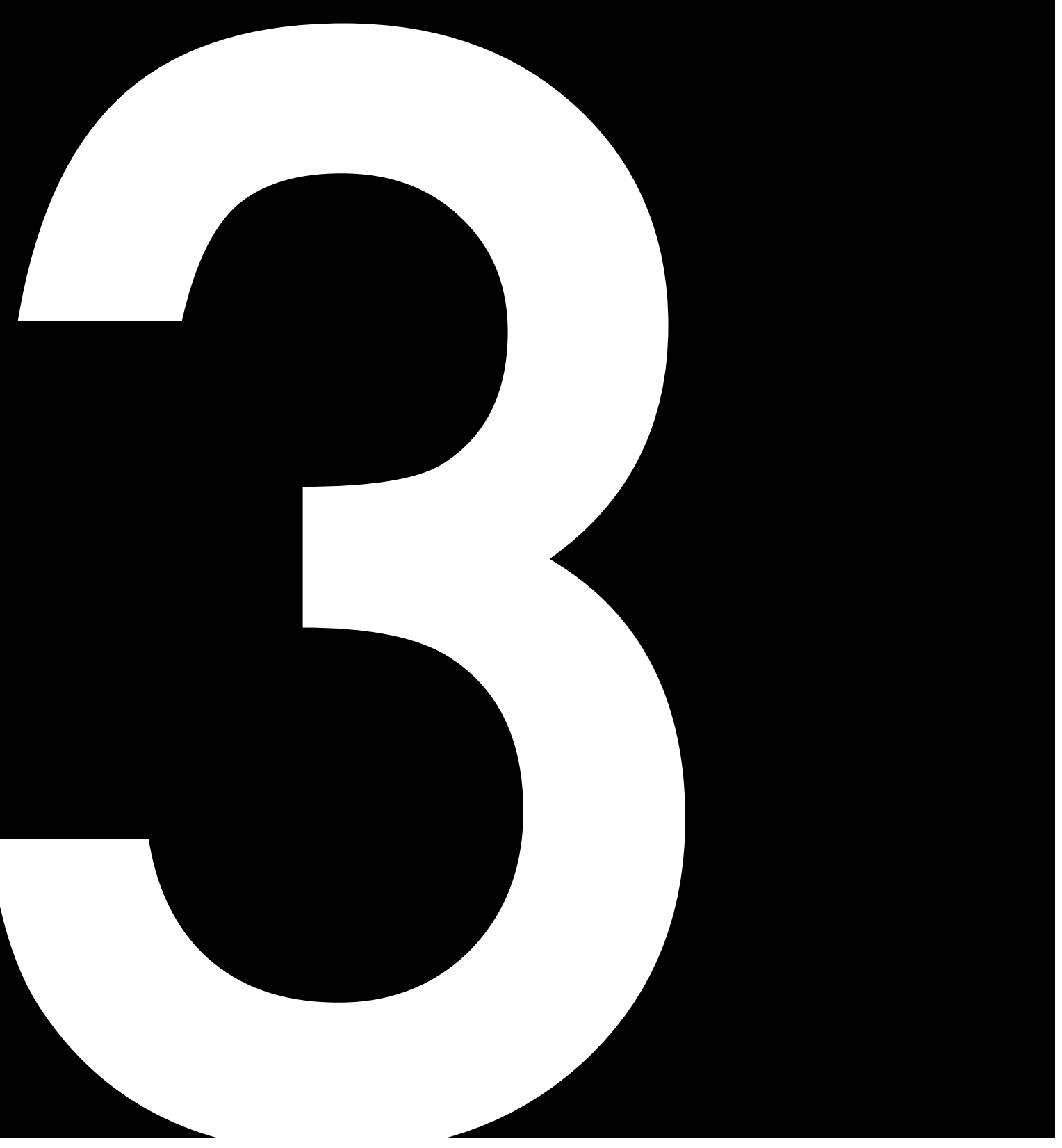


Smart Object Reviews 
To further develop a deeper contextual understanding of smart objects and surrounding technologies a selection of case studies were reviewed. This chapter includes the four key cases that had the most significant impact on the development of the project. A full list of case studies can be found in appendix (b). 

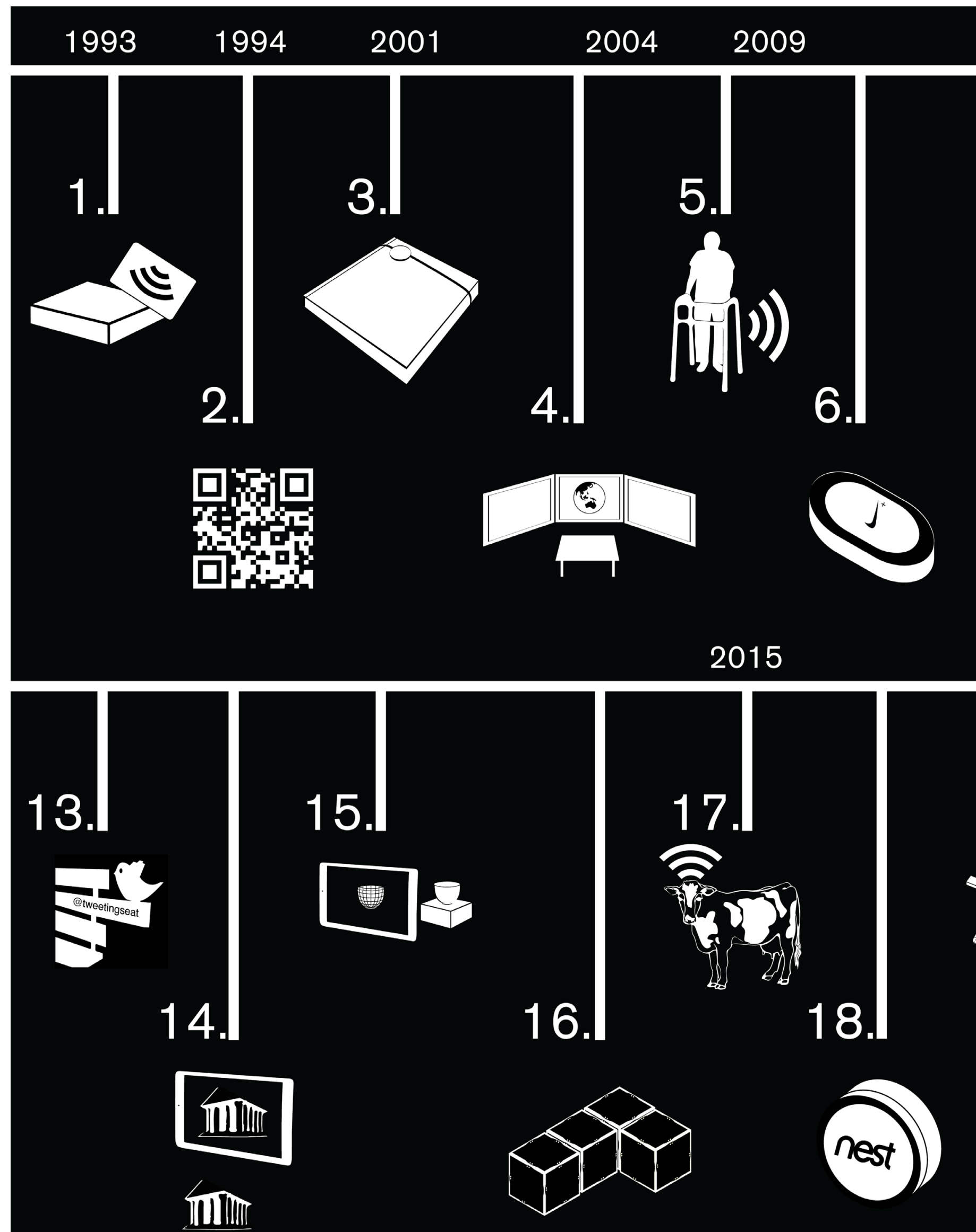

figure. 3-1 Timeline of a selection of smart objects, of which reviews can be found in appendix (b).

1.Radio Frequency IDentification (RFID), 1993 2.QR Codes, The Quick Response (QR) 1994. 3.MiME Tags, Philips,

2001. 4.Gaia, University Of Illinois, 2004. 5.Walky, Elena Nazzi 2009 6.Nike +, Nike, 2009. 7.Cence Me, A. T. Campbel

2009 8.Valle Giulia, Sorin Voicu, 2010. 9. Wolf Walk, North Carolina State University Library, 2013. 10.MemPhone, Bin 
Image Redacted

figure. 3-2 Maaike Roozenburg smart replicas AR app.

Image Redacted

figure. 3-3 Maaike Roozenburg original tea cups. 


\section{Maaike Roozenburg (2014)}

Maaike Roozenburg created 3D printed replicas of 17 th century tea cups for exhibition purposes and used augmented reality to connect and unlock different layers of information about the cups. The augmentation occurs with a digital overlay on top of the cup, created on screen using image tracking of the 3D printed cup. The cups are printed in Acrylonitrile butadiene styrene (ABS) with a FDM printer that captures only some details of the cup. The AR then shows the original cup in full detail while allowing the viewer to handle and engage with the replica. The augmentation also adds additional layers of contextual information to the cup. These smart objects give viewers a tactile interaction with the display item, allowing them to explore around items and discover new information using the cup and AR as the point of engagement.

This use of AR to overlay further contextual information about the collection item creates engagement with collections in new ways beyond the textual information typically used in a museum exhibition. Combining low resolution 3D printing with the ability to reveal the full detail of the cup creates an intriguing and tangible way of discovering content. 
Image Redacted

figure. 3-4 Dundee Central Librarian's with the 3D printed character.

Image Redacted

figure. 3-5 Dundee Central Librarian's with a 3D printer. 


\section{Dundee central library (2014)}

In the Dundee Central Library, in Scotland characters have been 3D printed from children's books and are used in the library's storytelling sessions. There is little explanation of how these models are generated, but it is likely they are made in-house by someone at the library who has $3 \mathrm{D}$ modelling experience.

Translating a drawing from $2 \mathrm{D}$ to $3 \mathrm{D}$ gives a new level of interaction with the story and the characters. The Dundee Library has limited their use of $3 \mathrm{D}$ printing technologies to what appears to be coloured sandstone, but this case study shows how $3 \mathrm{D}$ prints can be used to facilitate storytelling and encourage young children to read. The idea of models extending the learning experience is an important and effective way of bringing the narratives to life. 
Image Redacted

figure. 3-6 Quiver app in use.

Image Redacted

figure. 3-7 Quiver AR with sandstone 3D print. 


\section{Quiver (2013)}

Quiver is an AR colouring smartphone app created by HitLabNZ as an extension of their MagicBook (Billinghurst, Kato \& Poupyrev, 2001), which uses AR to bring a 2D image to life. Using a smartphone the user scans a $2 \mathrm{D}$ printed drawing to trigger the appearance of an animated AR model. The model can be altered by physically colouringin the $2 \mathrm{D}$ drawing. The colour from the image is picked up by the camera on the smartphone and mapped onto the AR model, creating a custom coloured model. This application offers a very interesting combination of digital and physical interactions that are very engaging. Quiver also has an educational version that is available for use in classrooms to show animated models and aid learning.

The technology used within this app combines a creative application of $A R$ and colour scanning in an engaging and rewarding manner. In the paper "An Interactive Augmented Reality Coloring Book" Hitlab introduces further uses of the app in its conclusion: "We believe that this technology would be a valuable tool for artists who wish to create $3 \mathrm{D}$ content but lack the necessary computer aided design skills. When combined with an automatic model generation technique, there are a number of possible fields which could benefit from this technology for example in architectural design, and rapid prototyping of 3D designs" (Clark \& Dünser, 2012). Quiver has briefly explored taking a further step from $\mathrm{AR}$ into $3 \mathrm{D}$ printing by $3 \mathrm{D}$ printing a colour version of one of the coloured-in models (Clark \& Dünser, 2012), clearly identifying opportunity to further connect the user to a physical output via AR 
Image Redacted

figure. 3-8 LEGO AR catalogue showing animation.

Image Redacted

figure. 3-9 LEGO AR catalogue app home screen. 


\section{LEGO catalogue (2014)}

The recent LEGO catalogue uses AR to create an experience around the catalogue itself. To do this LEGO has developed an accompanying app for its catalogue that is used to view an AR animated version of selected items in the catalogue. The animation instantly brings the item to life. This technology uses simple marker recognition of a golden LEGO block on each augmented page to load up the model. The inclusion of AR in the Lego catalogue is an interesting development from LEGO's first use of AR in stores (Liddane, 2012) that showed a completed model on a screen triggered by the original box. Through this app LEGO has created a quick and easy way to integrate purchasing items into the experience of catalogue browsing. The AR immediately brings the model to life in a way that is impossible to achieve from images and allows you to start building your own narratives into the item before buying. Over 1,000,000 downloads and 10,000 five-star reviews on the android app store $\left(\mathrm{LEGO}^{\circledR} 3 \mathrm{D}\right.$ Catalogue, 2014) demonstrate the popularity of the app. 


\section{Smart Object Technology}

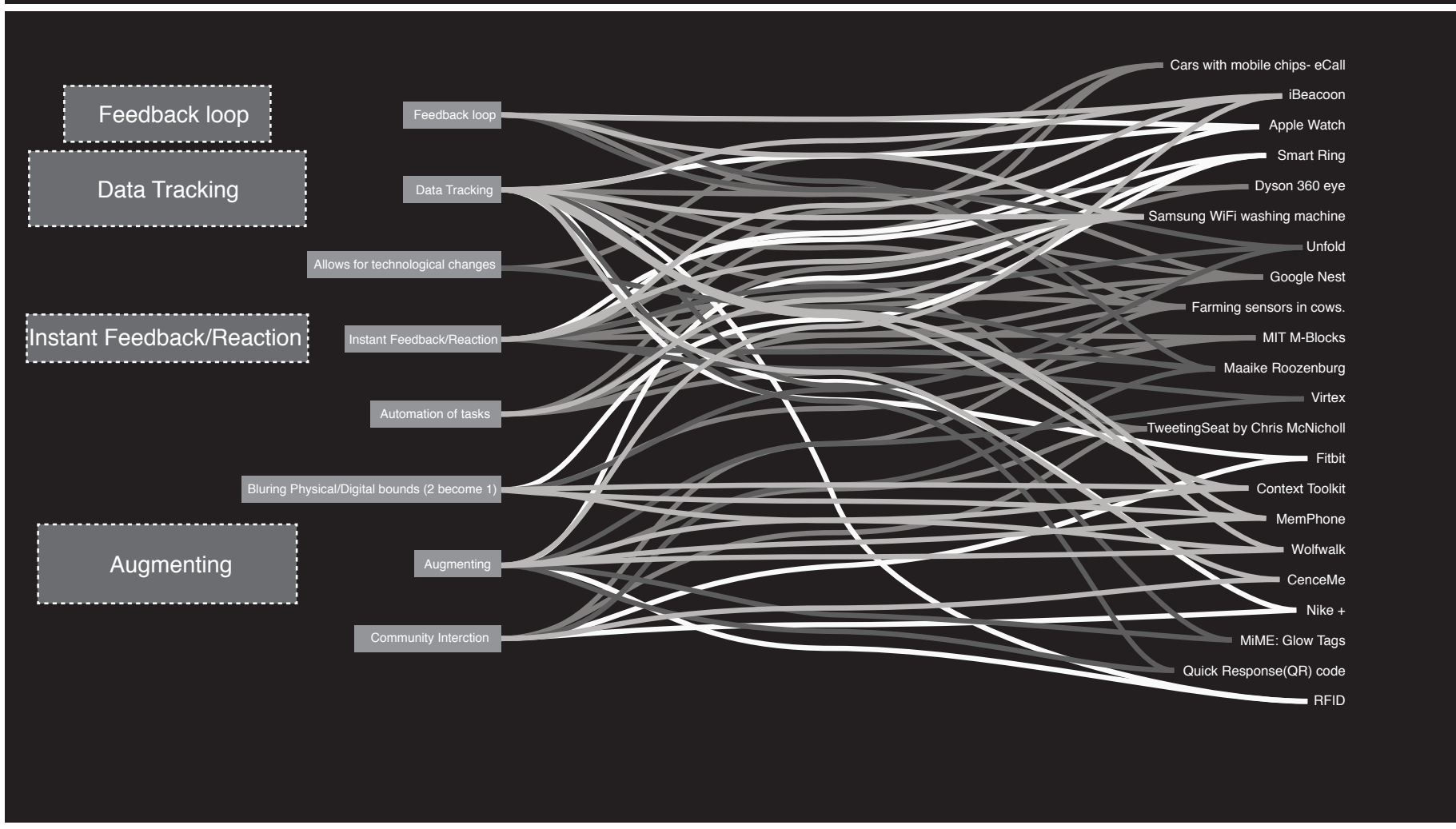

figure. 3-10 Smart Object Technology links. 


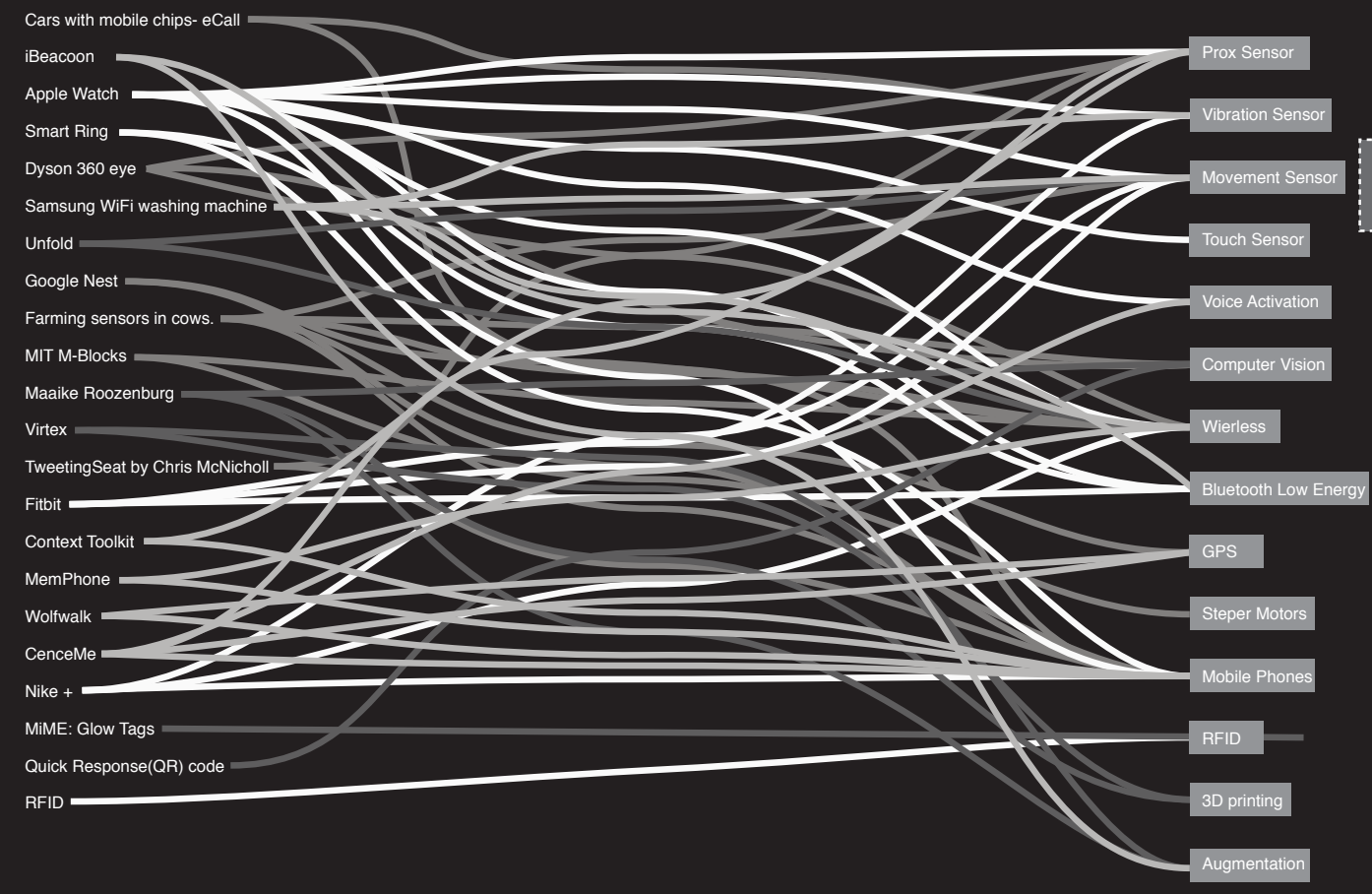

Prox Sensor

Movement Sensor

.

Wierless

Mobile Phones

M.................. 


\section{Smart Object Use and content}

\section{What content is used}

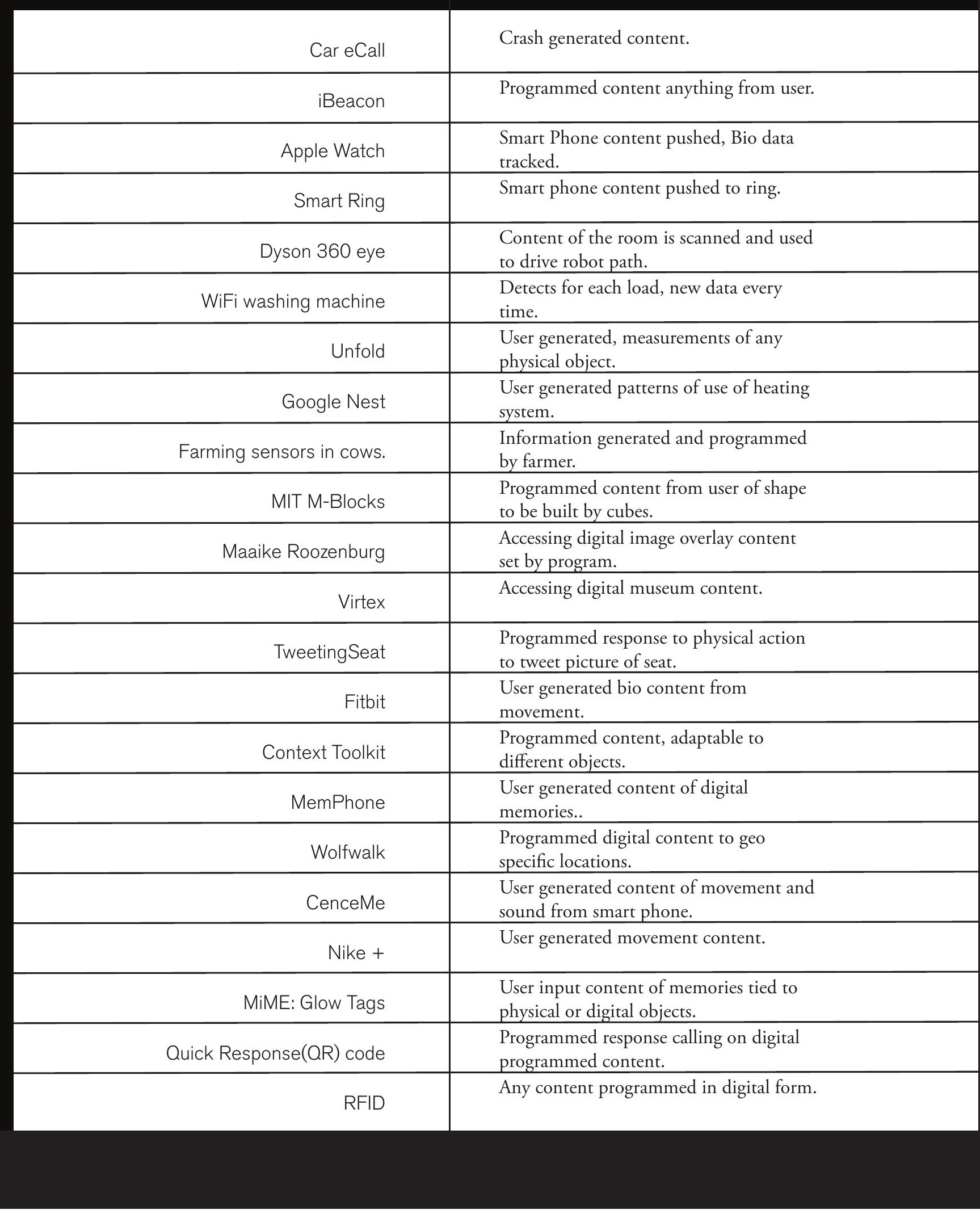

figure. 3-11 Smart Object Use and Content analysis. 


\section{How user engages it}

\section{What medium is used in communication}

\begin{tabular}{|c|c|}
\hline Activated by a user crashing. & Digital communication used. \\
\hline $\begin{array}{l}\text { Entering iBeacon space activates the } \\
\text { application. }\end{array}$ & $\begin{array}{l}\text { Digital media and communication via } \\
\text { BLE. }\end{array}$ \\
\hline $\begin{array}{l}\text { Swiping on touch screen and talking to } \\
\text { device. }\end{array}$ & $\begin{array}{l}\text { On screen digital media and haptic } \\
\text { feedback along with voice. }\end{array}$ \\
\hline $\begin{array}{l}\text { Only engagement though smart phone, } \\
\text { ring can only vibrate and light up. }\end{array}$ & Haptic and light medium only used. \\
\hline User starts robot and leaves it. & Physical medium of robot. \\
\hline $\begin{array}{l}\text { User input of clothes and can see data } \\
\text { generated. }\end{array}$ & $\begin{array}{l}\text { Viewing data on moblie device, physical } \\
\text { interaction with machine. }\end{array}$ \\
\hline $\begin{array}{l}\text { Measuring physical objects and inputting } \\
\text { on screen. }\end{array}$ & $\begin{array}{l}\text { Physical interaction with object to } \\
\text { measure objects. }\end{array}$ \\
\hline $\begin{array}{l}\text { By setting the initial data and letting Nest } \\
\text { learn. }\end{array}$ & $\begin{array}{l}\text { Digital medium of using device to change } \\
\text { temperature. }\end{array}$ \\
\hline $\begin{array}{l}\text { Farmer programmed information and } \\
\text { tracking. }\end{array}$ & $\begin{array}{l}\text { Digital interaction with readers along } \\
\text { with viewing the collected data. }\end{array}$ \\
\hline Programming content to be used. & $\begin{array}{l}\text { Digitally programming device and } \\
\text { physical with them self assembling. }\end{array}$ \\
\hline Through use of augmented reality. & $\begin{array}{l}\text { Digitally overlaying physical object using } \\
\text { device. }\end{array}$ \\
\hline $\begin{array}{l}\text { Through use buttons on object and a } \\
\text { digital screen. }\end{array}$ & $\begin{array}{l}\text { Interacting with physical object to call up } \\
\text { digital information. }\end{array}$ \\
\hline Activated by sitting on it. & $\begin{array}{l}\text { Digital interaction with the twitter feed } \\
\text { along with physically sitting on seat. }\end{array}$ \\
\hline $\begin{array}{l}\text { Tracks users bio data with every move } \\
\text { while wearing. }\end{array}$ & $\begin{array}{l}\text { Interaction with digital app to view data } \\
\text { generated from movement. }\end{array}$ \\
\hline $\begin{array}{l}\text { User programmes using smart phone to } \\
\text { tagged objects. }\end{array}$ & $\begin{array}{l}\text { Physically taggin objects to be tracked } \\
\text { with the digital application. }\end{array}$ \\
\hline $\begin{array}{l}\text { Smart phone used to tag digital } \\
\text { memories. }\end{array}$ & Digital communication witht cellphone. \\
\hline $\begin{array}{l}\text { Using smart phone to augment physical } \\
\text { with digital image in specific location. }\end{array}$ & $\begin{array}{l}\text { Agumenting current time using smart } \\
\text { phone application digitally. }\end{array}$ \\
\hline $\begin{array}{l}\text { Passively tracks users movement and } \\
\text { sound, to be accessed though v }\end{array}$ & Digital communication witht cellphone. \\
\hline $\begin{array}{l}\text { Data generated from activity, seen } \\
\text { through smart phone app. }\end{array}$ & $\begin{array}{l}\text { Interaction with digital app to view data } \\
\text { generated from movement. }\end{array}$ \\
\hline $\begin{array}{l}\text { User programmes information using } \\
\text { tagging device to tagged objects. }\end{array}$ & $\begin{array}{l}\text { Physical interactions with objects tied to } \\
\text { the MiME system. }\end{array}$ \\
\hline $\begin{array}{l}\text { User programmes QR using computer to } \\
\text { have desired response, scanned to engage }\end{array}$ & $\begin{array}{l}\text { Physically scanning object to retrieve } \\
\text { data. }\end{array}$ \\
\hline $\begin{array}{l}\text { Activated using RFID reader and } \\
\text { computer, engaged though reader. }\end{array}$ & $\begin{array}{l}\text { Physically swiping object to } \\
\text { retrieve/gather data. }\end{array}$ \\
\hline
\end{tabular}




\section{Case Analysis}

\section{Maaike Roozenburg}

2014

Content Used

Digital overlay on physical item.

Engagement

Through Augmented Reality

Communication

Kinesthetic, digital and textual.

Customizability

3D printing

Augmented Reality

Text

Physical

Animation

\section{Dundee central library \\ 2014}

Content Used

Childrens books.

Engagement

Through the book and 3D print.

Communication

Kinesthetic, textual.

Customizability

3D printing

Augmented Reality

Text

Physical

Animation $\bigotimes$

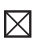

$\square$

$\nabla$

$\square$

\section{Quiver \\ 2014}

Content Used

Animation of character.

Engagement

Through the application annimation and physical colouring.

Communication

Digital and physical.

Customizability

凶

3D printing

Augmented Reality

Text

Physical

Animation

$\nabla$

$\nabla$

\section{LEGO catalogue}

2015

Content Used

Animation of catalouge item.

\section{Engagement}

Through digital exploration of the Augmented Reality animation.

Communication

Digital interaction with model.

Customizability

$3 \mathrm{D}$ printing

Augmented Reality

Text

$\nabla$

Physical

Animation

凶 


\section{Smart Object Case Analysis:}

From these case studies it became evident that an increasing number of companies are becoming aware of the impact $A R$ can have and are integrating it into different applications. Maaike Roozenburg, Dundee Central Library, Quiver, and LEGO all use AR very effectively to encourage different interactions with information.

A number of conclusions can be drawn from these examples. The use of narrative throughout these cases was identified as a key theme that was encouraged by interactions with other media. Interaction points can be used to connect narrative and allow users to bring their own interpretation to the narrative. This user-based interpretation could allow extension of the narrative being used.

Connecting multiple modes of media together has created engaging interactions for both Quiver and Maaike Roozenburg. Connecting different modes of media is vital to creating more complex, richer, and ultimately engaging experiences. These connecting different modes of media can also be used as a bridge to introduce $3 \mathrm{D}$ printing to users. As there are many different forms of 3D printing, selecting the specific $3 \mathrm{D}$ printing technology and aligning it appropriately with the intended experience is an important consideration. Using full colour sandstone printing worked well in for the Dundee Central Library, while using low resolution monocolour (white) lent itself well to the augmentation for Maaike Roozenburg. The selective use of 3D printing in different forms assists the narrative.

Summarising the above considerations identified criteria to inform the initial ideation:

- Multiple modes of media offer richer and more engaging interactions (from $2 \mathrm{D}$ via $\mathrm{AR}$ to $3 \mathrm{D}$ printing).

- Connecting multiple modes of media facilitates and encourages narrative extension (physical/digital, 2D, 3D, and 4D)

- Different 3D printing technologies should be selected according to application and desired output 


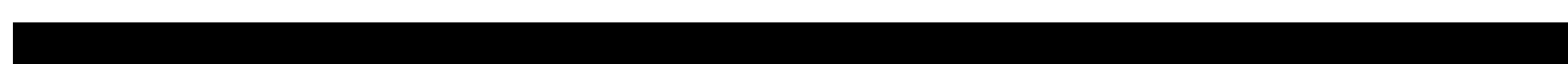




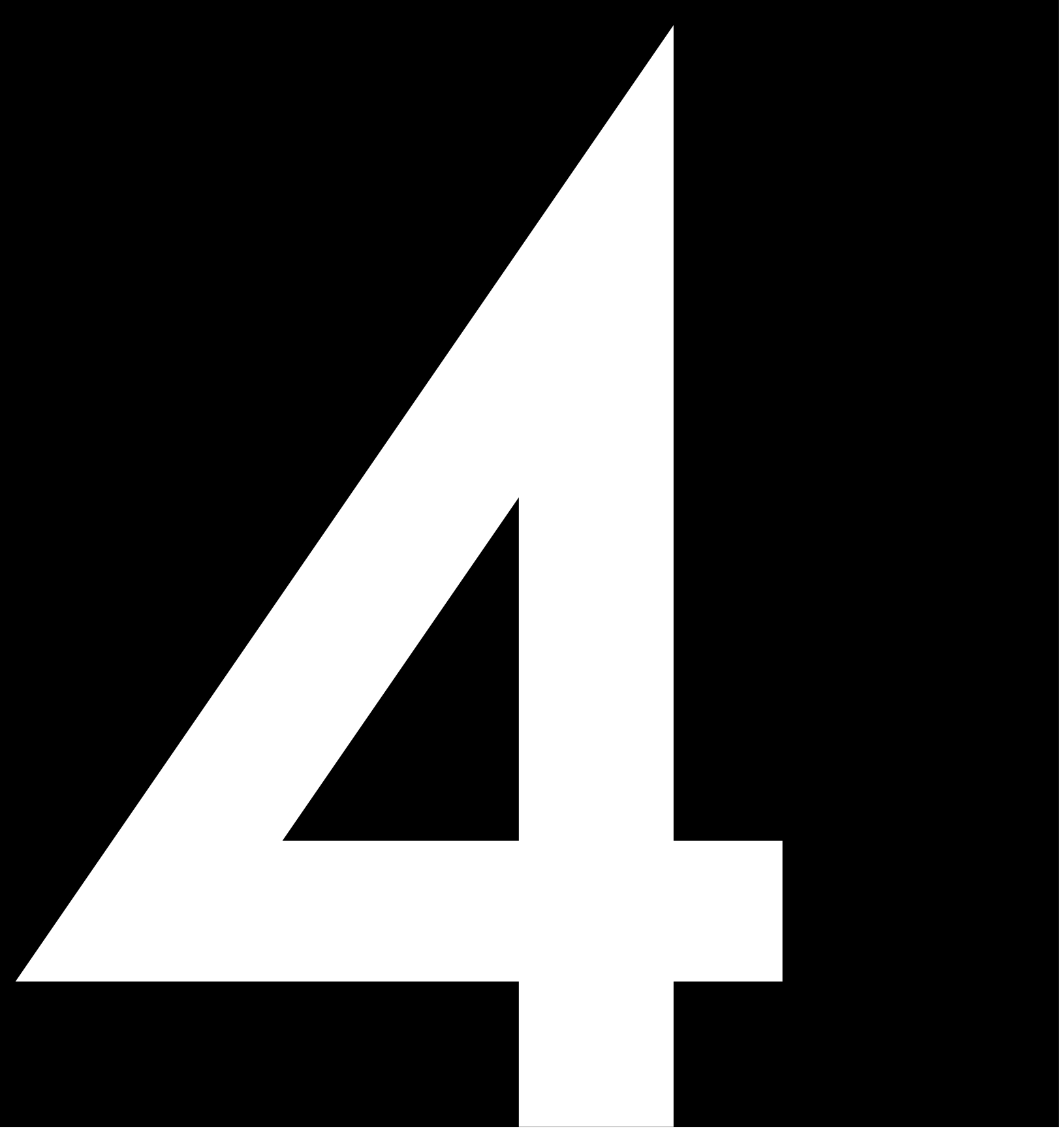




\section{Initial Designs}


The context analysis and the smart object review provided a basis for the design phase and informed or initiated possible concepts for connecting people with collections through different combinations of $3 \mathrm{D}$ printing, AR, and smart objects. Storyboards were used to explore different ways that collections, technical and potential user connections can occur. 


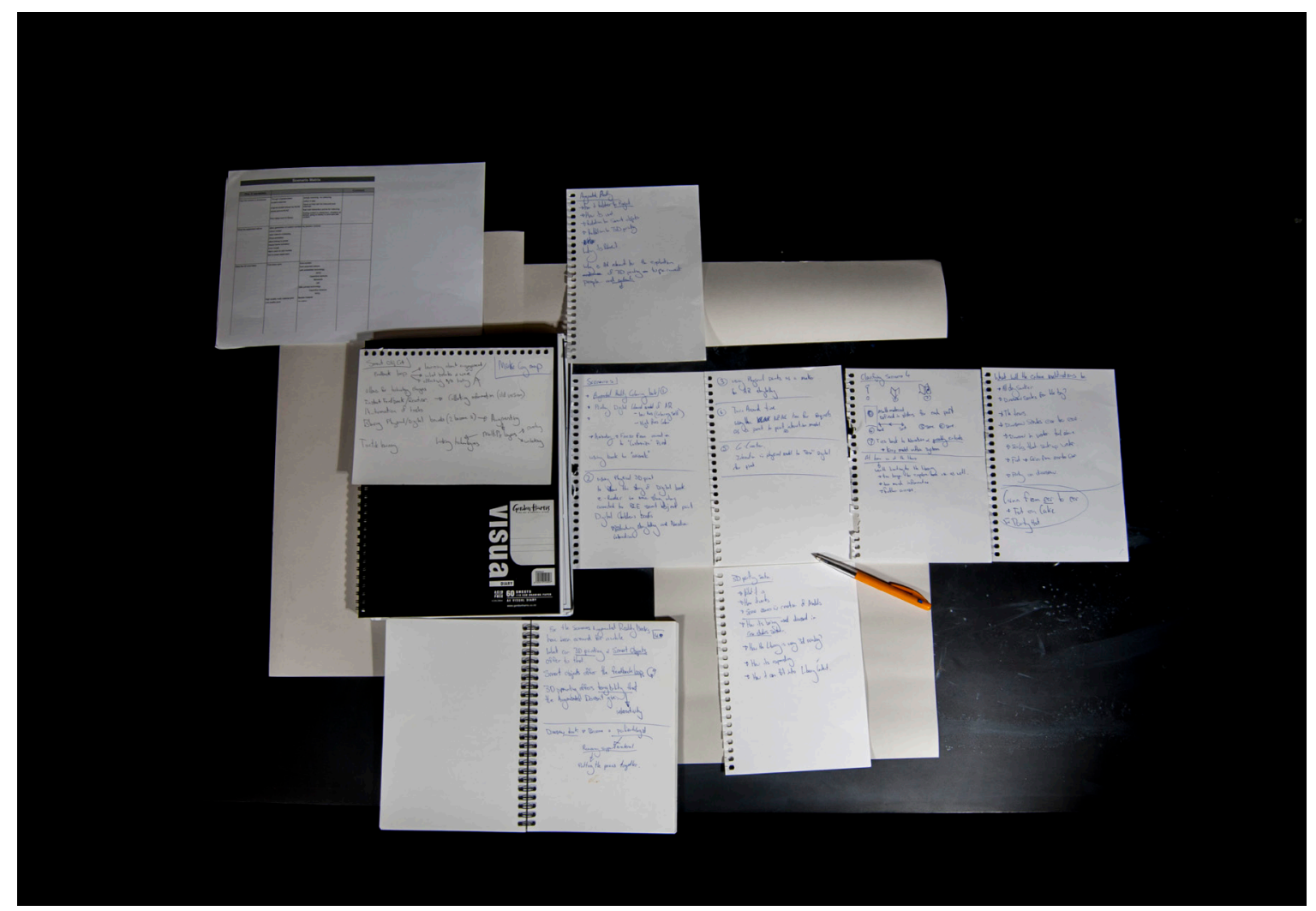

figure. 4-1 Brainstorming.

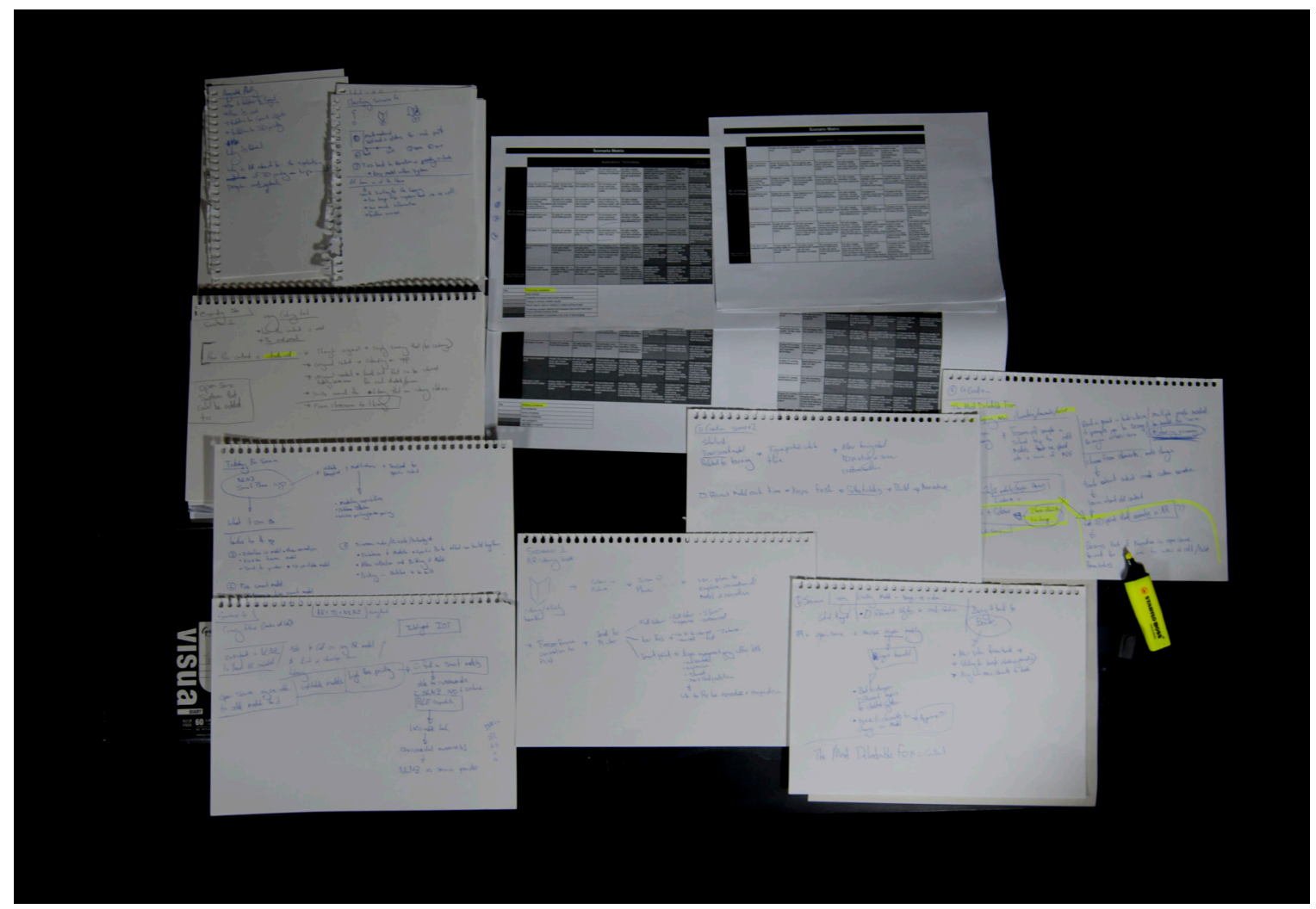

figure. 4-2 Brainstorming. 


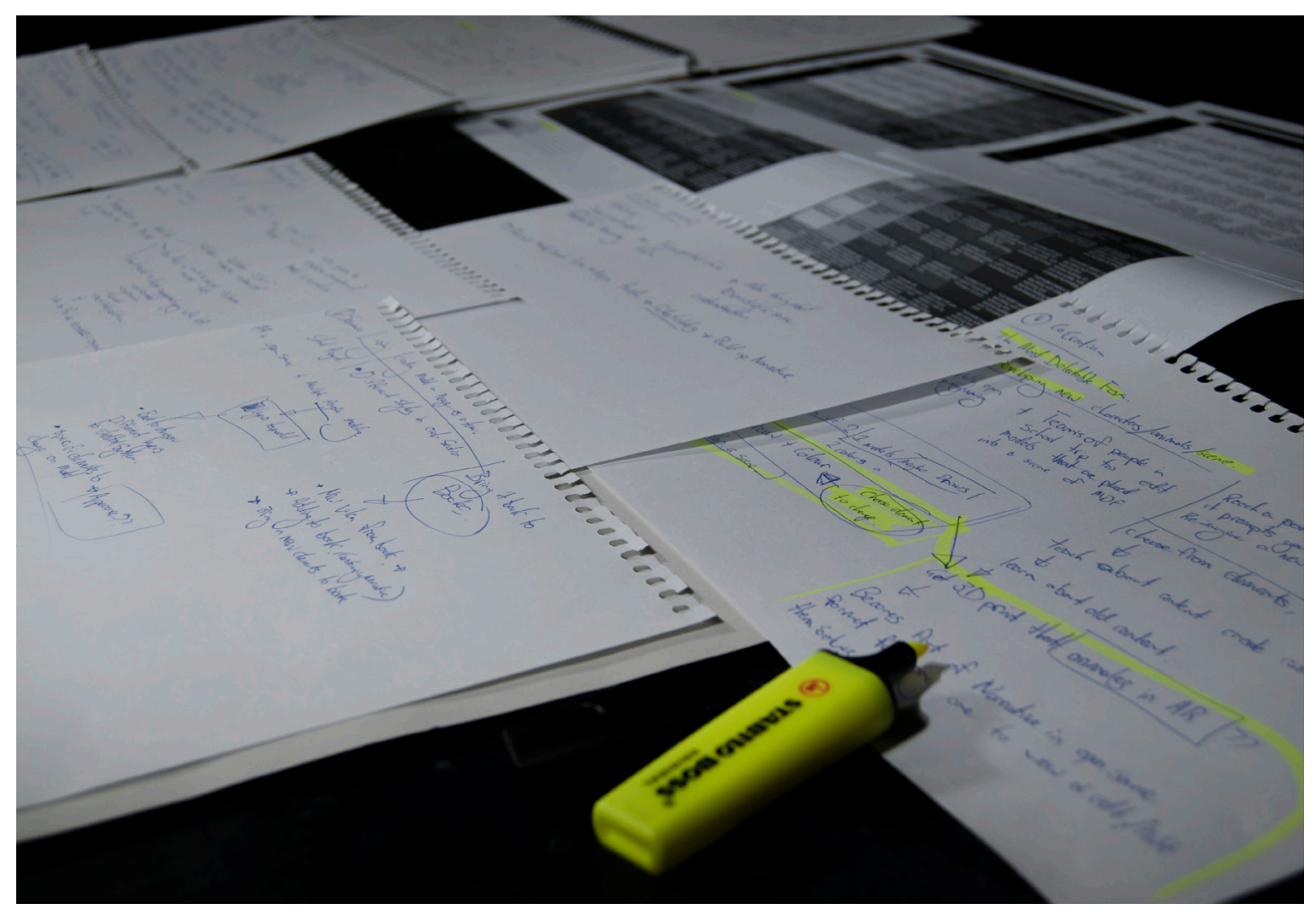

figure. 4-3 Brainstorming.

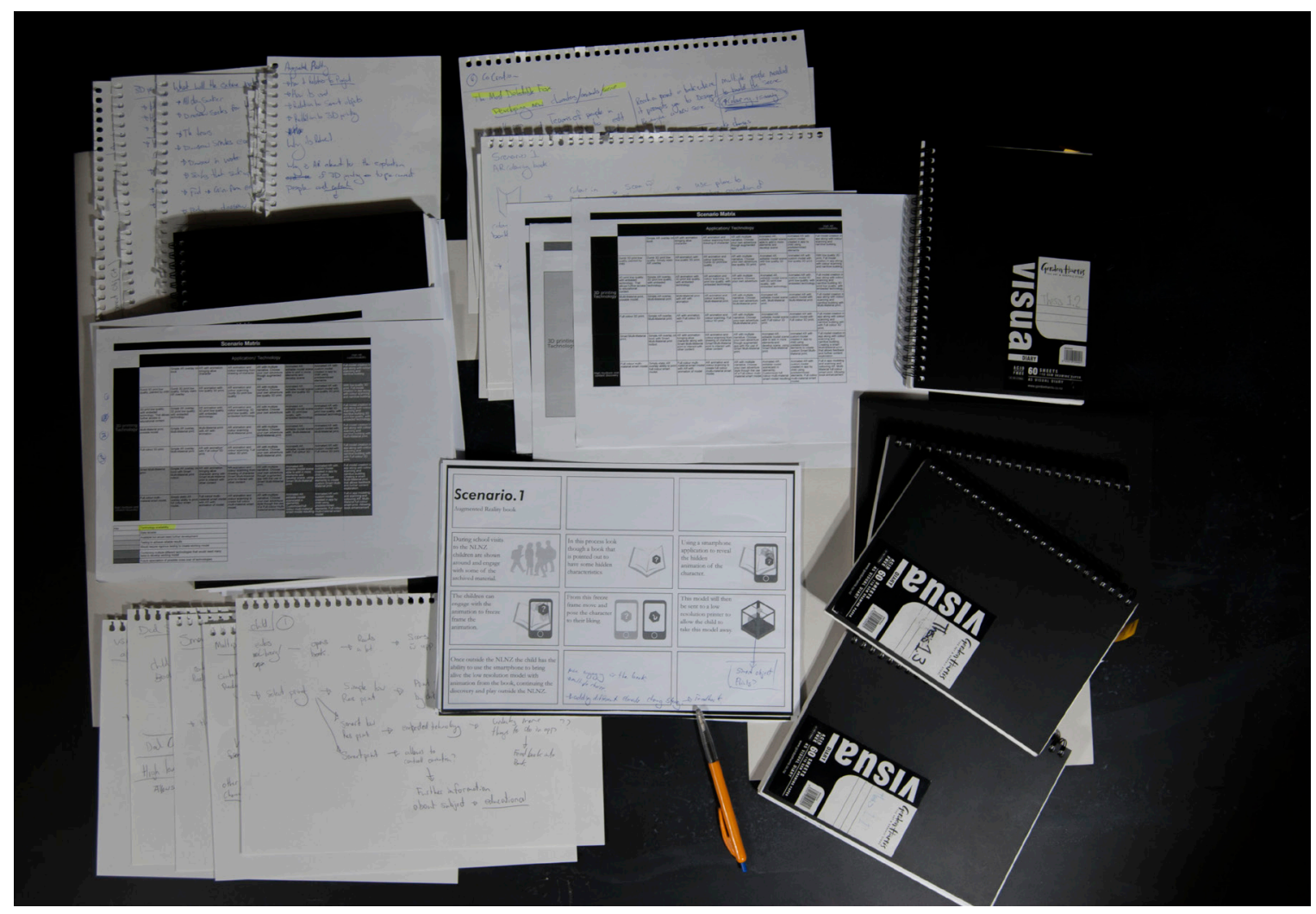

figure. 4-4 Brainstorming. 


\section{Storyboard.1}

Augmented Reality book

The first storyboard looks at implementing AR with an app to augment content when scanning over a book from the Library's collection.

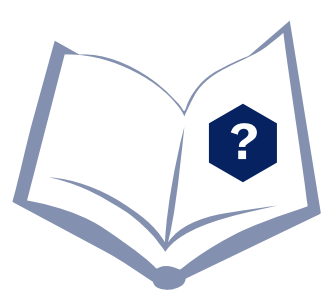

The children interact with the AR character as they follow narrative of the book.

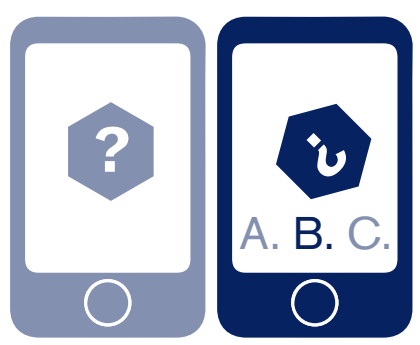

The narrative ends with a 3D printed model of the final character through a high quality print from a continuous Liquid Interface Production technology (CLIP) 3D printer.
School children looking through the book discover the book has some hidden AR characters.

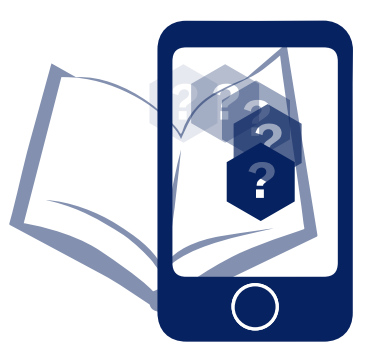

Scanning the book using a smartphone app triggers the appearance of a digitally animated AR character.

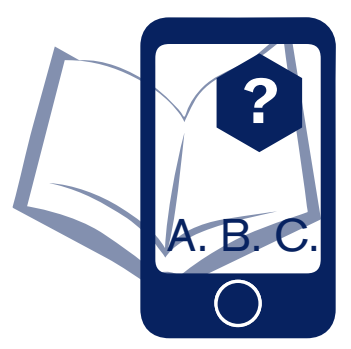

The app then prompts the children to change the trajectory of the narrative by answering multiple choice questions.

The decisions made change the appearance of the character and extend the narrative along the new trajectory.
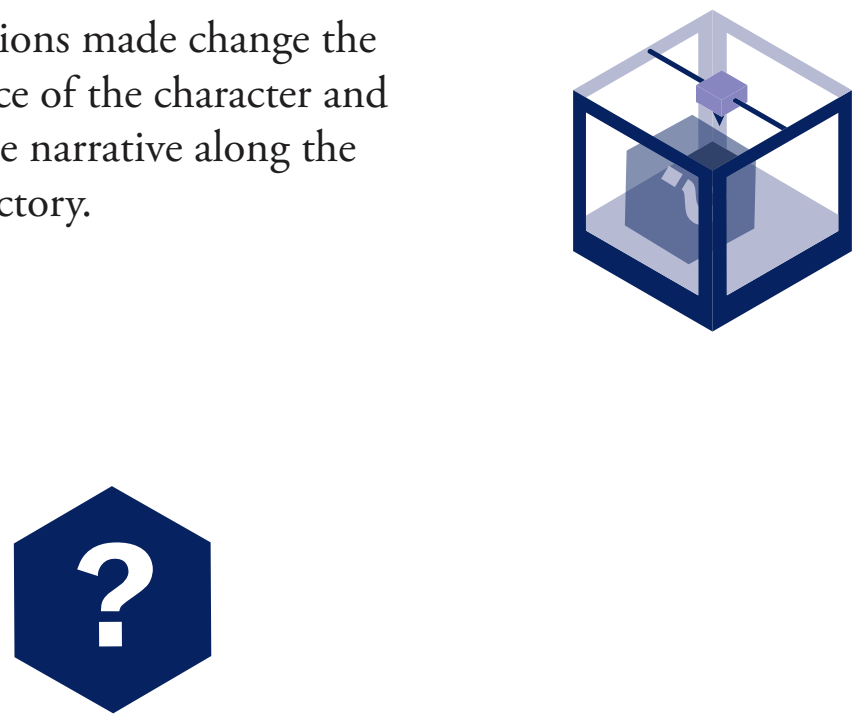


\section{Storyboard 1 Reflection:}

Creating an app that can conduct this level of user interaction and variation would be extremely complex and require many different elements working in unison.

However, using the emerging technology of high resolution (CLIP) 3D printer, this scenario allows quick on-site printing of the character for immediate delivery to the user when they leave the Library.

The smart technology in this storyboard is the app itself, where a loop of information and different narrative trajectories occur.

In this storyboard the interaction takes place and is completed during the Library visit. This interaction could help create a clear link to the physical book or limit its use to people who already frequent the Library. 


\section{Storyboard.2}

Co-Discovery

Storyboard 2 uses the Library as the basis for research on a specific topic; this is currently one of the main uses of the Library, primarily by researchers or schools.

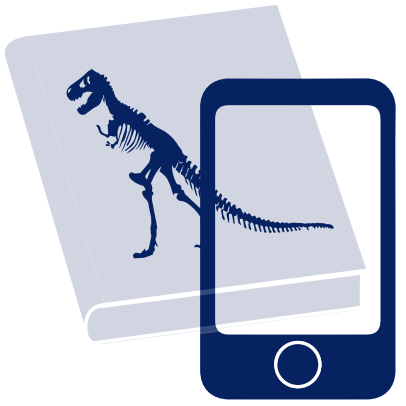

These questions would unlock parts of an AR model. Once unlocked, the model would be $3 \mathrm{D}$ printed and embedded with BLE technology.

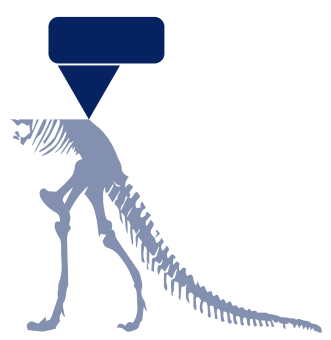

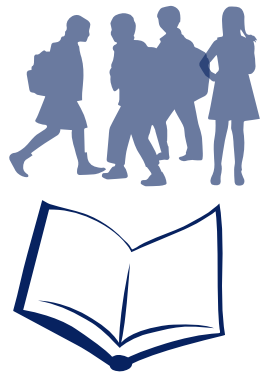

In this particular example the Library is used to research dinosaurs on a school visit. To participate in the research smart devices would be used to research information from diverse sources.

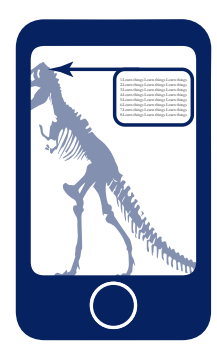

During this process, prompts would require students to answer questions about the information.

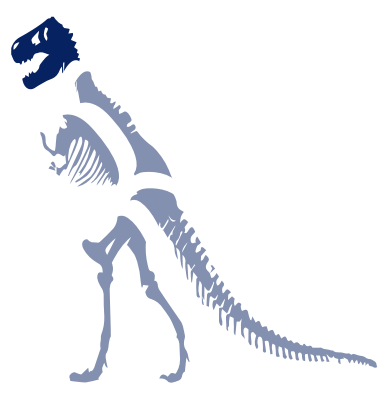

The 3D print would then become a form of embodied knowledge through the BLE chip, which would hold links to the research process and the diverse sources of information.
The embodied information could then be recalled by activating it with a smartphone app.

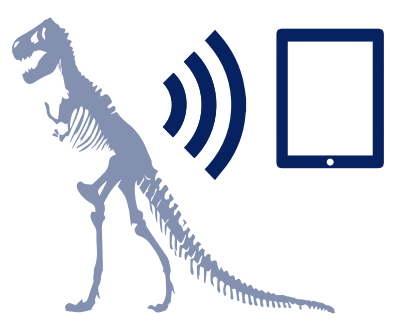




\section{Storyboard 2 Reflection:}

The connection of collected material and the $3 \mathrm{D}$ print gives the research process a tangible outcome -the main objective of this storyboard. This invites further engagement with the collections, reiterating the Library's status as a place of research. The augmentation plays a small role in this scenario, with the focus on the information collected and tracked by a smart device. It creates more of a link to the physical as the information is held in the print itself, not unlike a custom flash drive. It also allows engagement outside of the Library via the BLE chip. However, the storyboard relies on the information being stored/collected in a smart device or on a library profile, which needs to allow for information tracking and unlocking of printable pieces. The ability to make custom topic areas for research would be needed to allow a wider audience to engage with the storyboard. Furthermore, the loss of research by not completing the task and embedding the information into the print would need to be resolved. 


\section{Storyboard.3}

\section{AR Station}

AR station creates a dedicated area or station for exploring AR content, similar to the way the Library uses stations for reading microfilm content.

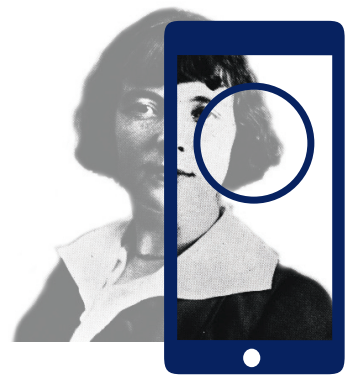

The Katherine Mansfield print can be scanned with a smart device to display the AR content in diverse forms, such as text, photos, and specially designed 3D objects.

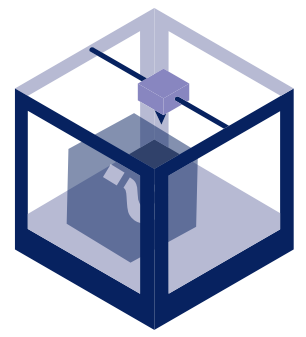

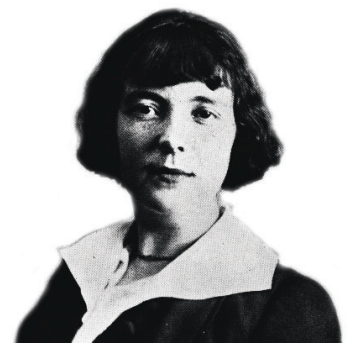

The station would consist of a textured laminated object manufacturing (LOM) 3D print of Katherine Mansfield.

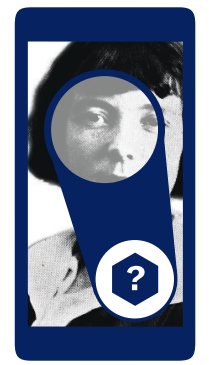

The RFID chip would then be activated with a smartphone to re-access the embedded information.
The chosen content for this storyboard is the wide variety of media and artefacts surrounding Katherine Mansfield held at the Library, including books, cutlery, and a lock of her hair.

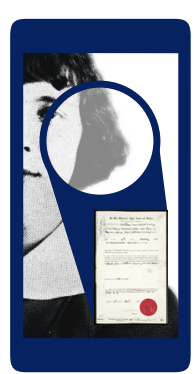

The $3 \mathrm{D}$ objects could then be printed by the user with a low quality FDM plastic print.

Once printed, the objects would hold additional information to be explored in AR using a RFID tag.

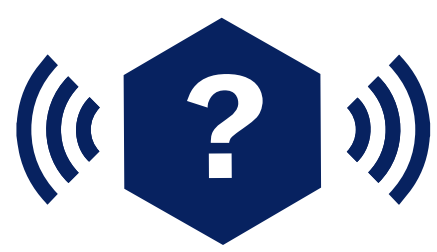




\section{Storyboard 3 Reflection:}

This storyboard requires a visit to the Library, providing an opportunity to widen the public's knowledge of the content at the Library. The theme of the station can be updated as required with other themes that are of key interest to the Library. The physical print-out of the artefact viewed at the Library is a tangible reminder of the visit as is the knowledge embedded in the item. To build on this further, the ability to feedback into the AR station would be necessary and would begin to facilitate repeat visits to the Library. This could encourage ongoing exploration of the physical content the Library holds. 


\section{Storyboard.4}

\section{Co-Creation}

The Library holds the idea of co-creation in high regard, as its mission statement testifies. This storyboard focuses on facilitating co-creation through $3 \mathrm{D}$ printing and $\mathrm{AR}$.

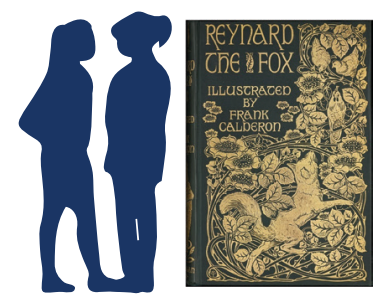

Simulating Quiver technology, this AR content gives access to a line drawing of the character from the book. Once printed out the line drawing can be coloured-in by hand and scanned by the app to give life and colour to the AR model.
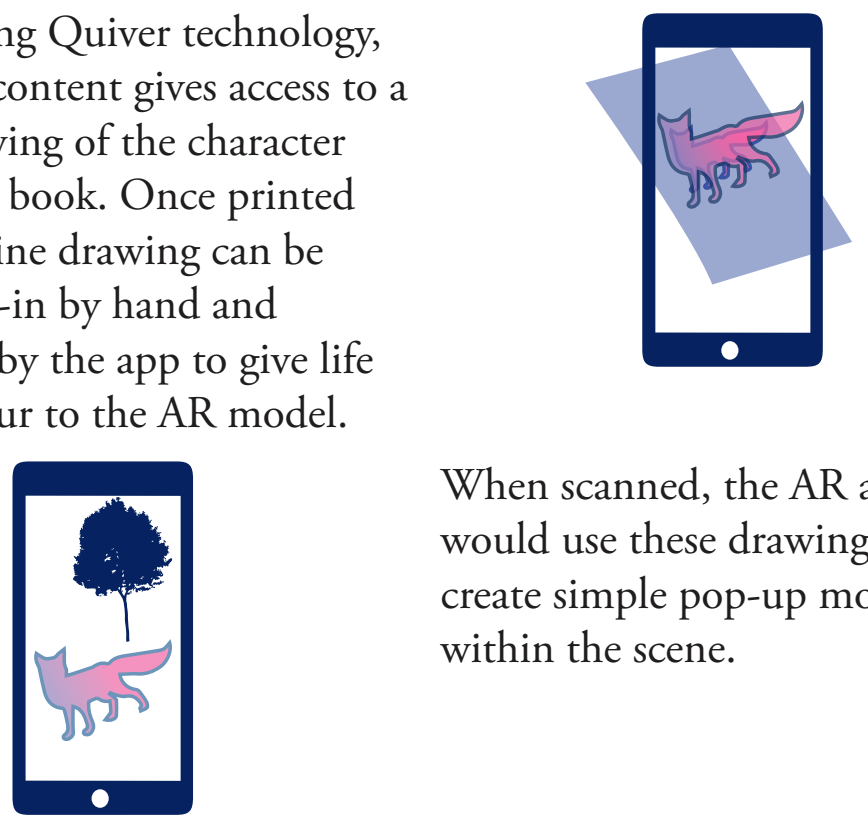

The children look through the content and discover it has been augmented and basic grayscale $\mathrm{AR}$ content can be viewed using a smart device.

When scanned, the AR app would use these drawings to create simple pop-up models within the scene.

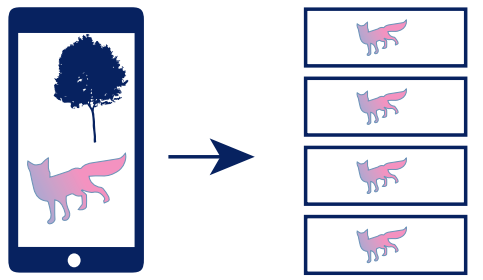

It starts with a school trip where the children are introduced to the book Most Delectable Fox

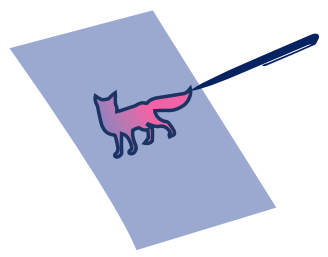

Further interaction with the scene from the coloured AR model can occur by drawing new items into the original line drawing.

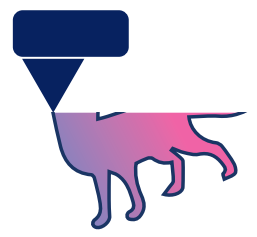

Once finished the coloured AR model can be sent to a colour $3 \mathrm{D}$ printer for printing and delivery to the school. Stories.

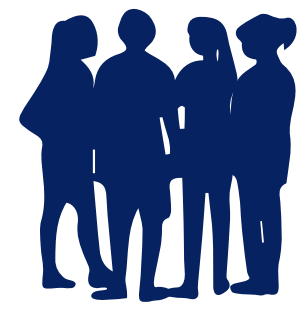
drawing. 


\section{Storyboard 4 Reflection:}

With this scenario a collection of scenes is developed, inviting multiple interpretations of the narrative extending beyond the book. This storyboard relies on linking a number technologies together in a seamless manner, including automatic model generation (pop-up models), AR colour updating (Quiver), multiple custom coloured models and linking to 3D printers. While this is extremely complex and involves new software, the possibility of narrative extension though colouring gives this storyboard interesting aspects that invite co-creation. 


\section{Storyboards key insight}

A review of the storyboards highlighted both advantages and disadvantages. The following shortcomings emerged.

- The technological interactions are limited to within the Library, therefore limiting access to sections of the app outside the Library and may not attract a wide audience.

- Proposed use of the technology needs development and clarity.

- Intensive AR apps are the forefront interaction, diverting attention from the content.

Opportunities also emerged such as:

- Being able to build upon existing content/collections in new ways.

- Inspiring unexpected forms of narrative extension.

- Inviting co-creation.

- Creating more tangible interactions by combining physical and virtual domains.

A key insight these storyboards provided was the integration of smart objects with collection information. By definition, a smart object "is able to acquire, to receive and to distribute information in a near or distant environment, and is able to carry out diverse actions on its own initiative or request help from others objects" (Bajic, 2009, p. 37). In these storyboards a smart object is formed through an app that acquires and distributes information. This led to a re-evaluation of where the interactions with the content was occurring, with the key path intended to be from book (analogue) to AR (digital) and back to physical in the form of a $3 \mathrm{D}$ print. Further exploration of smart objects and how to make connections to content is needed in the final scenarios. Moving the focus to 3D exploration using an AR app as a conduit between inputs and outputs also needs to be explored in the development of final scenarios. 



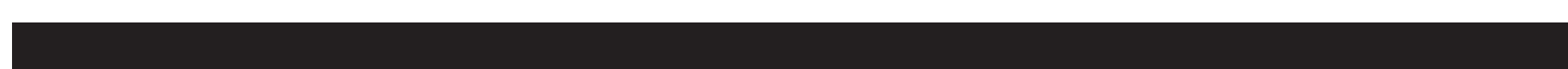




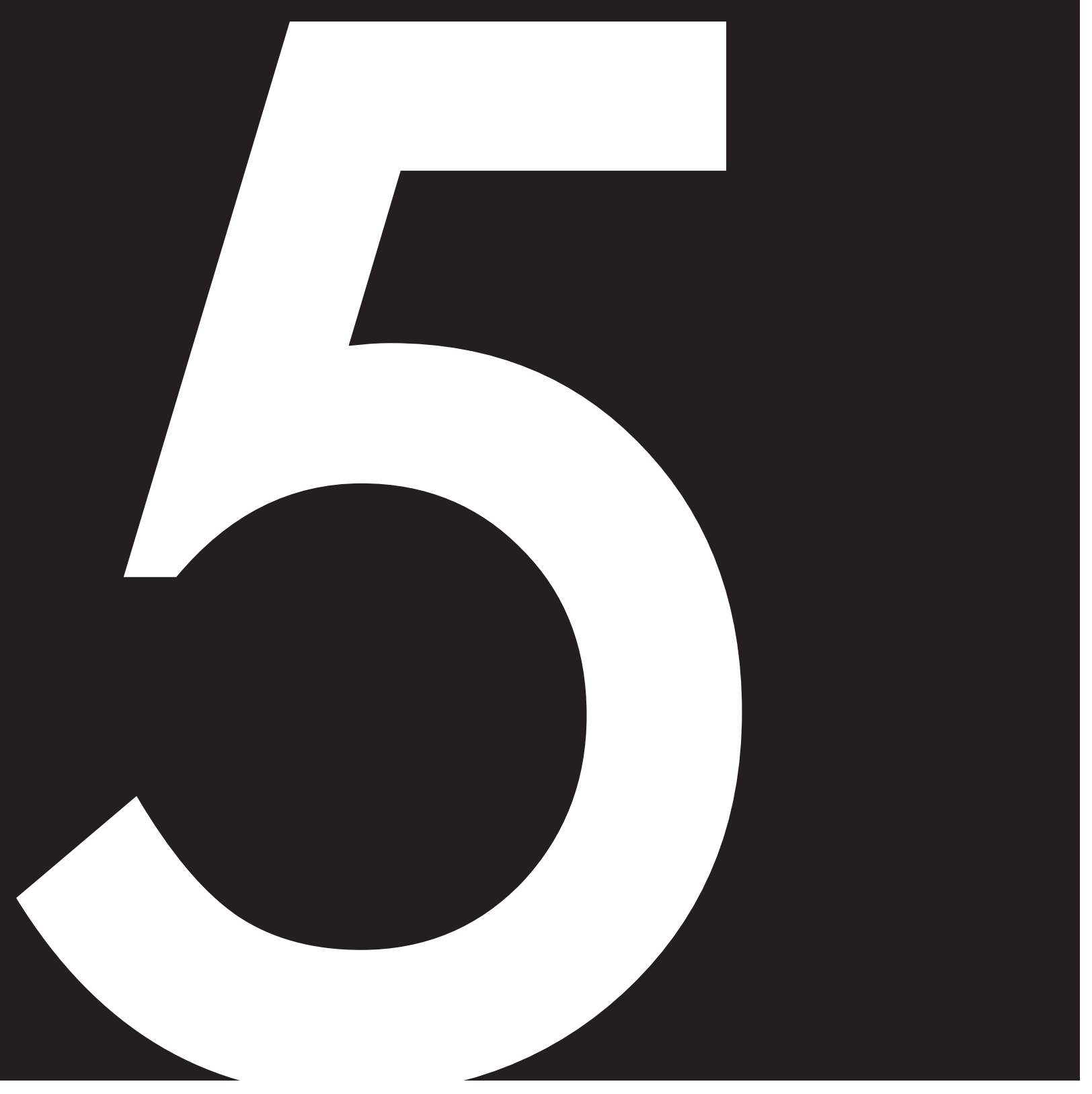




\section{Collections analysis}


In order to develop the initial scenarios further, suitable content had to be identified and selected from the Library's collections. This chapter outlines how the content was filtered and analysed for suitability, with particular reference to 3D printing applications.

\section{Areas of interest}

The Library has a vast collection of over 30,000,000 unique items, from books to chronicles and registers, and everything in between. This makes choosing suitable content difficult. This problem was encountered during the summer scholarship, where, to facilitate selection, a matrix of all the collections at the Library was created. It documented the name of each collection, its content, and potential applications.

In the process some areas were identified as more suitable, such as the Manuscripts Collection, Cartographic Collection, Drawings, Paintings and Prints (from 1642), National Children's Collection, Photographic Archive, Printed Ephemera Collection, Turnbull Library pictures, and the Curios Collection (which includes 3D media, Burt Munro's pistons, Captain Cook's knife and fork, and a lock of Katherine Mansfield's hair).

The actual exploration of the collections then started, with areas identified from the matrix. Those areas identified were quickly narrowed down to the National Children's Collection and a combination of the Cartographic Collection and the Drawings Collection under a topical umbrella of Wellington earthquakes. These areas were selected for their suitability for 3D treatment and their potential for creating narrative engagement.

Meetings were requested with the relevant experts at the Library to see if they had any advice on identifying suitable areas of focus. Mary Skarott and Jenni Chrisstoffels were a great help in the initial explorations and in confronting the large amount of content at 


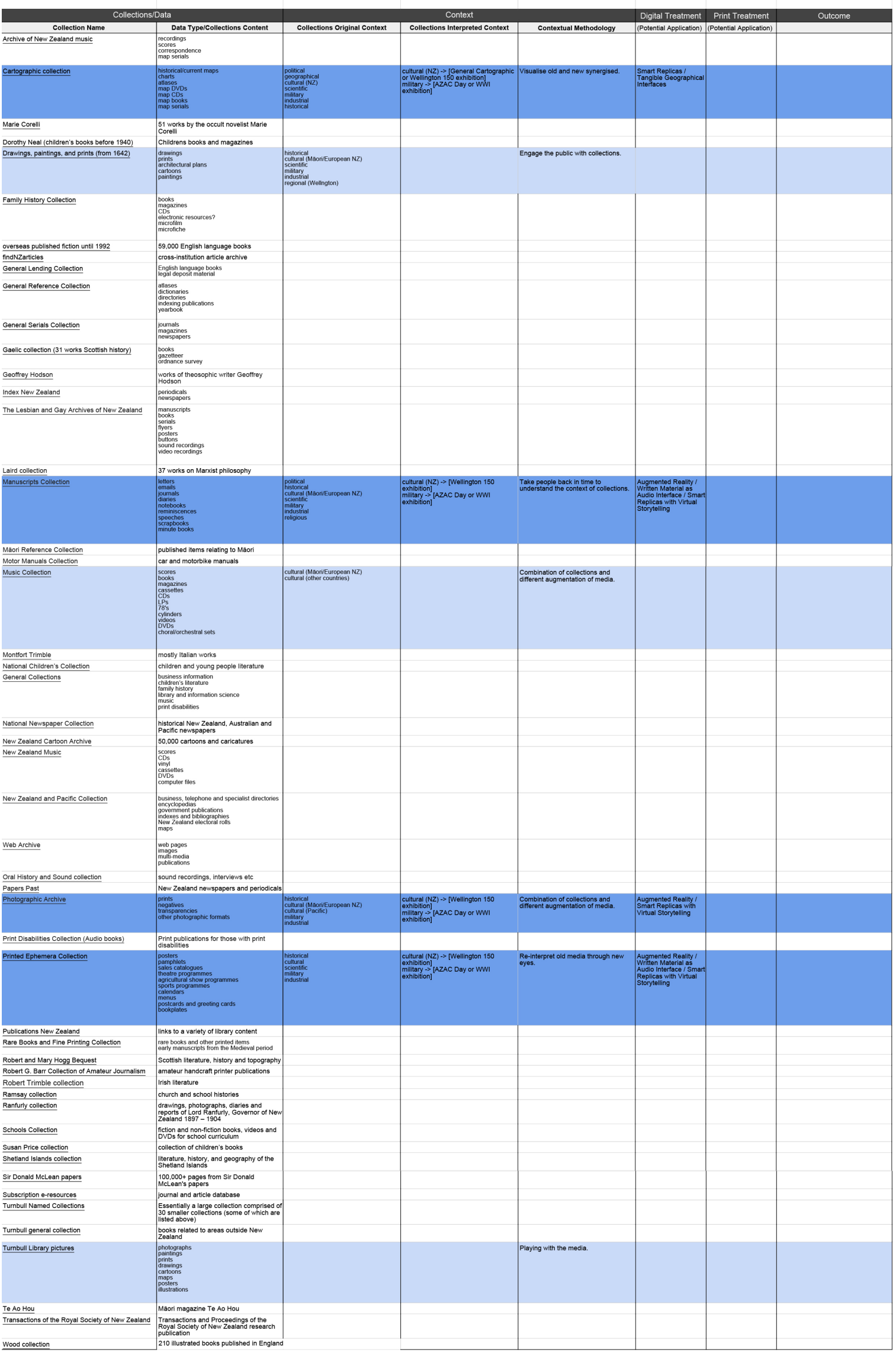

figure. 5-1 Content matrix generated from the Library 
the Library. With the wise words "spending hours trawling in the collections isn't that bad" (J. Chrisstoffels, personal communication, November 19, 2015) exploration of the collections began. Many hours were spent on the Library's website and in the Library calling up items to view when no digitised copy was available.

The Library allows online browsing of the entire collections; however, only some items are digitised and accessible on the website. This creates a divide between digitised and un-digitised content, with digitised content being much easier to browse. To view an un-digitised physical item it must be ordered on a computer at the Library. Once ordered, it is retrieved from the vaults and sent up to the viewing rooms. This creates a serendipity with un-digitised items, as only a small amount of information from the item description is available, with full appraisal only possible when the physical item is encountered. 


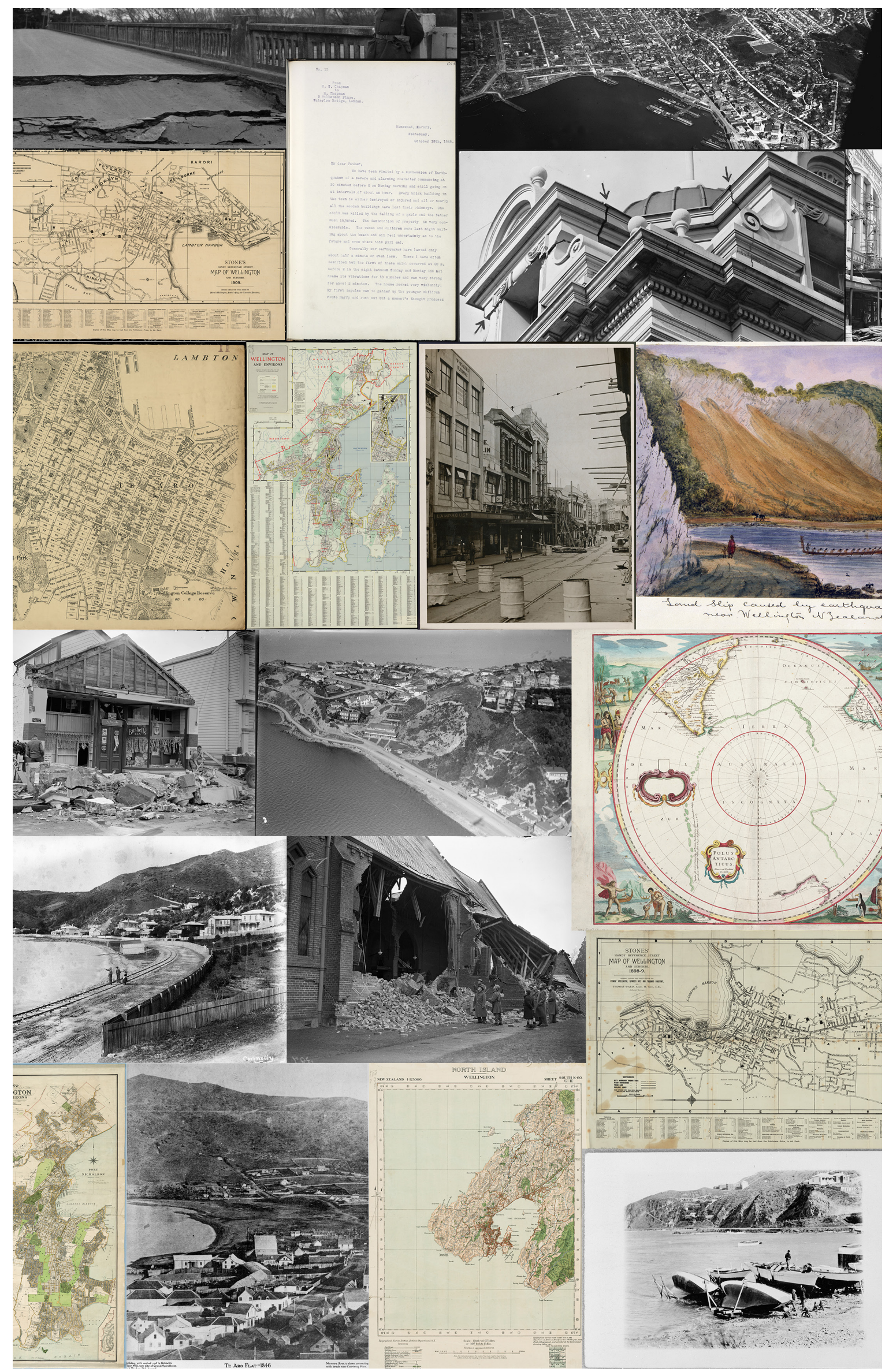

figure. 5-2 Content viewed from the Library. 

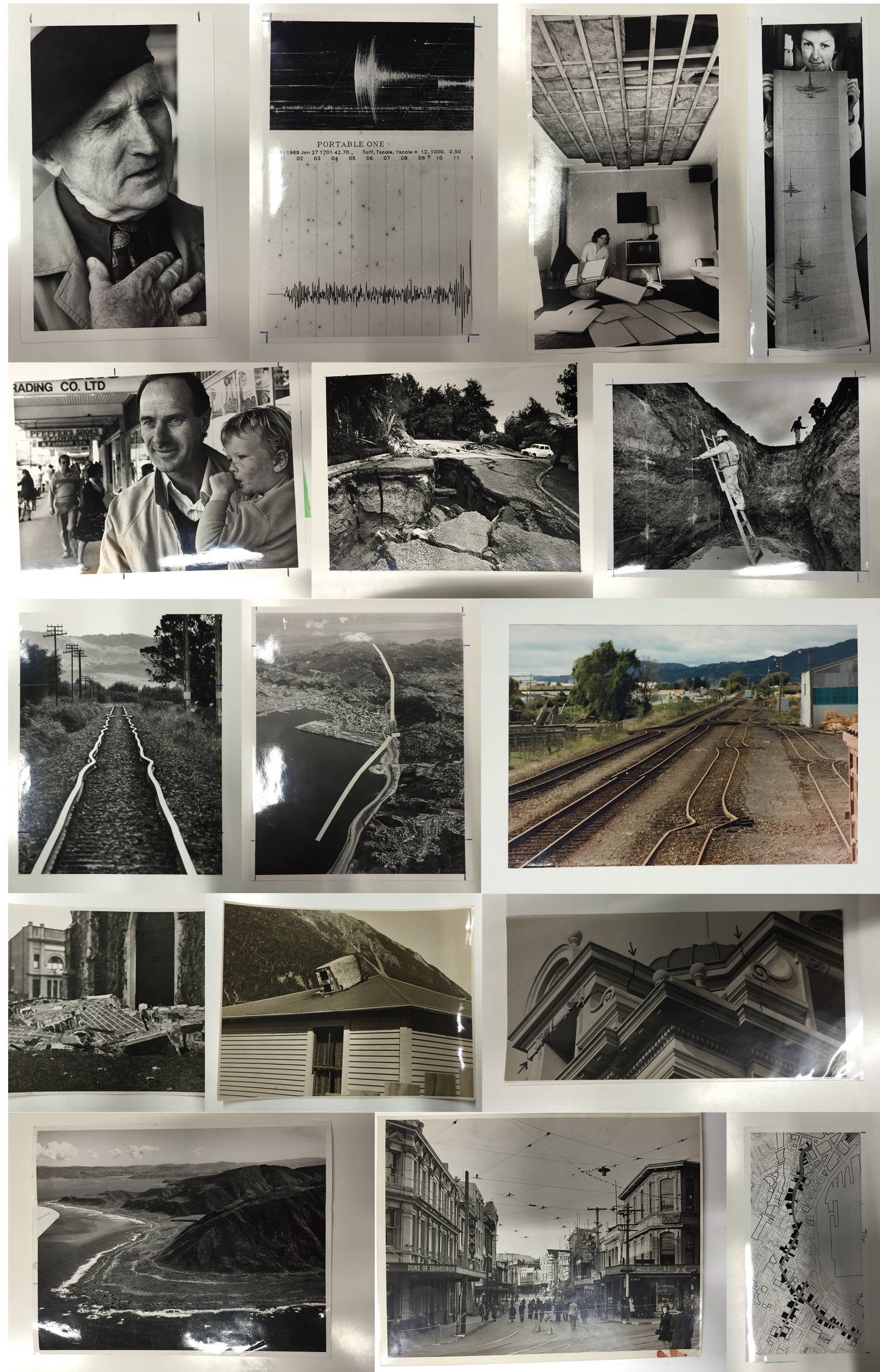

figure. 5-3 Content viewed from the Library. 


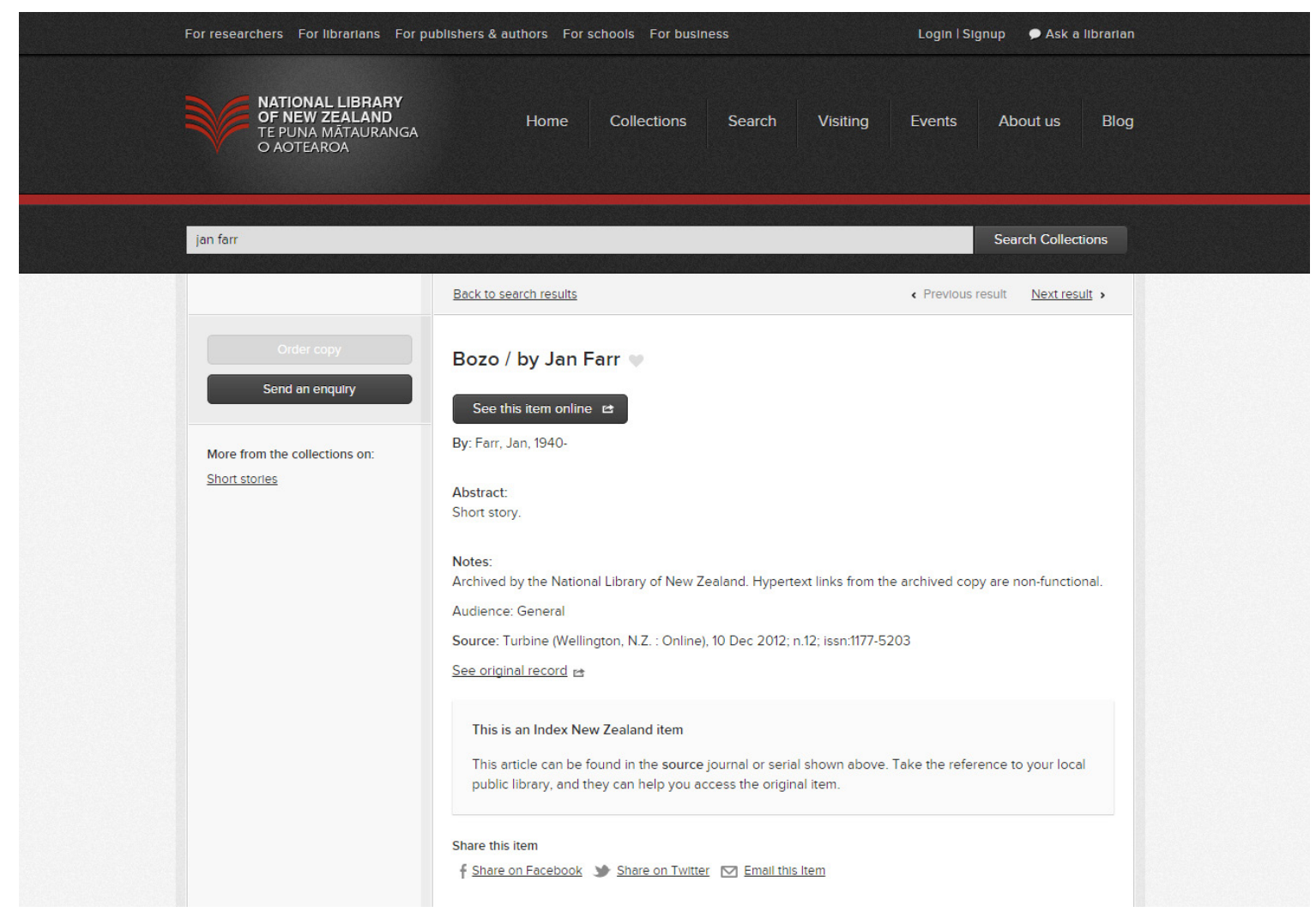

figure. 5-4 Un-digitised item from the Library.

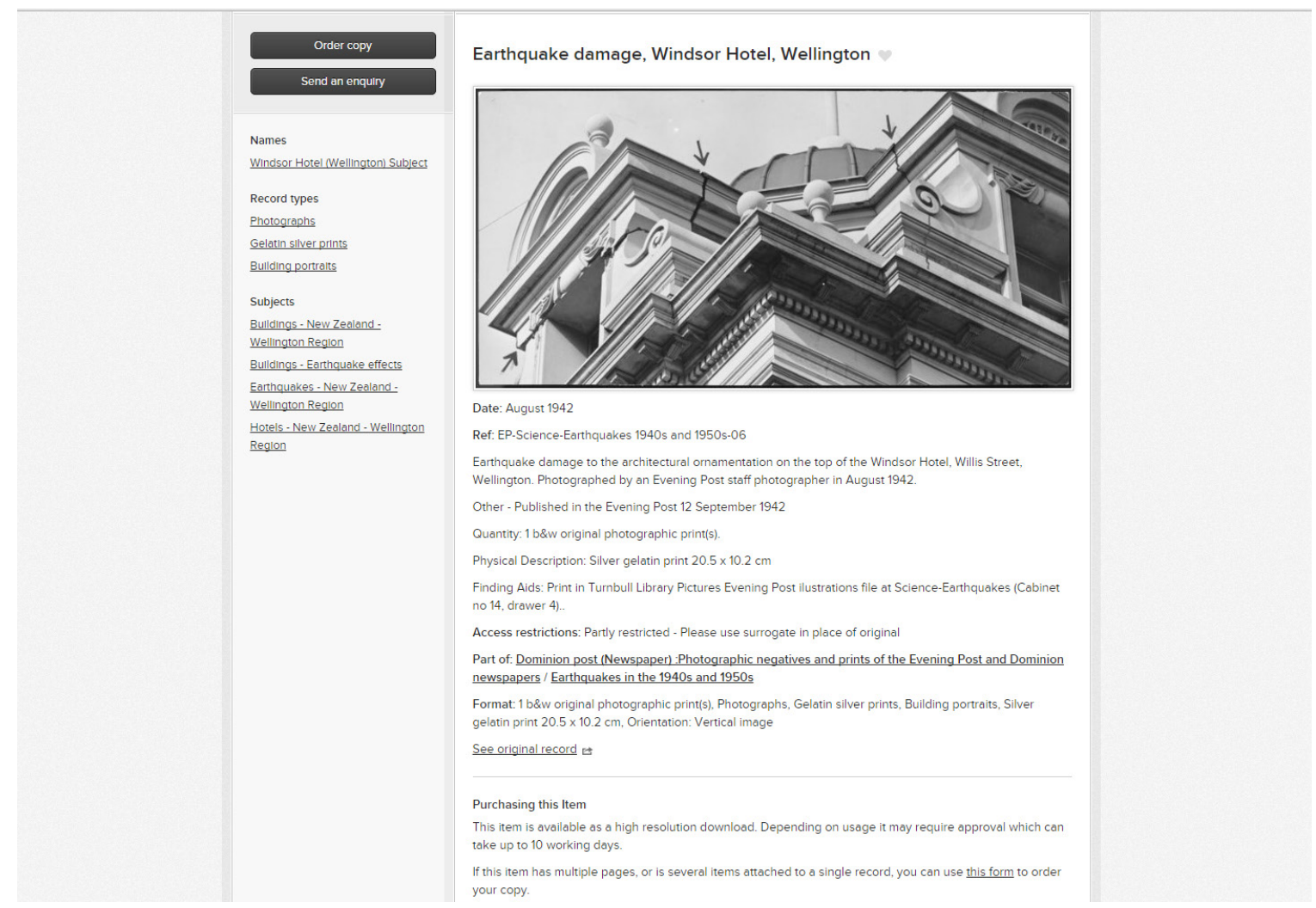

figure. 5-5 Digitised item from the Library. 


\section{Specific areas}

Despite narrowing the search to the topic of Wellington earthquakes and the National Children's Collection, it soon became clear that a choice needed to be made between the two. The individual collections were still too large to comprehend with unspecified searching, thus the search was narrowed to the National Children's Collection.

The National Children's Collection was selected on the basis of its suitability for $3 \mathrm{D}$ treatment and its potential for creating narrative engagement, as well as children's ability to adopt and adapt to new technologies. Children's books also hold a wide appeal for any age group, particularly intergenerational interaction.

Narrowing the scope of the search made identifying suitable material significantly easier and one of the orders revealed the book Big Sloppy Dinosaur Socks, a story about a dinosaur at a birthday party written by Jan Farr and illustrated by Pamela Allen. This modest book, published in 1977, with its black and white illustrations stood in stark contrast to the hyper-real digital stimulus available to children now. However, the narrative value of the book has not diminished with time; which raised the question how can children be re-connected to this book? For this reason the publication became the focus of the scenario development - as a model to explore how AR and 3D printing can encourage both interactions with the Library's collections and co-creation.

During this process Jan Farr and Pamela Allen were contacted to seek permission to use the book and reproduce images in this thesis. I am indebted to them, not only for approving its use, but also for the valuable exchange that has since taken place, capturing quite unexpectedly the spirit of co-creation (figures 7-1 and 7-2). 


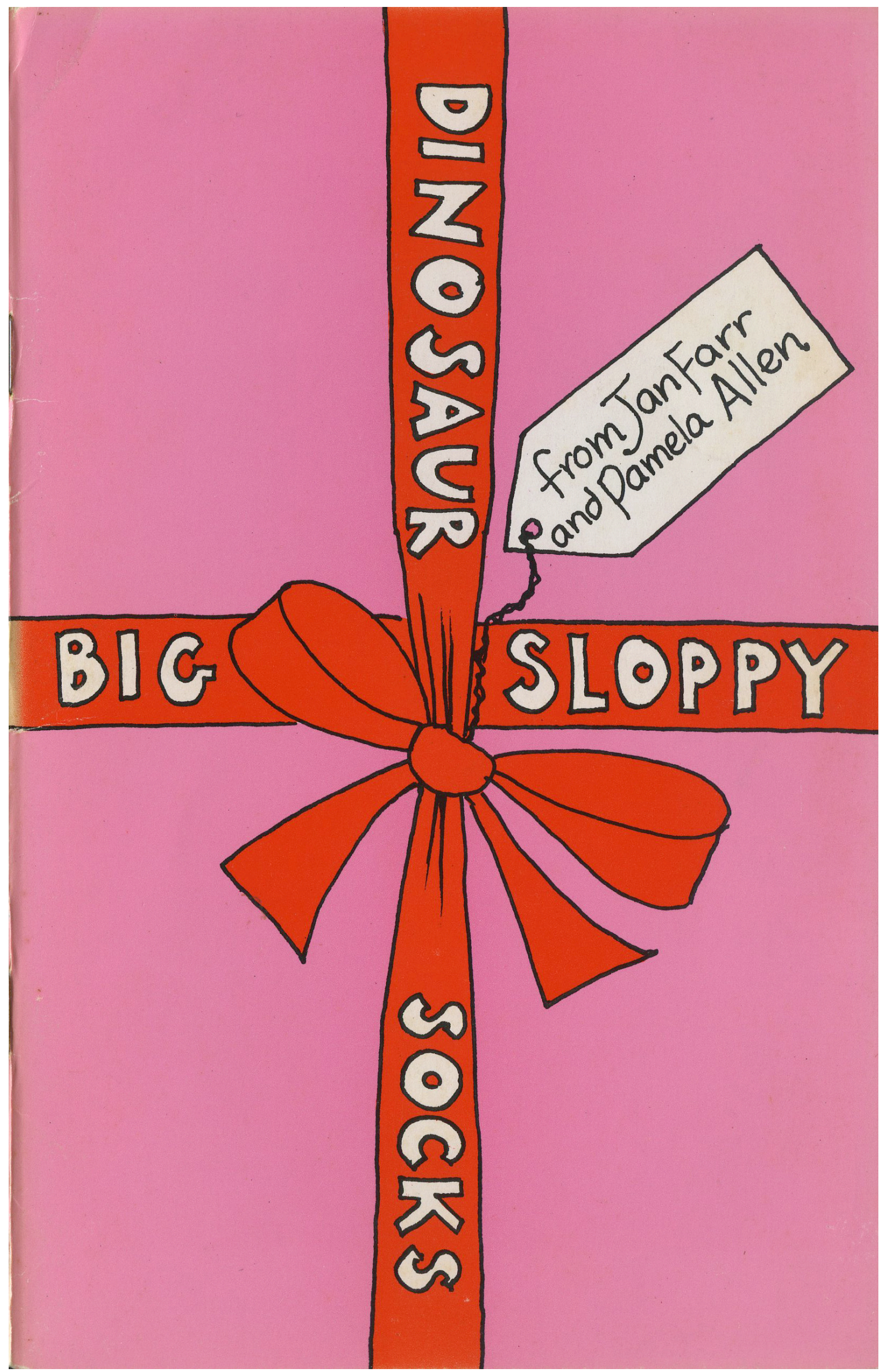

figure. 5-6 The cover of Big Sloppy Dinosaur Socks by Jan Farr. 


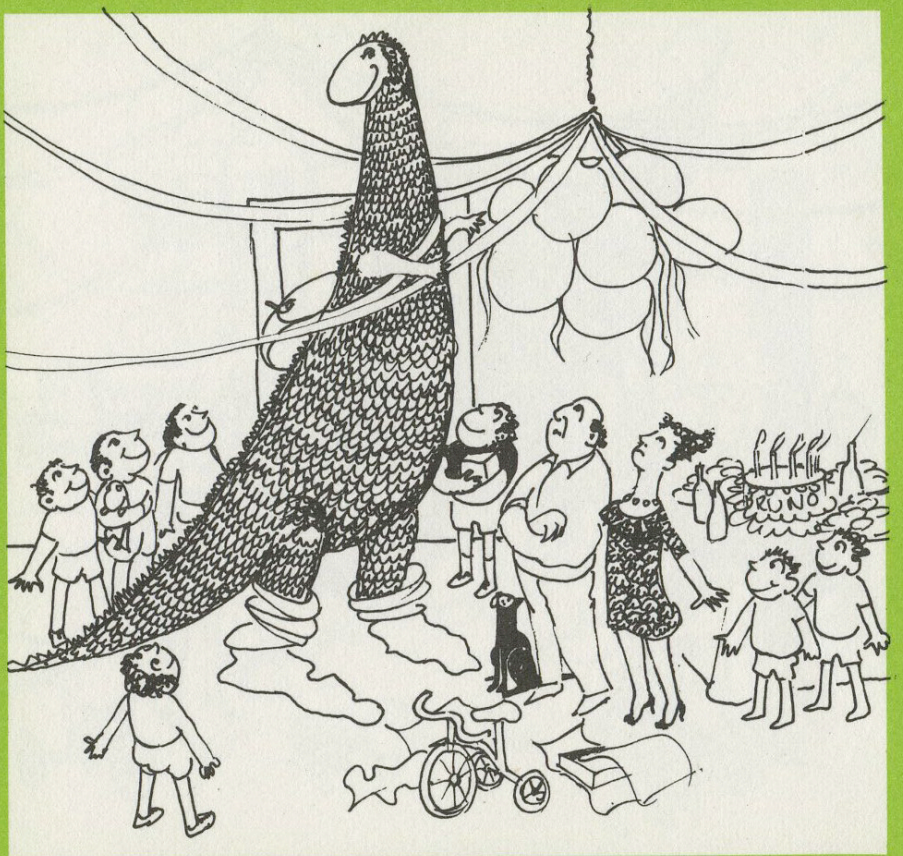

A dinosaur went to a birthday party

All dressed up in big sloppy dinosaur socks;

Slung over his shoulder he carried a school-bag,

Tucked inside the bag was a brightly wrapped box.

figure. 5-7 The first page of Big Sloppy Dinosaur Socks. 


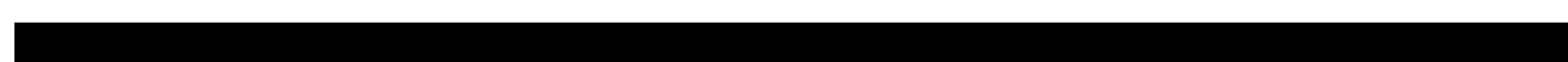




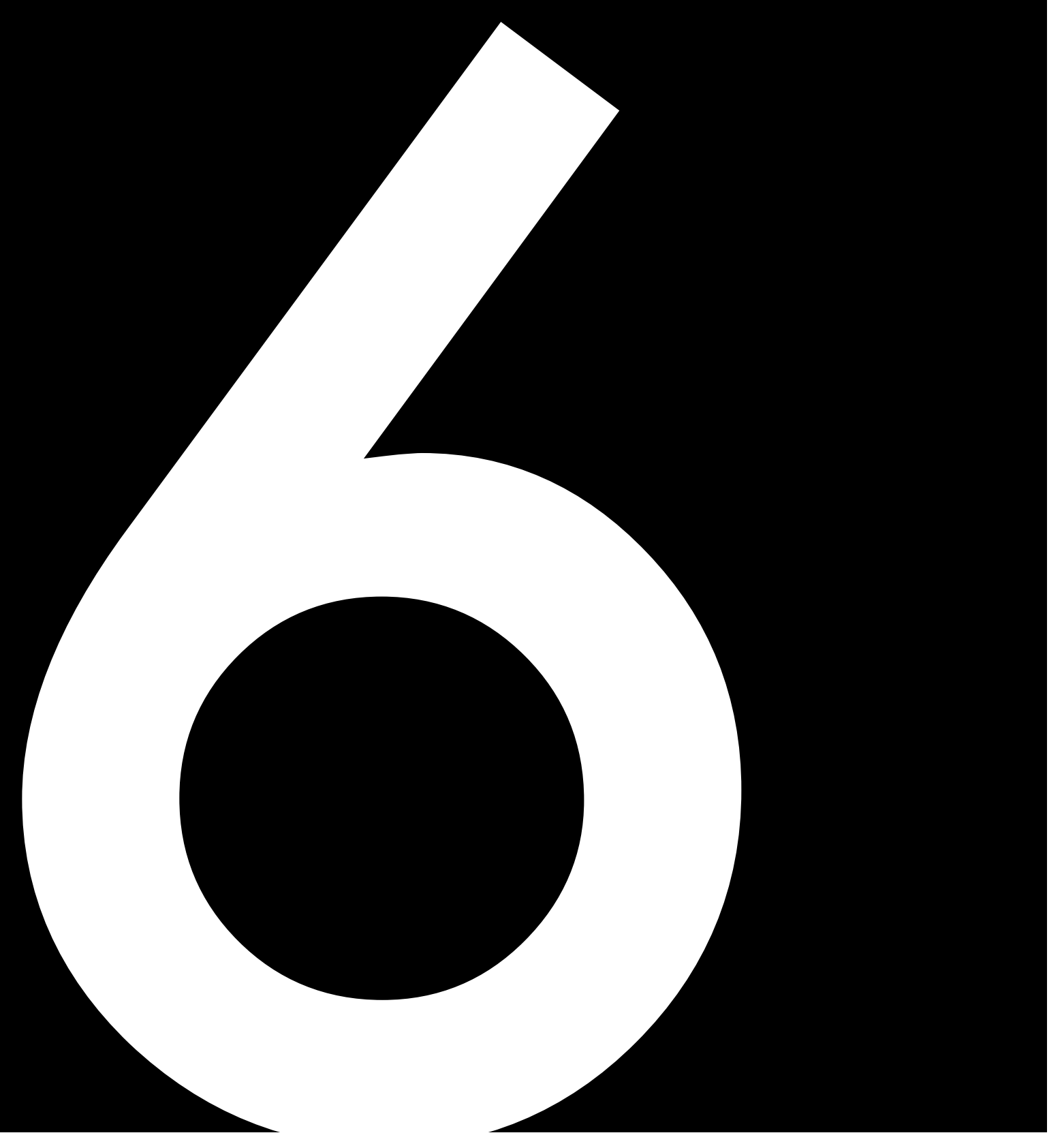




\section{Design Scenarios}


The following scenarios have been developed from the storyboards using Big Sloppy Dinosaur Socks as

a speculative reference for enhancing existing collections. The scenarios simulate the use of AR in connection with $3 \mathrm{D}$ printing to create a unique output for each. This called on iterative design experimentation using a wide range of CAD tools and $3 \mathrm{D}$ printing processes.

To do this 3D CAD software was used in conjunction with visual programing based generative software to create a parametric 3D model of the dinosaur illustrated in Big Sloppy Dinosaur Socks.

Rhinoceros 3D (Rhino) is a 3D CAD software that creates models using Non-Uniform Rational Basis spline (NURBS) mathematical curve modelling. It is used across many different applications in industry such as rapid prototyping, 3D printing, engineering, architecture, and industrial design to develop 3D models for production. Grasshopper is a visual programing language plugin for Rhino that creates geometries by adding components onto a canvas. It allows control over numerous parameters via a visual interface. With these components you can build up a definition of a geometry in Grasshopper with a rendered display of the geometry in Rhino. With a combination of these two programs a parametric fully posable $3 \mathrm{D}$ model of the dinosaur from Big Sloppy Dinosaur Socks was created.

Although defining the parametric model is complex and time consuming, once constructed in Grasshopper, it results in an interface using screen based sliders to articulate the model and facilitate changes in the pose and size of the dinosaur. The parametric model demonstrates in principle how a 3D artefact can be manipulated on screen, however the ultimate user interface, would ideally in the form of an app, is beyond the scope of this project.

The scenarios also call on a variety of different 3D printing technologies and demonstrate how they can be used, not only to achieve different outputs but also to expand on the narrative in a number of different ways. This included exploration in FDM plastic printing, Connex multi-material printing in colour and full colour Projet sandstone printing. For a full breakdown of the modelling process and printing refer to appendix (a). 


\section{Scenario.1}

Randle, a year 4 (age 8) student, is on a school trip to the Library He loves dinosaurs and wants to find out if the Library has any cool books about dinosaurs.

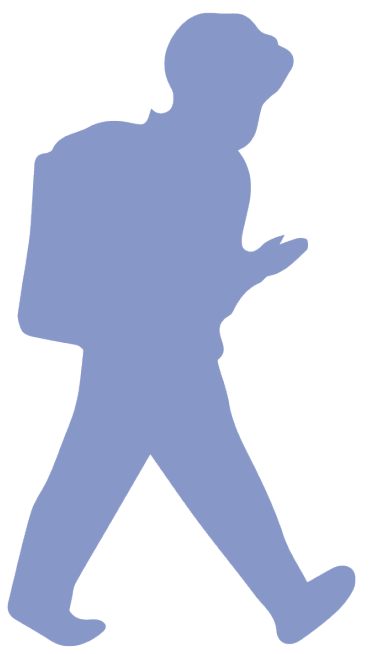

On this trip the children have been instructed to find books about a topic they are interested in, using the search engine techniques they have been taught in class. Randle begins by looking up dinosaurs, but there are too many results. Adding the word "big" to the search narrows it down and viewing only "book" in "results" narrows it down further.

Half way down the page he finds a book called Big Sloppy Dinosaur Socks and decides to call it up.

Twenty minutes later the book arrives and he can read through it. While reading it he discovers that this book has been seeded with an AR model and finds a librarian to help him access the AR using a smart device.

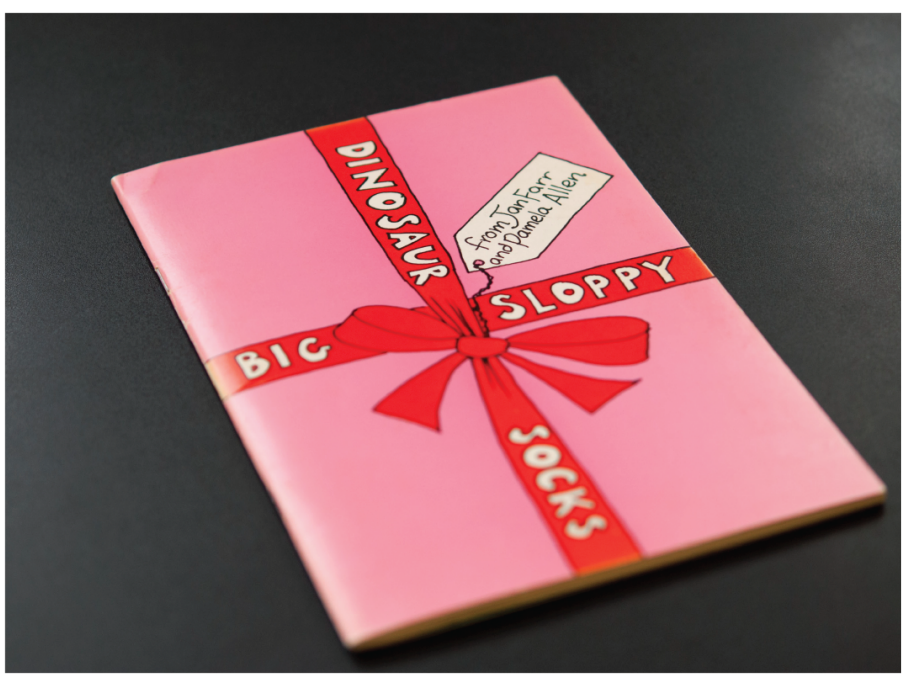




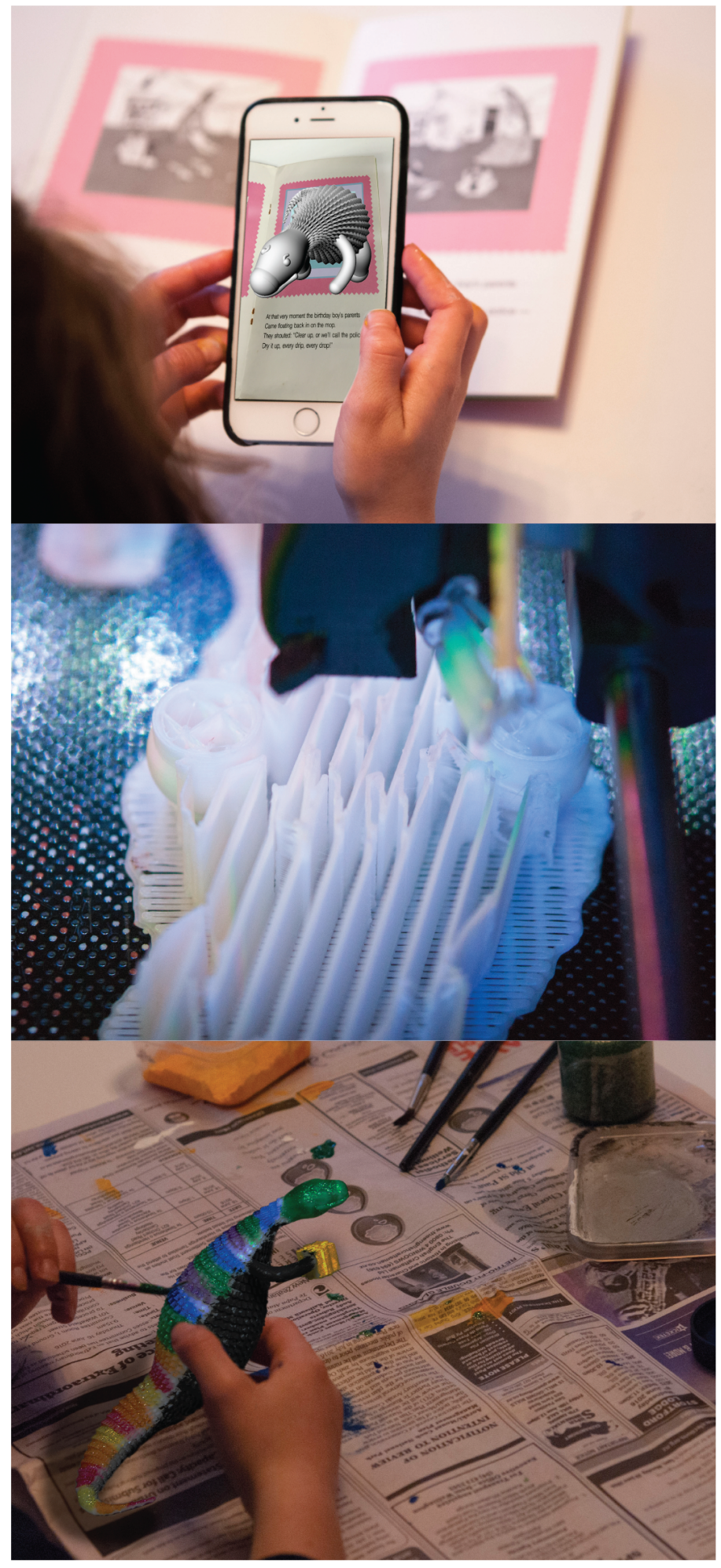

After some time playing with the mesmerising AR mode and imagining the adventures they could get up to, the Librarian points out that he can actually use the Library's 3D printing services to print out the dinosaur.

Randle quickly finds three dollars in his bag and starts the $3 \mathrm{D}$ print.

Just as the group is ready to leave the Library Randle's print finishes and he can take it with him.

At home Randle and his Dad clean the support material from the print. Randle thinks the dinosaur will look much better with a paint job and hand paints the dinosaur. 


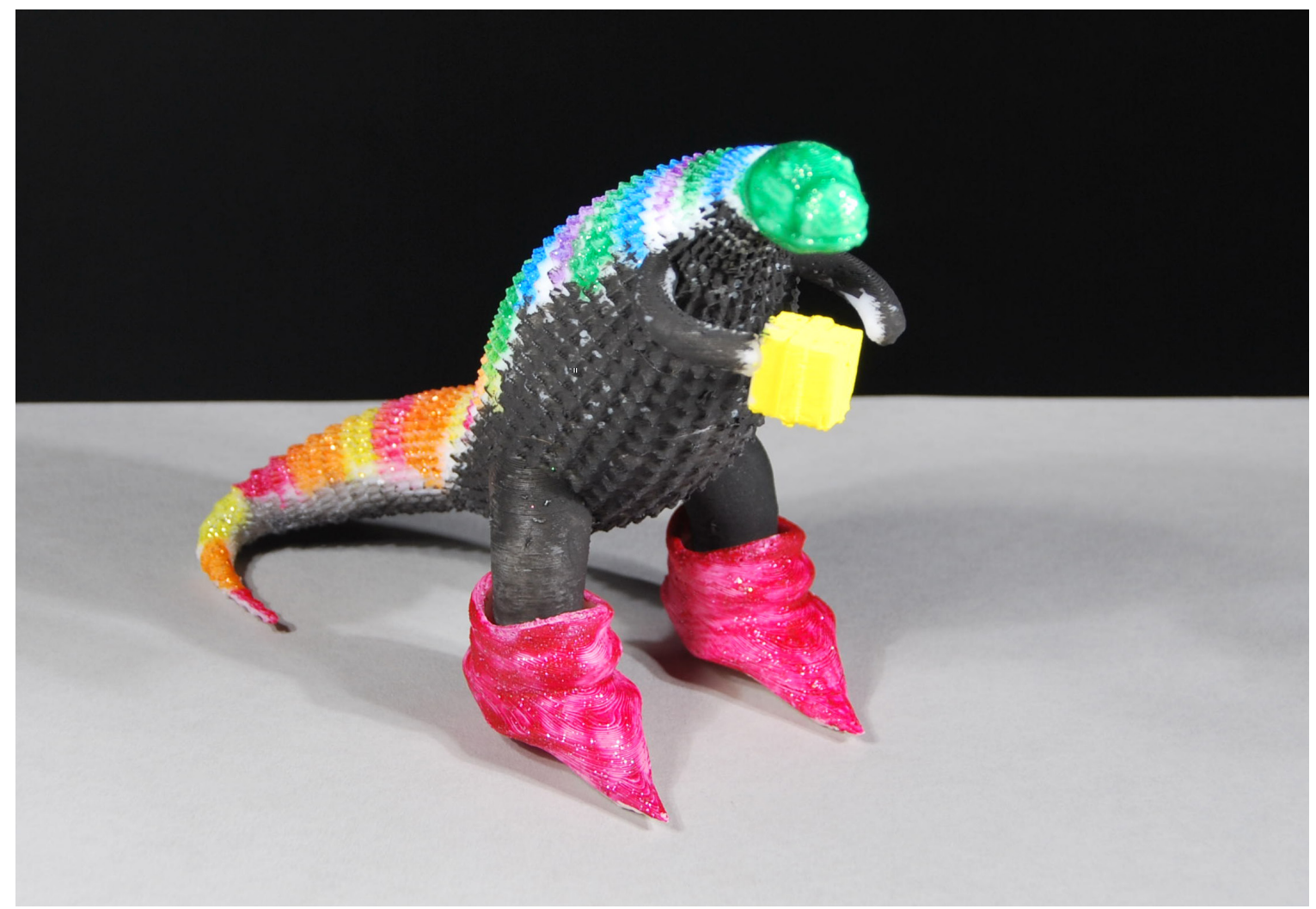

figure. 6-1 Showing the full painted dinosaur.

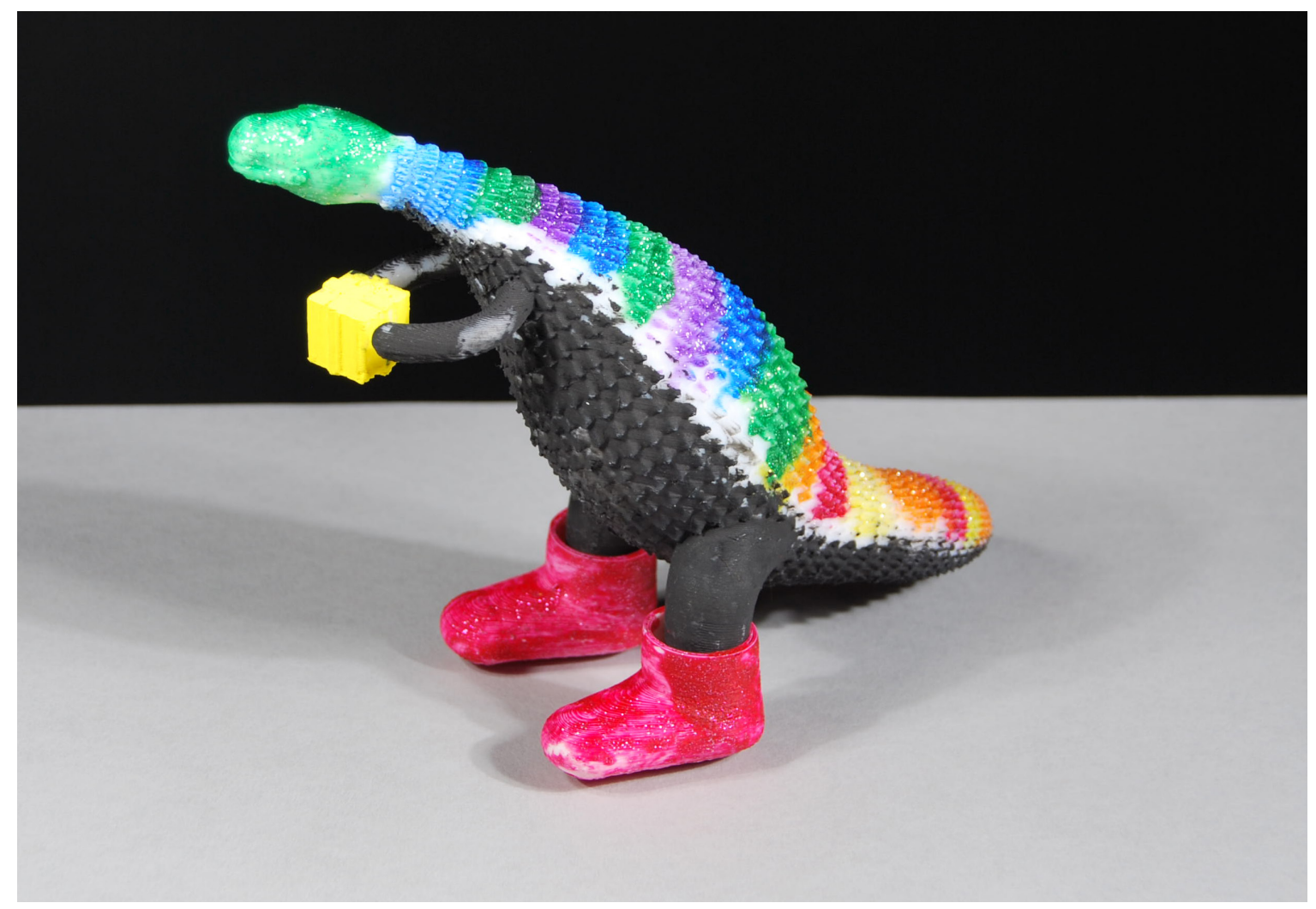

figure. 6-2 Showing the full painted dinosaur in a different socks. 


\section{Scenario. 1 Reflection:}

This scenario creates a clear connection between the Library collections and how interactions with content can be expanded into both digital and physical interactions. A functionally simple AR app is used to mediate between the content and the $3 \mathrm{D}$ printing. The app connects to the Library's current implementation of 3D printing, the UP! printers. This scenario speculates about how these technologies could be implemented at the most straightforward entry level. The print has been downloaded without any additional manipulation and the personalization that occurs within this scenario is the hand painting of the $3 \mathrm{D}$ print. This gives the child the opportunity to impart their own creative vision to the appearance of the dinosaur. The personalization begins to show how the narrative can be developed through simple hand painting and it follows an interesting trajectory from the physical into digital and back to physical. This scenario speculates that following a class trip to the Library no two hand painted dinosaurs would look the same. 


\section{Scenario.2}

Charlotte, a year 7 student (age 12) is doing a research project on illustrator Pamela Allen and her illustrations. Charlotte is looking for older books illustrated by Pamela to find out how her illustration style evolved. She calls up the first two books she finds: The Pow Toe and Big Sloppy Dinosaur Socks.

While reading these books she sees that Big Sloppy Dinosaur Socks has an animated AR model. Using a smart device she can view the animation and bring the dinosaur to life. The animation captivates her attention as she watches the dinosaur move around.

Charlotte chooses a pose for the dinosaur by freezing the animation and sends it off to a low resolution $3 \mathrm{D}$ printer as one of the options from the app. Charlotte takes her print home.
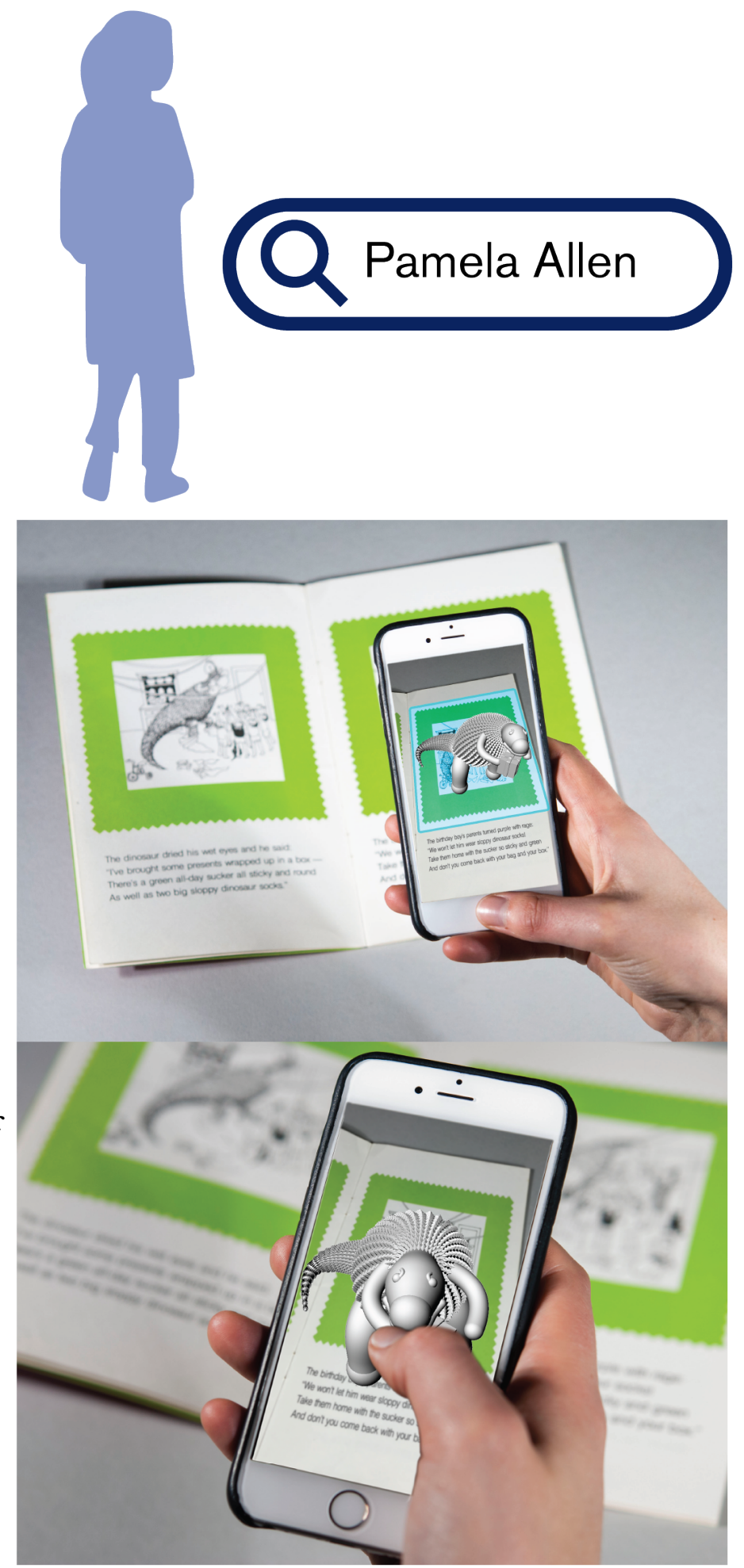


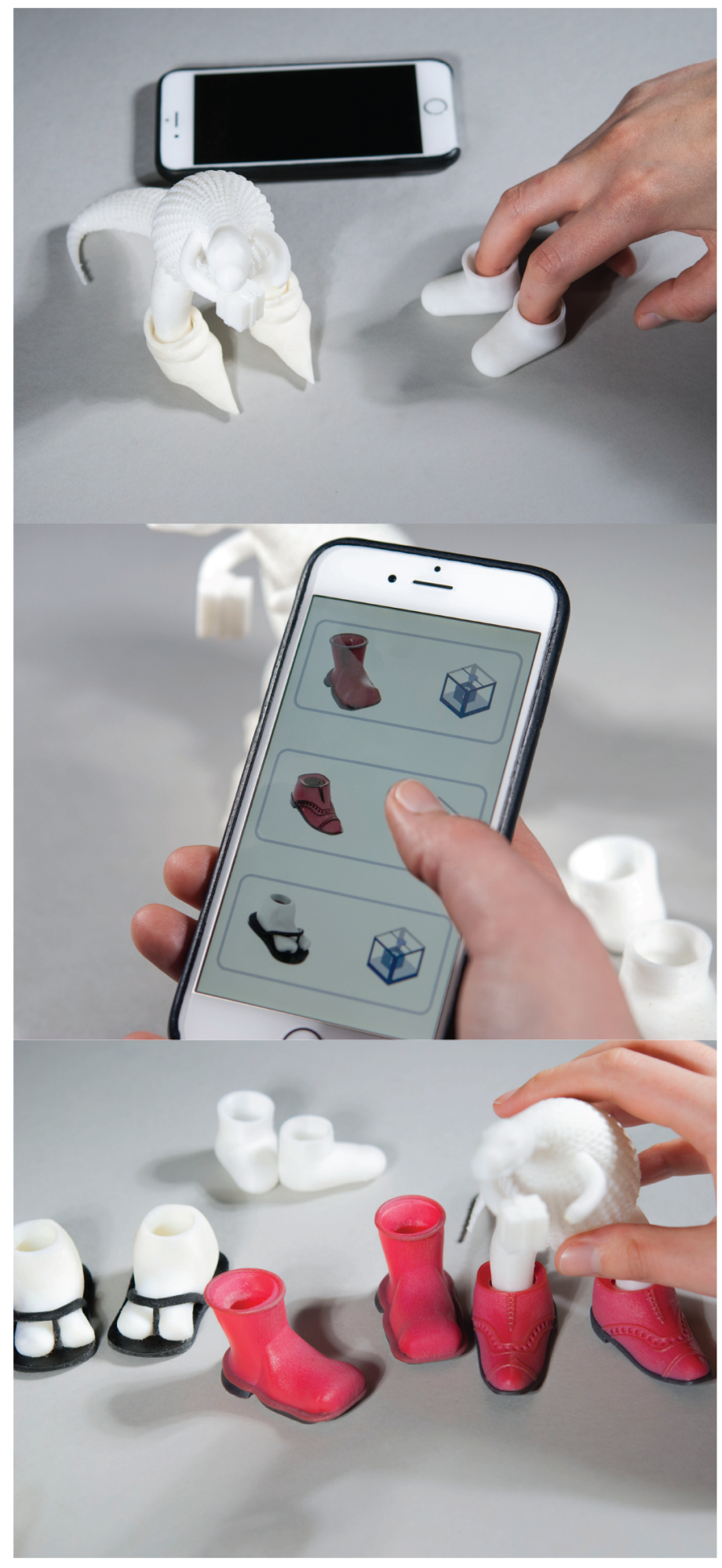

While playing with it she remembers that in the book the dinosaur becomes a better person by changing socks. She thinks she could help the dinosaur even more if he had shoes. Looking through the app she finds that someone has already modelled some dress shoes, gumboots, and jandals with socks.

In the corner of the page with the shoes, Charlotte sees a link to printable 3D files. Clicking on the link, she discovers they can be printed in colour. She begs her Dad to buy her the shoes so she can turn the Dinosaur into a dapper dinosaur with the dress shoes, a farmer with the gumboots, and a classic kiwi dinosaur in the socks and jandals. Eventually caving in, he orders her the coloured shoes.

Once they arrive in the mail she quickly puts them on the dinosaur and updates her AR model with her fantastic new shoes. Charlotte begins to wonder if she could model her own shoe for the dinosaur and turn it into a prince. 


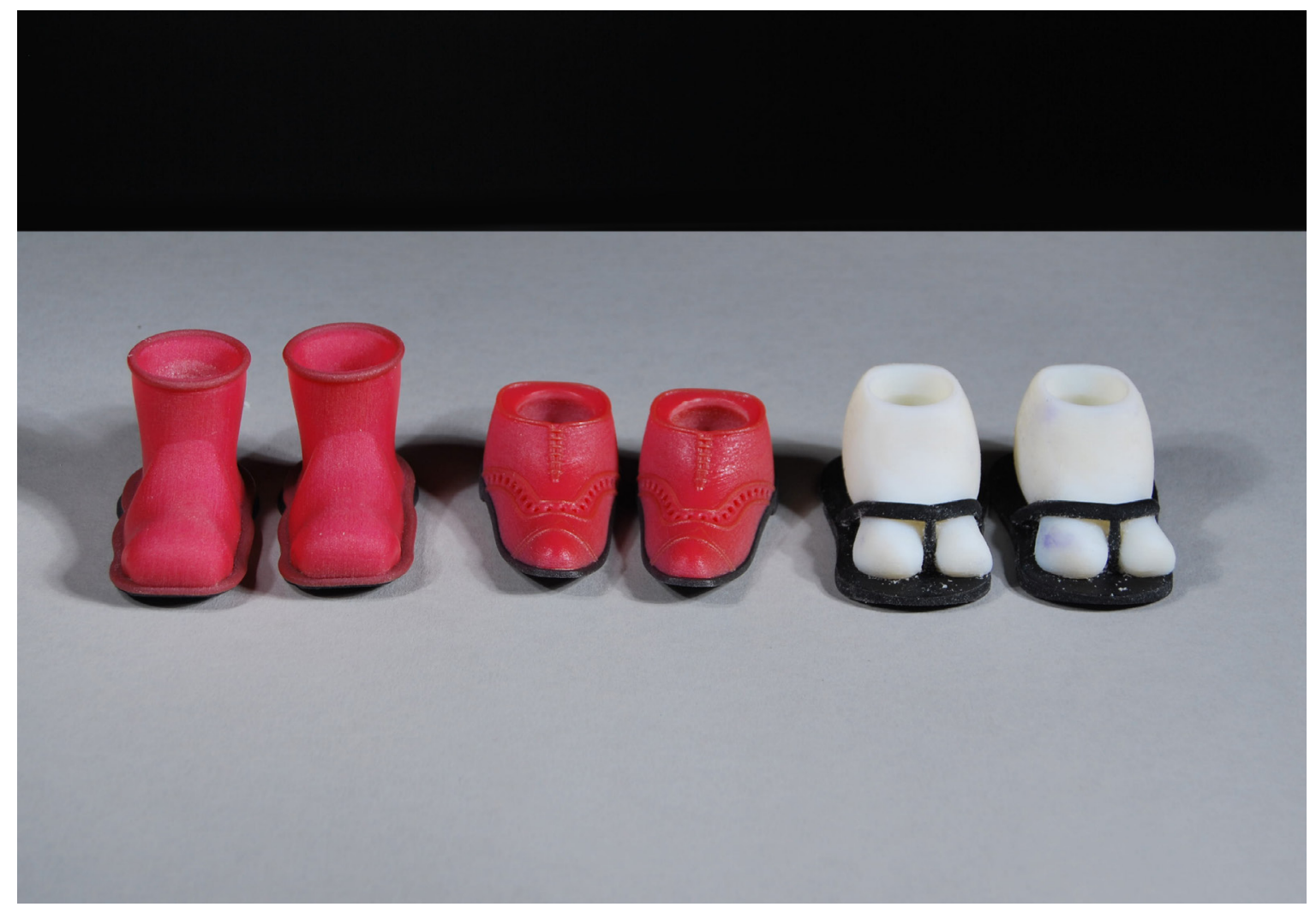

figure. 6-3 Image showing all three sets of shoes.

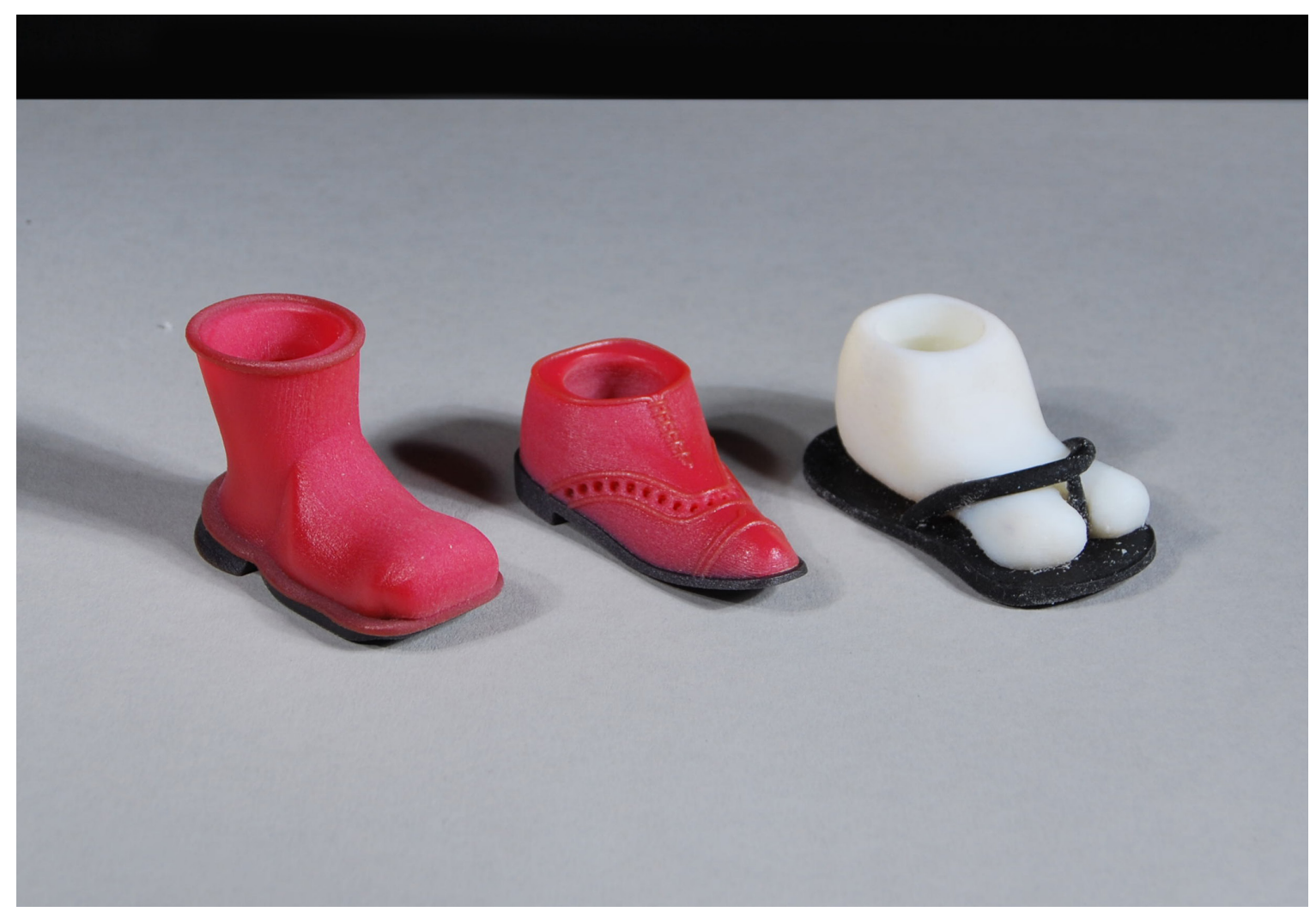

figure. 6-4 Further image of the three types of shoes. 


\section{Scenario.2 Reflection:}

This scenario speculates on another level of AR with an animation to further bring the dinosaur to life before it is printed. The animation allows some customisation of the printed model by frame freezing the pose of the print. An additional narrative has been created by adding a variety of shoes. This extension invites co-creation in the form of unexpected contributions that can be supplemented or modified by anyone with access to CAD software. Along with this physical feedback of receiving the shoes, the shoes could also be digitally applied to the AR model and animation, reconnecting the $3 \mathrm{D}$ printing back to the on screen model. 


\section{Scenario.3}

Daniel, a year 10 (age 14) student, is part of a holiday programme at the Library to showcase how the Library's collections connect with their 3D printing program. While attending the holiday programme Dan uses the book the Big Sloppy Dinosaur Socks to get his initial model.

Using the fascinating AR to interact with a 3D model of the dinosaur, Dan decides he wants a really fat dinosaur because, he proposes, it ate all the cake at the end of the book and blew up just like the balloons. He can customise the model using sliders and get instant visual feedback about the model.

He also wants to make the dinosaur able to cry: to do this he must make the dinosaur hollow so it can be filled with water. Using the app he shells the skin of the dinosaur.
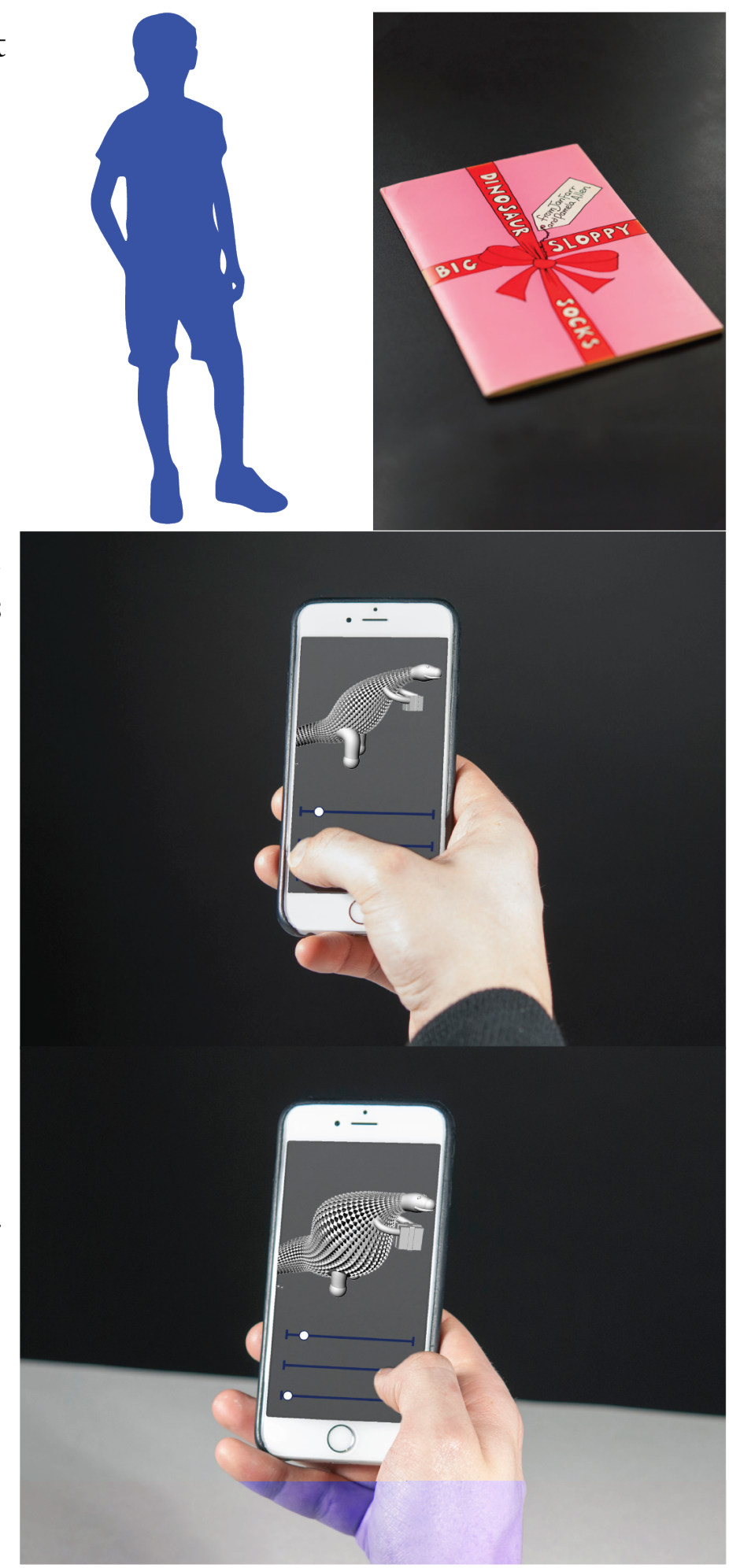


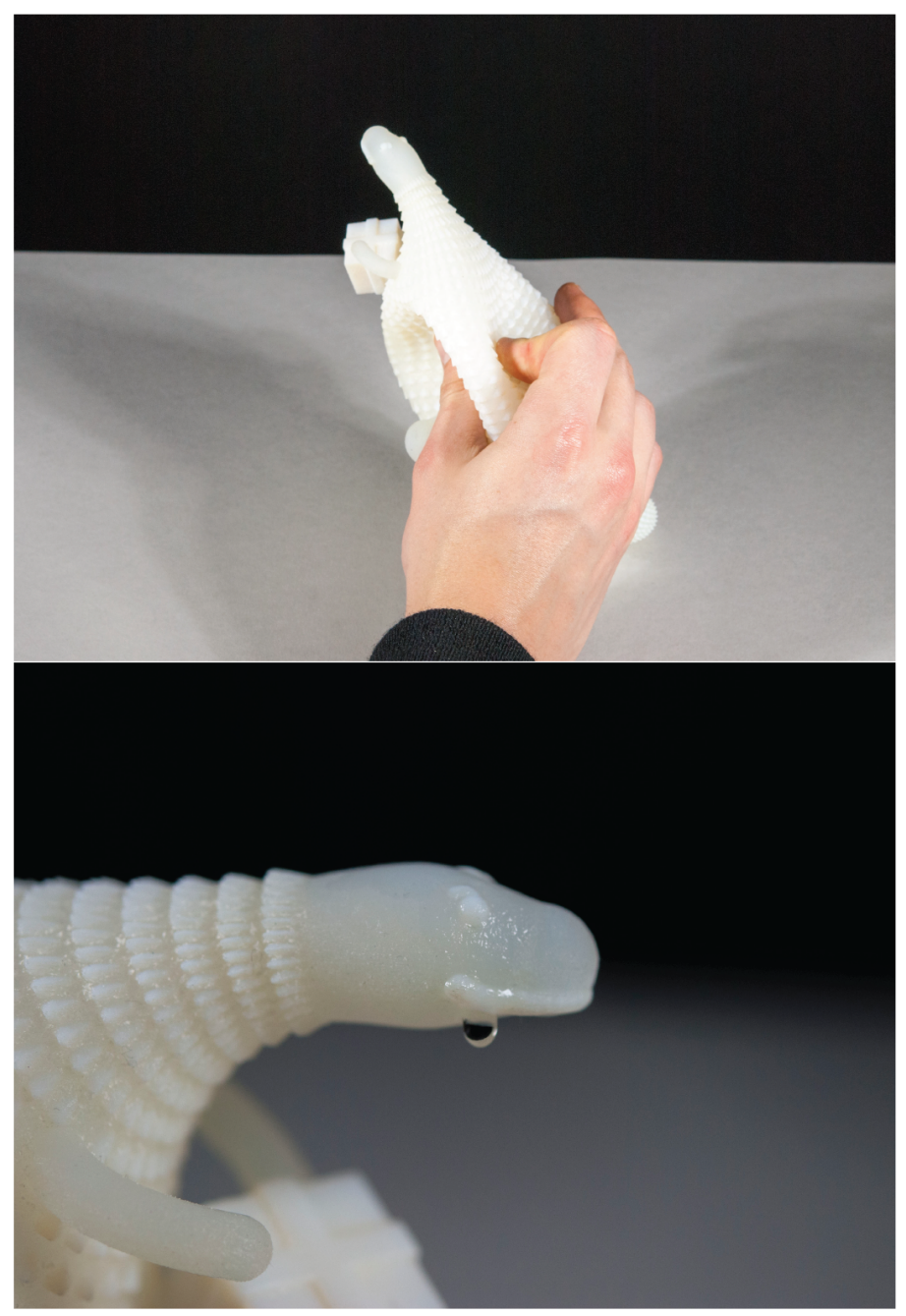

He also chooses a soft body material from the multi-material (Connex) printing selection so it can be squeezed.

Once this model is created it can be sent it off to be printed on a multi material $3 \mathrm{D}$ printer. Once printed Dan receives the flexible fat dinosaur that can cry. The custom model is uploaded to the apps database and made available for further use/modification. 


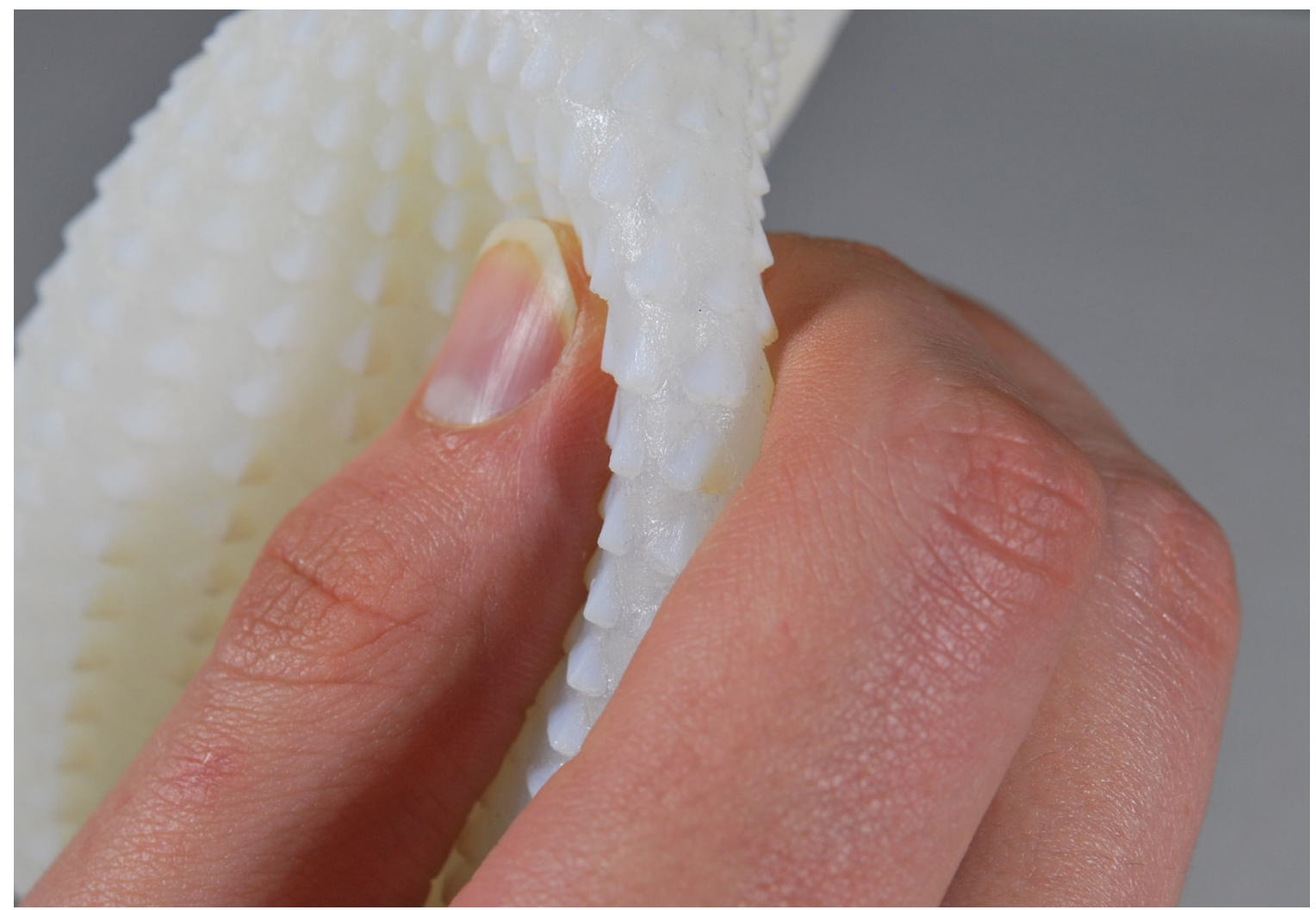

figure. 6-5 An image of the flexible dinosaur.

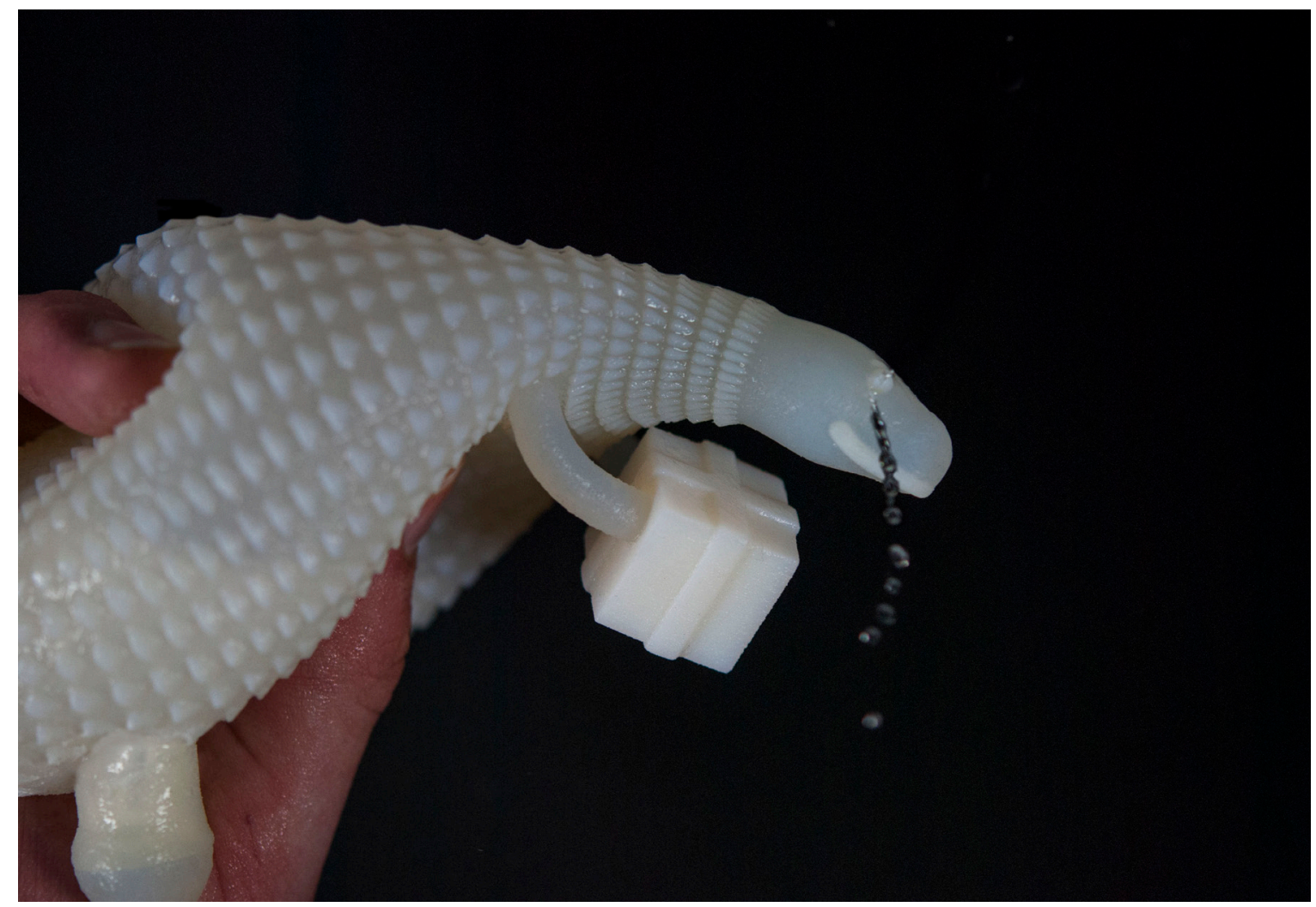

figure. 6-6 Showing the dinosaur crying. 


\section{Scenario.3 Reflection:}

This scenario uses a complex AR app that allows a large variety of modifications to be made to the model, giving users the ability to customise the model with a wide variety of tools similar to those in many open-source 3D modelling apps. This customisation gives users opportunity to take the narrative of the book to places never imagined and thus extend the narrative.

With the app connecting to multiple different methods of 3D printing the highly customised models are able to be printed in any way the user decides; multi-material is used here to showcase the tactile nature of $3 \mathrm{D}$ printing. The inclusion of a model database gives users the opportunity to start building on other models, creating co-created models. 


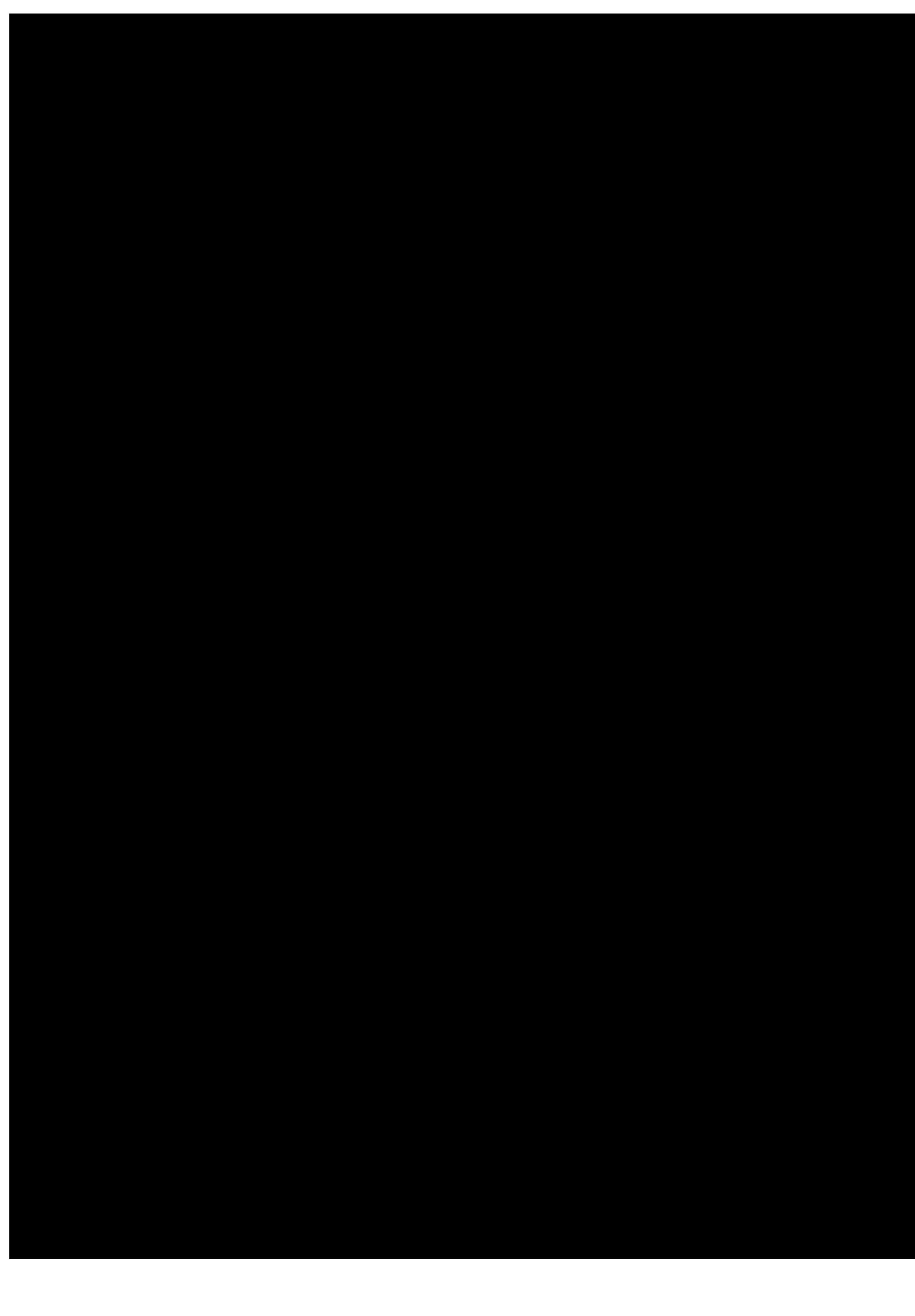




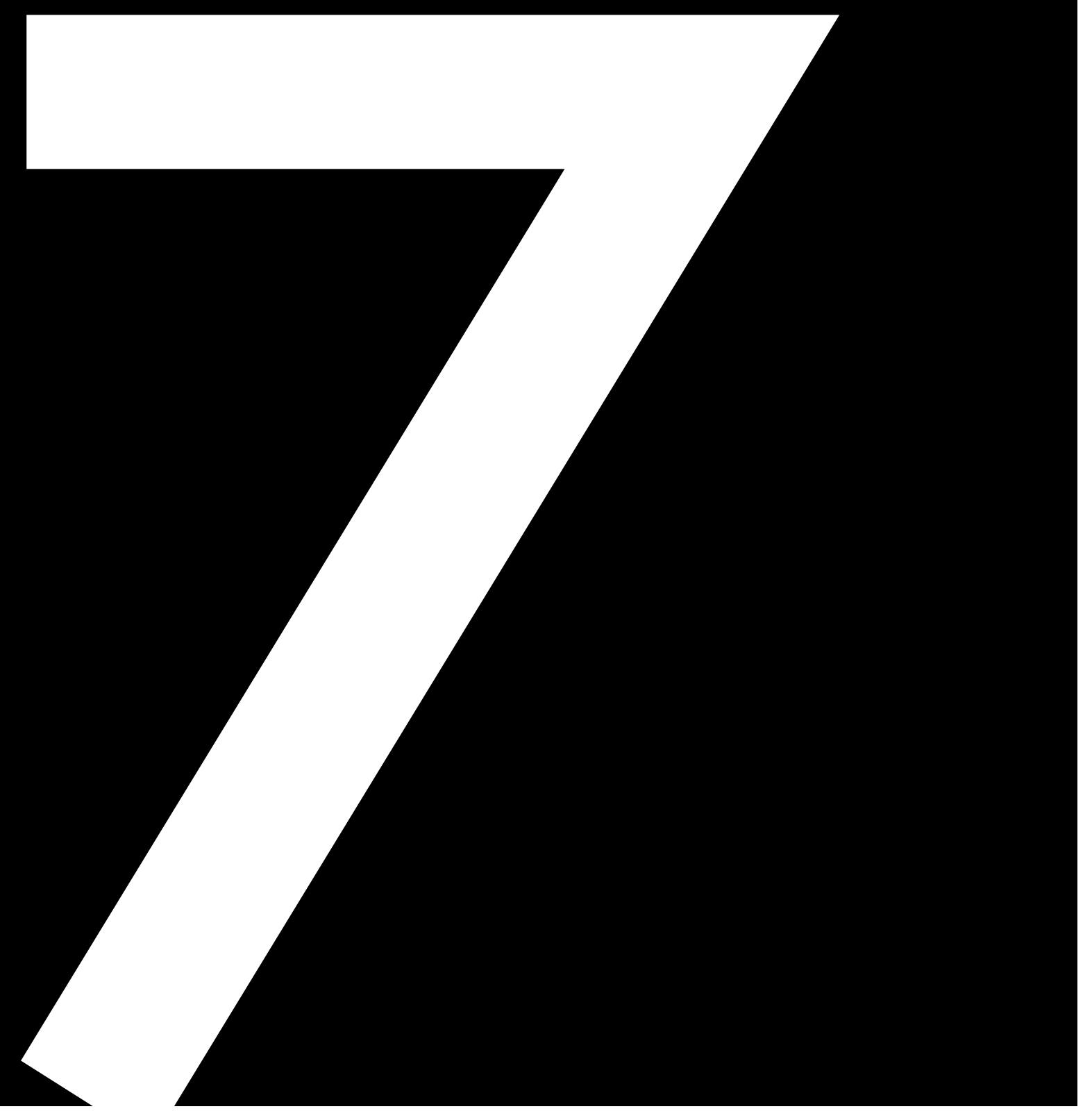


Conclusion 
In responding to the question "But why exactly is it appropriate for a library service to provide $3 \mathrm{D}$ printing?" this thesis project provides a plausible group of scenarios as a reference point for future development. As a design response to the question it is speculative, but nevertheless informed by an in-depth exploration of the surrounding technological context and access to the Library's collections.

The initial context exploration into smart objects, technologies, and collections developed a clear and grounded understand of the surrounding context. In response, the case studies identified opportunities to develop connections between a broad range of technologies and media, gave a departure point for ideation and development of scenarios.

The subsequent scenarios demonstrate potential applications of 3D printing. To focus the scenarios a specific collection item was used to create cohesion between the scenarios while demonstrating how different outputs can emerge from the same item. The scenarios also allowed connections between different forms of media $-2 \mathrm{D}$ analogue to $3 \mathrm{D}$ virtual, to $3 \mathrm{D}$ physical and back to $2 \mathrm{D}$ analogue - to emerge. This sequence honors the physical nature of books taking advantage of digital technologies to rejuvenate and enliven them, then returning to physical play as a way of inspiring narrative extension. Along with the diversity of potential outputs from a singular input, the scenarios highlight how potential applications of different types of 3D printing can in themselves be an inspiration for new narratives. While the scenarios still need to be resolved on a technical level, they are intended to awaken interest in future possibilities.

In providing an opportunity for narrative extension, the intention of the scenarios is to invite a response from the Library community; important to this was Jan Farr's contribution. When asked if she would contribute to a scenario she graciously obliged. 
Jan Farr was asked to colour in a line drawing of the dinosaur from Big Sloppy Dinosaur Socks.

From this coloured-in drawing, it was then possible to texture the digital model of the dinosaur with these colours, simulating Quivertype technology. Using 3D full colour sandstone (Projet) printing resulted in a physical reincarnation of the dinosaur from the book, co-created with the author herself, revitalising her own content and bringing the dinosaur to life in a new form nearly 40 years after the book's publication. Jan Farr's engagement demonstrates in a microcosm how participation from unexpected sources might occur when suitable systems of co-creation and networks of making are implemented. The opportunity for the Library, and indeed libraries worldwide, to update physical collections not only has implications for re-empowering their existing collections - it could potentially change the way new books are written, produced, and published.

The technologies and media speculated on in the scenarios are still nascent in everyday use. The growing trend to $3 \mathrm{D}$ and $4 \mathrm{D}$ data collections will only accelerate the development of this process, as these technologies become ubiquitous. With ease of access to increasingly sophisticated online networks, with more 3D printing service providers, faster and more varied 3D printing methods, more intuitive $\mathrm{CAD}$ modelling software, and with libraries diversifying their collections to suit the increasing range of digital images, websites, 3D scans, 3D models, and other dynamic media, it is clear that digital technologies will play a significant role in the future of libraries. Just as the need for computers in society was debated, the discussion about a place for $3 \mathrm{D}$ printing within library services may soon become superfluous. 


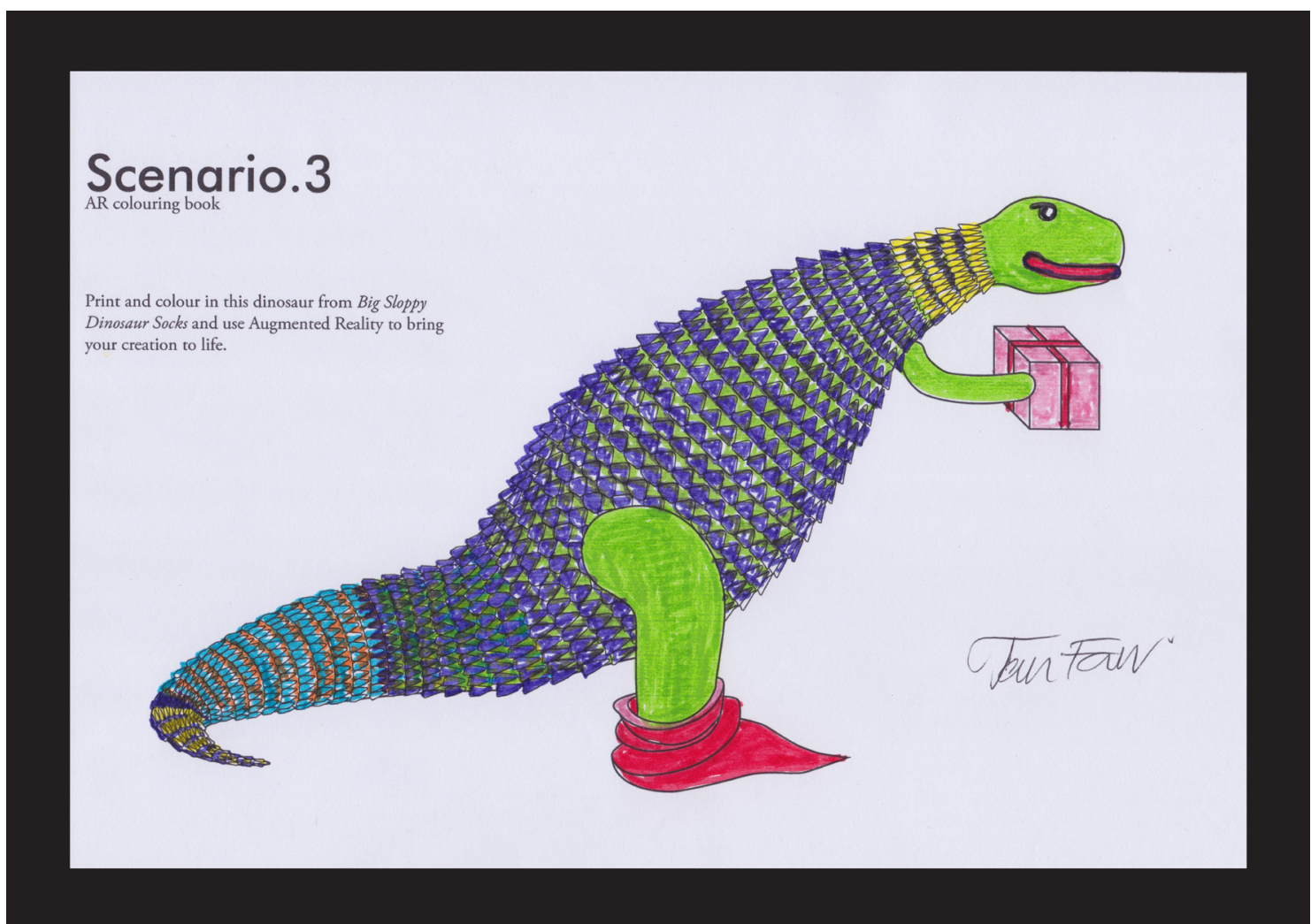

figure. 7-1 Jan Farr's colouring of the dinosaur.

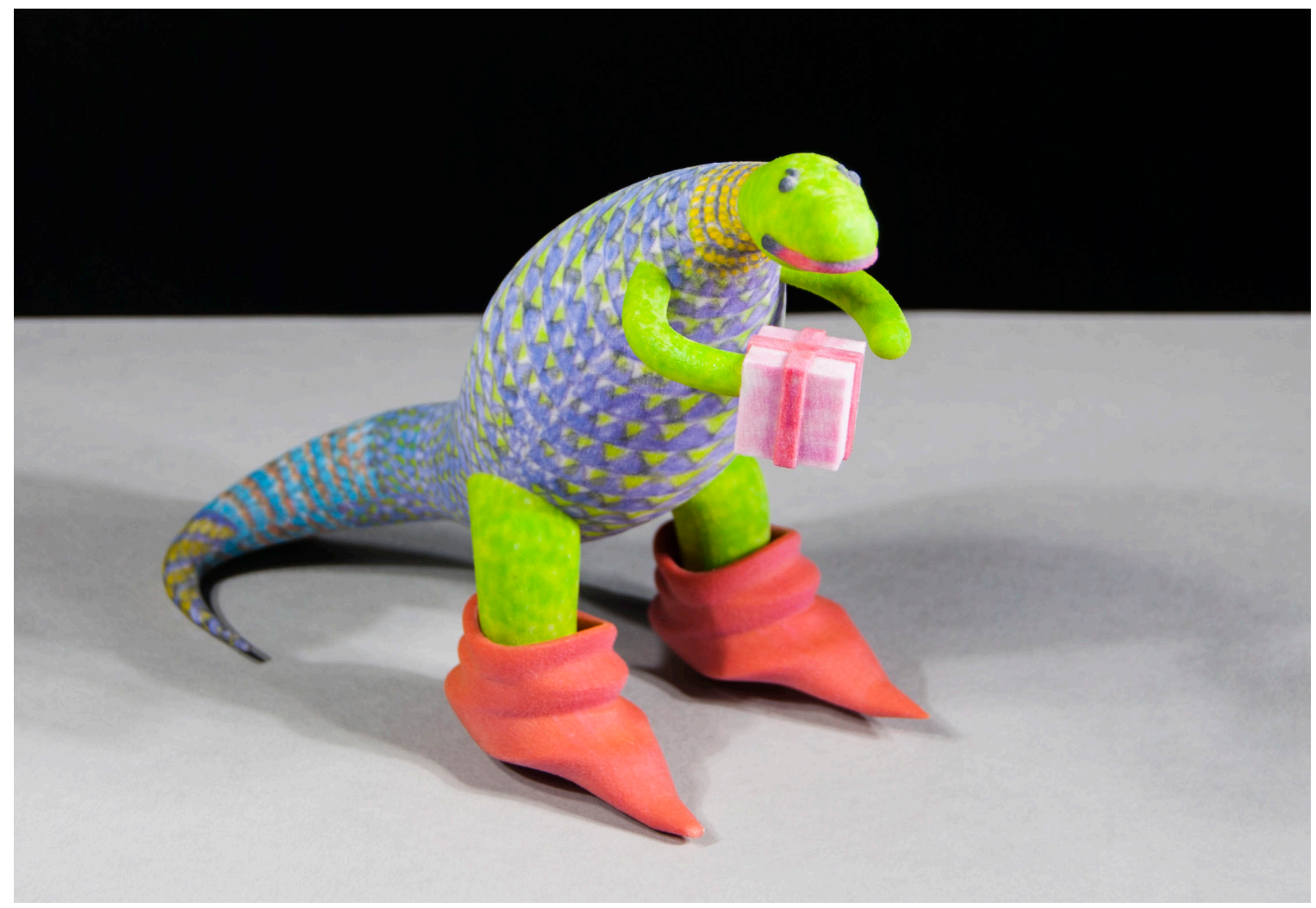

figure. 7-2 The textured sandstone colour 3D printed dinosaur. 
Figures List 
figure. 3-2 Maaike Roozenburg smart replicas. (n.d.). Maaike Roozenburg smart replicas AR app. Retrieved November 13, 2016, from http://payload283.cargocollective. com/1/2/69884/7968847/B01_kl_900.jpg

figure. 3-3 Maaike Roozenburg combines augmented reality and digital prototyping to create smart fakes. (2014). Retrieved November 13, 2016, from https://static.dezeen.com/uploads/2014/07/3D-printed-cup-by-Maaike-Roozenburg_dezeen_784_24.jpg

figure. 3-4 The Courier Reporter (2014). Central Library's 3D printer is the shape of things to come [News site]. Retrieved March 31, 2016, from https://www.thecourier.co.uk/wp-content/uploads/sites/12/2016/04/image.jpg1_.394139.jpg

figure. 3-5 Dundee Central Library. (n.d.). Retrieved Janurary 13, 2016, from https://fbcdn-sphotos-g-a.akamaihd.net/hphotos-ak-xtp1/t31.08/10338683_728240883906247_5509553033216049493_o.jpg

figure. 3-6 Quiver. (n.d.) Retrieved Janurary 13, 2016, from https:// pbs.twimg.com/media/CTsLI2rWsAAzS_o.jpg

figure. 3-7 Quiver Augmented Reality. (2013). Quiver - 3D printing test. Retrieved from https://www.youtube.com/watch?v=UxYqhmEB4G8\&feature=youtu.be

figure. 3-8 LEGO AR catalogue (n.d.). Retrieved 7 July 2016, from https://lh3.googleusercontent.com/IdnTj9HemxZguWV-XgPYx42IDxwlt9KsvnaKkOwBZHYcKxfJqjJlQC3FjdKfk5UCn$\mathrm{NnP}=\mathrm{h} 900-\mathrm{rw}$

figure. 3-9 LEGO AR catalogue app home screen. $(675 \times 900)$. (n.d.). Retrieved 7 July 2016, from https://h3.googleusercontent. com/PYPR4TvFv8y0hl-oJjuJko6iahRrlCS1B5M8qHTmGRwDINyumWdQDRW7mxIHjil9B8A=h900

All subsequent figures are credited to the author. 
Reference List 
Ashley, S. (1997). From CAD art to rapid metal tools.

Mechanical Engineering, 119(3), 82-87. Retrieved from http://search.proquest.com/docview/230175522/ abstract/3FC8578DFF204026PQ/1

Azuma, R., Baillot, Y., Behringer, R., Feiner, S., Julier, S., \& MacIntyre, B. (2001). Recent advances in augmented reality. IEEE Computer Graphics and Applications, 21(6), 34-47. http:// doi.org/10.1109/38.963459

Bajic, E. (2009). A Service-Based Methodology for RFID-Smart Objects Interactions in Supply Chain. International Journal of Multimedia and Ubiquitous Engineering, 4(3), 37-55

Billinghurst, M., Clark, A., \& Lee, G. (2015). A Survey of Augmented Reality. Foundations and Trends in HumanComputer Interaction, 8(2-3), 73-272. http://doi. org/10.1561/1100000049

Billinghurst, M., Kato, H., \& Poupyrev, I. (2001). The MagicBook - moving seamlessly between reality and virtuality.IEEE Computer Graphics and Applications, 21(3), 6-8. http://doi. org/10.1109/38.920621

Clark, A., \& Dünser, A. (2012). An interactive augmented reality coloring book. In 2012 IEEE Symposium on $3 D$ User Interfaces (3DUI) (pp. 7-10). http://doi. org/10.1109/3DUI.2012.6184168

Colegrove, T. (2013). Editorial board thoughts: Libraries as makerspace? Information Technology and Libraries (Online),32(1), 2-5. Retrieved from http://search.proquest. com/docview/1356913023/abstract/7D105387950E485FPQ/1 
The Courier Reporter (2014). Central Library's 3D printer is the shape of things to come [News site]. Retrieved March 31, 2016, from http://www.thecourier.co.uk/news/local/dundee/central-librarys-3d-printer-is-the-shape-of-things-to-come-1.394146

Department of Internal affairs. (n.d.). Logo National Library of New Zealand. dia.govt.nz [government Website]. Retrieved June 16, 2016, from https://www.dia.govt.nz/Logo-National-Library-ofNew-Zealand

Goumopoulos, C., \& Kameas, A. (2009). Smart Objects as Components of UbiComp Applications. International Journal of Multimedia and Ubiquitous Engineering, 4(3). Retrieved from http://www.sersc.org/journals/IJMUE/vol4_no3_2009/1.pdf

Gui Cavalcanti. (2013, May 22). Is it a Hackerspace, Makerspace, TechShop, or FabLab? | Make: Retrieved from http://makezine. com/2013/05/22/the-difference-between-hackerspacesmakerspaces-techshops-and-fablabs/

Hardesty, L. (2013). Surprisingly simple scheme for self-assembling robots. MIT News. Retrieved from http://news.mit.edu/2013/simplescheme-for-self-assembling-robots-1004

Honey, S., \& Milnes, K. (2013). The annotated america's cup. IEEE Spectrum, 50(9), 36-42. http://doi.org/10.1109/ MSPEC.2013.6587187

Hsu, H.-H., Lee, C.-N., Hung, J. C., \& Shih, T. K. (2011). Smart object reminders with RFID and mobile technologies. Mobile Information Systems, 7(4), 317-327.

Lankes, R. D. (2013, January 3). Beyond the Bullet Points: Missing the Point and 3D Printing. Retrieved from http://davidlankes. 
$\operatorname{org} / \mathrm{p}=2538$

LEGO. (2016, February 1). LEGO ${ }^{\oplus}$ 3D Catalogue [App store].

Retrieved from https://play.google.com/store/apps/ details?id=com.lego.catalogue.global\&hl=en

LEGO $^{\odot} 3$ D Catalogue - Android Apps on Google Play. (2016). Retrieved June 25, 2016, from https://play.google.com/store/ apps/details?id=com.lego.catalogue.global\&hl=en

Liddane, L. (2012, May 23). Lego store shows off remodel at Downtown Disney. Orange County Register (Santa Ana, CA). Retrieved from http://go.galegroup.com/ps/i.o?id=GALE\%7CA $290478579 \& v=2.1 \& u=v u w \& i t=r \& p=I T O F \& s w=w \& a s i d=b 1 c$ d793d50a595a88a600a975f8cb9f0

Lipson, H., \& Kurman, M. (2013). Fabricated: The new world of 3D printing. John Wiley \& Sons.

Lougee, W. P. (2002). Diffuse libraries: Emergent roles for the research library in the digital age. Council on Library and Information Resources (p. 28). Retrieved from http://www.clir.org/pubs/ reports/pub108/digital.html

Lutero, L. (2016, March 23). Alice's Adventures in Wonderland as you've never seen. Retrieved June 28, 2016, from http:// www.psfk.com/2016/03/sony-presents-a-future-of-magicalstorytelling.html

Madakam, S. (2015). Internet of Things: Smart Things. International Journal of Future Computer and Communication, 4(4), 250-253. http://doi.org/10.7763/IJFCC.2015.V4.395 
Maloney, J. (2014, June 30). New York Public Library Looks at Innovative Models for Renovation. Wall Street Journal.

Retrieved from http://www.wsj.com/articles/new-york-publiclibrary-looks-at-innovative-models-for-renovation-1404090627

Milton, A., \& Rodgers, P. (2013). Research methods for product design. London: Laurence King.

MiME: Glow Tags - Creative Innovation Works | Innovation

Consultancy. (2001). Retrieved June 28, 2016, from http:// www.creativeinnovationworks.com/work/mime-glow-tags/

National Library of New Zealand. (2015). About the Library.

Retrieved from http://natlib.govt.nz/about-us

Retrieved July 4, 2016, from http://natlib.govt.nz/visiting/ wellington/3d-printing

National Library of New Zealand. (n.d.). 3D printing | Wellington centre | Visiting | National Library of New Zealand. Retrieved July 4, 2016, from http://natlib.govt.nz/visiting/wellington/3dprinting

National Library of New Zealand. (n.d.). The digital archive of the future | [Blog]. Retrieved June 2, 2016, from http://natlib.govt. $\mathrm{nz} / \mathrm{blog} /$ posts/the-digital-archive-of-the-future?search\% $5 \mathrm{Bpath}$ $\% 5 \mathrm{D}=$ items\&search $\% 5 \mathrm{Btext} \% 5 \mathrm{D}=$ digital + archive + of + the + fut ure

PB Tech. (2016). Retrieved June 25, 2016, from http://www.pbtech. co.nz/index.php? $z=p \& p=P T R P T S 0003 \&$ name=UP-Plus-23D-Printer-Gloss-Black-colour 
Pence, H. E. (2010). Smartphones, Smart Objects, and Augmented Reality. The Reference Librarian, 52(1-2), 136-145. http://doi. org/10.1080/02763877.2011.528281

Pletinckx, D. (2014). VIRTEX - VIRtual EXhibition | Digital Heritage. Retrieved May 4, 2016, from http://www. digitalheritage2015.org/portfolio/virtex/

Pryor, S. (2014). Implementing a 3D Printing Service in an Academic Library. Journal of Library Administration, 54(1), 1-10. http:// doi.org/10.1080/01930826.2014.893110

Praca, D., \& Barral, C. (2001). From smart cards to smart objects: the road to new smart technologies. Computer Networks, 36(4), 381-389. http://doi.org/10.1016/S1389-1286(01)00161-X

Quiver - 3D Coloring App. (n.d.). Retrieved June 25, 2016, from http://quivervision.com/

Quiver Augmented Reality. (2013). Quiver-3D printing test. Retrieved from https://www.youtube.com/ watch? $v=\mathrm{UxYqhmEB} 4 \mathrm{G} 8 \&$ feature=youtu.be

Roozenburg, G. door M. (2013). Smart Replica’s: Smart Replicas at MuseumNext Fringe Symposium. Retrieved from http:// smartreplicas.blogspot.co.nz/2013/05/smart-replicas-atmuseumnext-fringe.html

Rundle, H.. (2013, January 2). Mission creep - a 3D printer will not save your library [Web Blog post]. Retrieved from http://www. hughrundle.net/2013/01/02/mission-creep-a-3d-printer-willnot-save-your-library/ 
Sinha, A., \& Couderc, P. (2013). A Framework for Interacting Smart Objects. In S. Balandin, S. Andreev, \& Y. Koucheryavy (Eds.), Internet of Things, Smart Spaces, and Next Generation Networking (pp. 72-83). Springer Berlin Heidelberg. Retrieved from http:// link.springer.com/chapter/10.1007/978-3-642-40316-3_7

Vasseur, J.-P., \& Dunkels, A. (2010). Interconnecting Smart Objects with IP : The Next Internet. Burlington: Elsevier Science.

Warnier, C., Verbruggen, D., Ehmann, S., \& Klanten, R. (2014). Printing things : visions and essentials for $3 d$ printing / edited by Claire Warnier, Dries Verbruggen, Sven Ehmann, Robert Klanten. Berlin: Gestalten.

Wagner, D., \& Schmalstieg, D. (2009). Making Augmented Reality Practical on Mobile Phones, Part 1. IEEE Computer Graphics and Applications, 29(3), 12-15. http://doi.org/10.1109/ MCG.2009.46

Wiberg, N., Hafssteinsson, H., \& Jonasson, S. (2013). Tangible geographical interface. Digital Heritage International Congress 2013. Retrieved from http://www.digitalheritage2013.org/ tangible-geographical-interface/

Wust, M. (2010, January 14). WolfWalk. Retrieved from https://www. lib.ncsu.edu/wolfwalk/ 

Appendices 


\section{Appendix (a)}

\section{$3 D$ modelling}

A number of different $\mathrm{CAD}$ and parametric modelling techniques were used to create the final outputs of the scenarios; these are detailed below.

Breaking down the parametric model used.

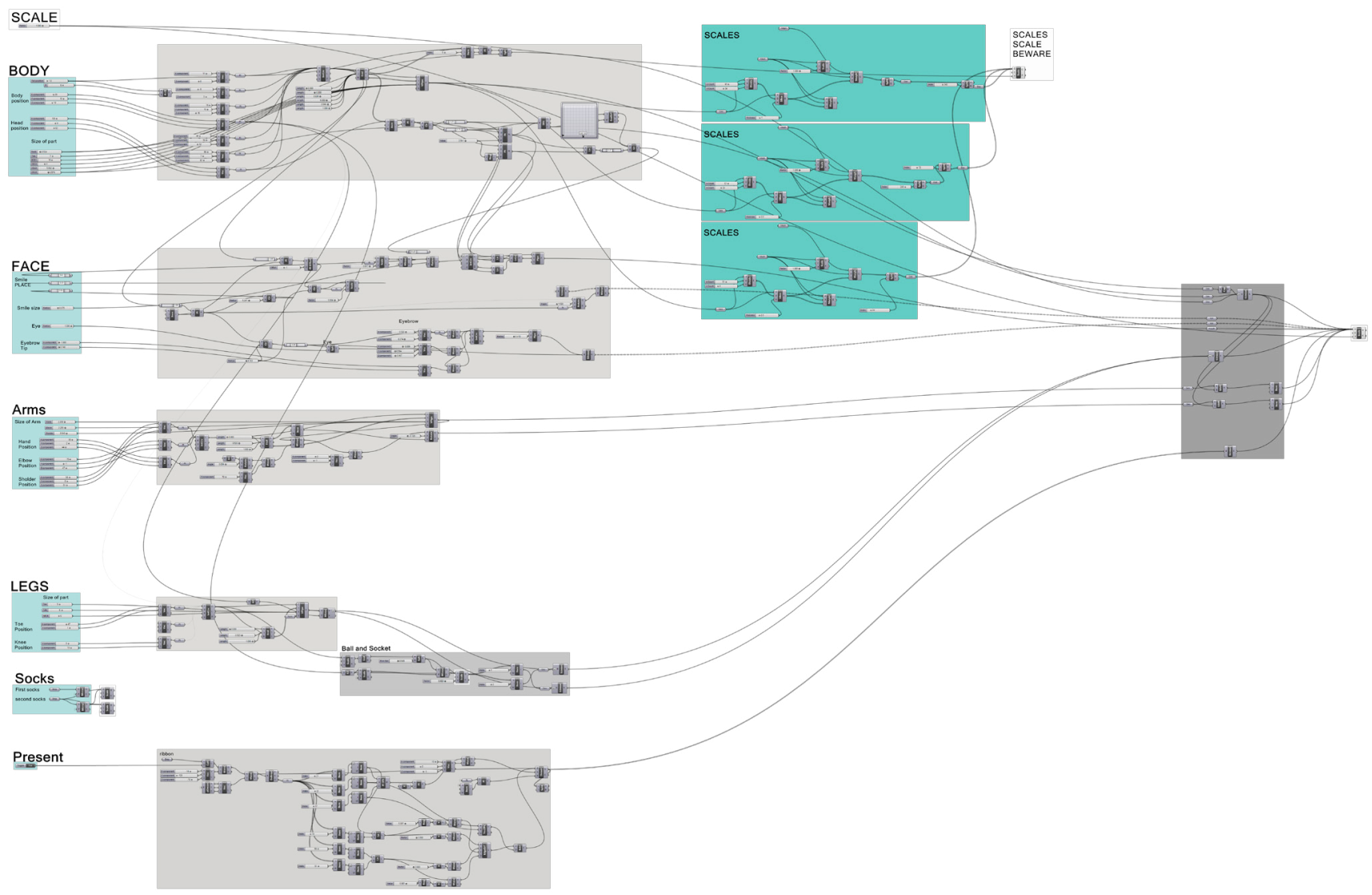


Below is the first section of the Grasshopper definition used to create the dinosaur.

1. Controls the size of each component.

2. Defines points to build the geometry from.

3. Turns those points into a curve.

4. Creates a variable size pipe around the curve that defined the main shape of the dinosaur.

5. Creates a cap for the tail end of the pipe.
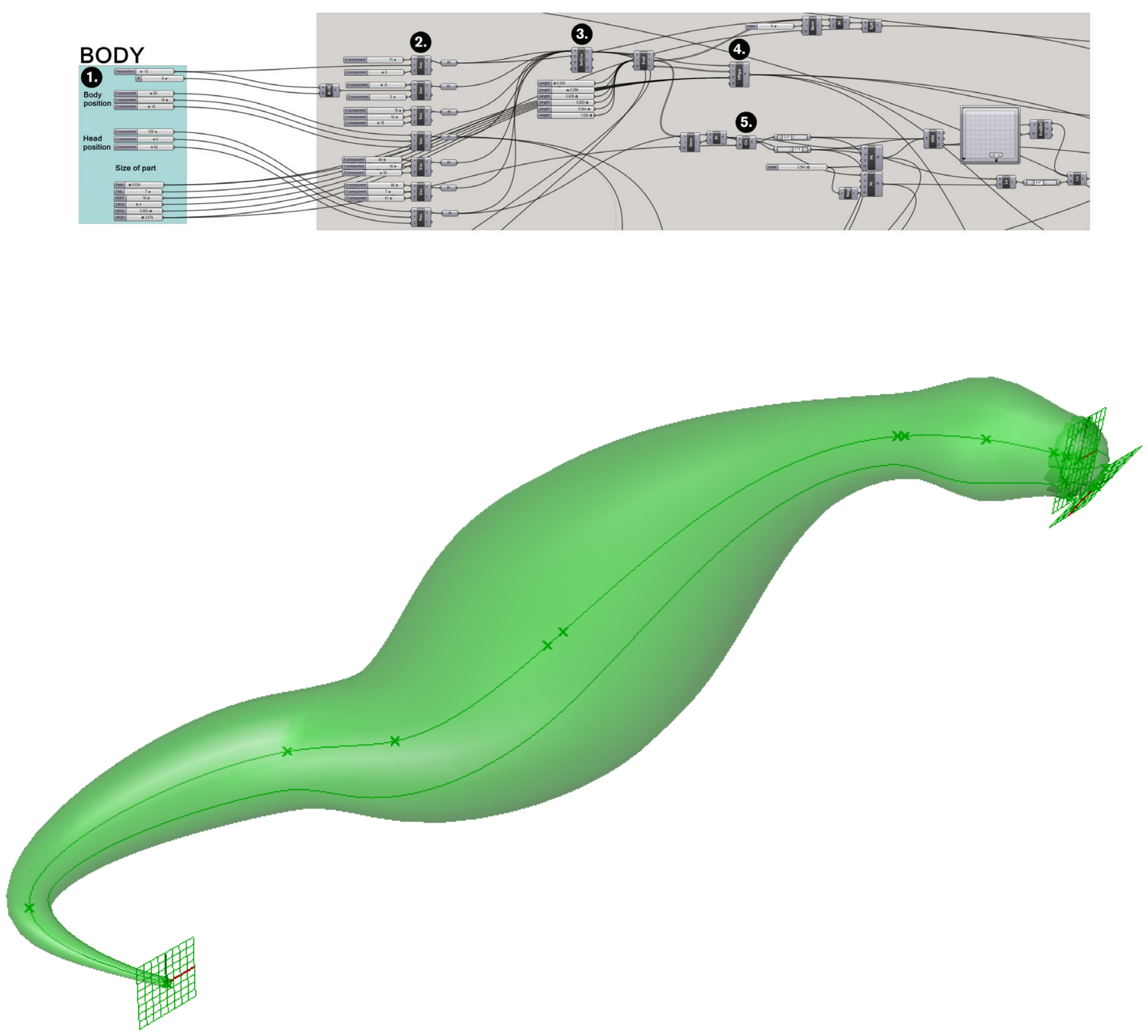
Below is the section of the Grasshopper definition used to create the facial features.

1. Controls the size of each component.

2. and 3. Are used to define what plane and the placement of the smile.

4. Uses those planes and points from the body section to create a curve.

5. Creates a pipe around the curve to give the dinosaur a smile

6. Defines where the first eye is built, from points on the body.

7. Uses those points to create a sphere.

8. Builds from the eye to make an eyebrow, defining points and a curve.

9. A pipe is then created around this which is mirrored along with the eye.
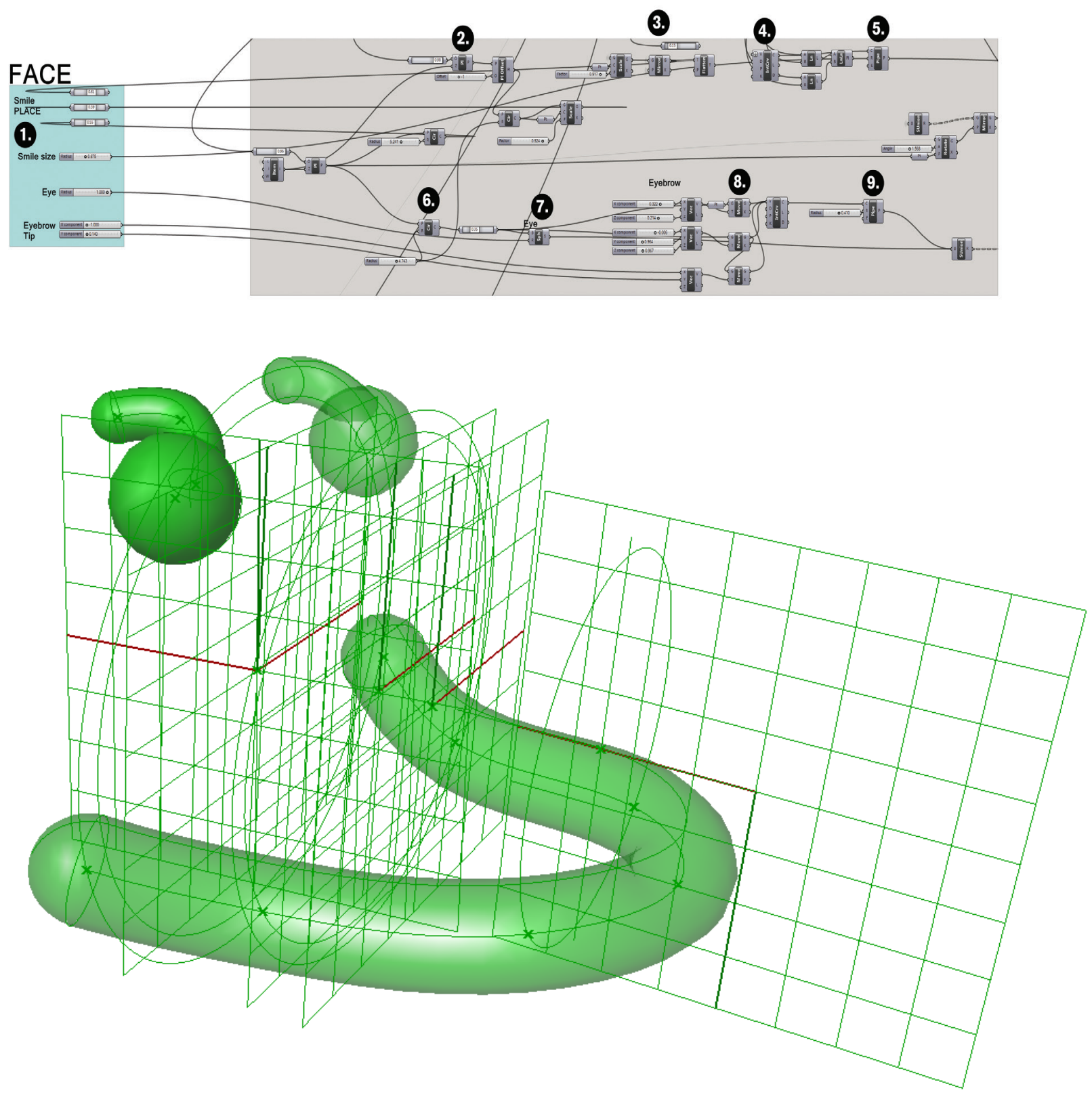
This section of the definition is used to create the arms.

1. Controls the size of each component.

2. Defines points used to place the arms and create curve from them.

3. Is piping the curve.

4. Mirrored this pipe to create the second arm.

5. Rotates this second arm slightly to create a more natural look.
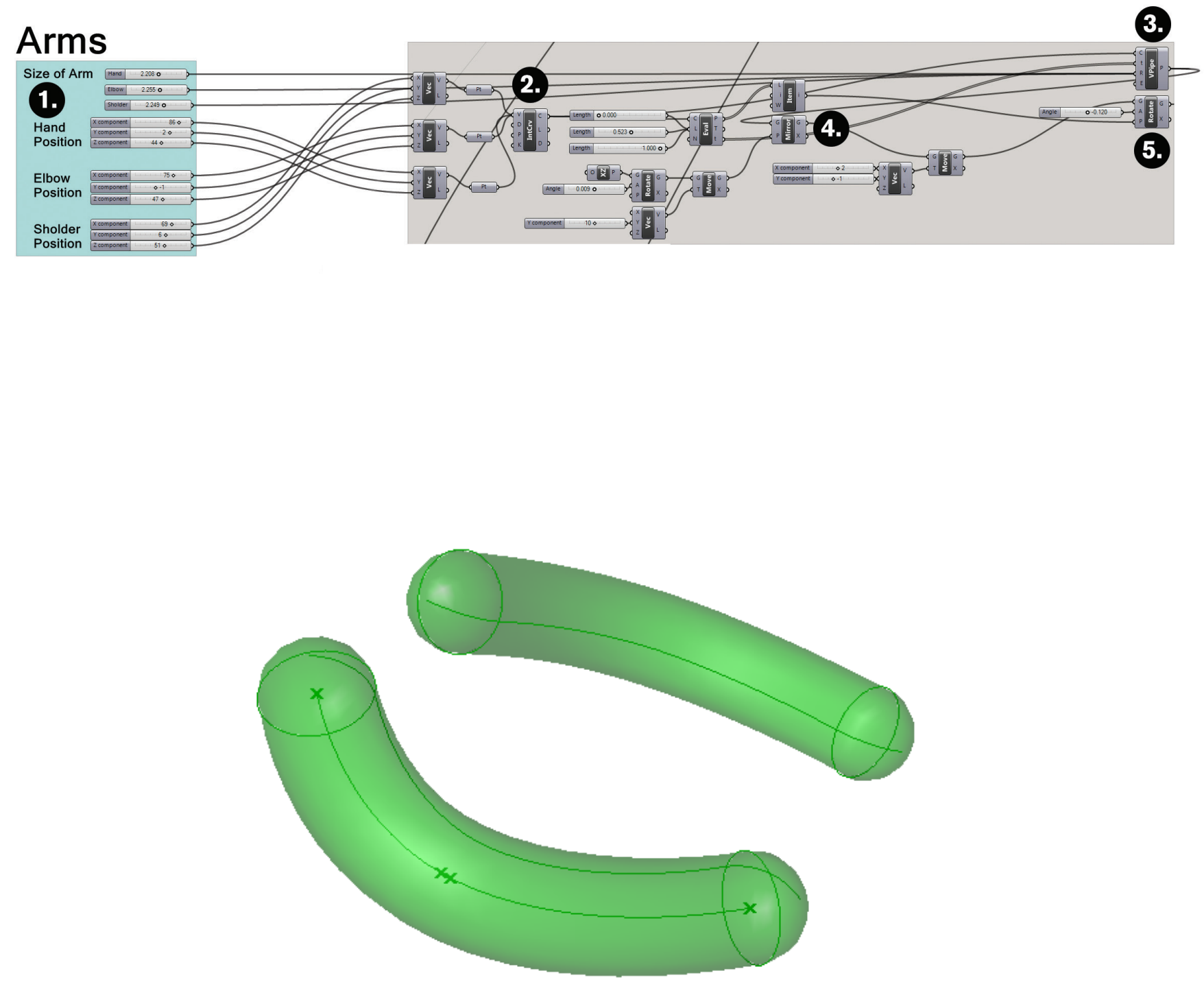
This following definition is used to define the present at the end of one arm

1. Creates a link to a box and wrap around it.

2. Moves this box to close to the arm.

3. Breaks apart this box to create a plane that will align with the arm.

4. Is used to create the plane.

5. Brings the geometry from the arm down and creates a plane to align with.

6. Aligned these two items together.
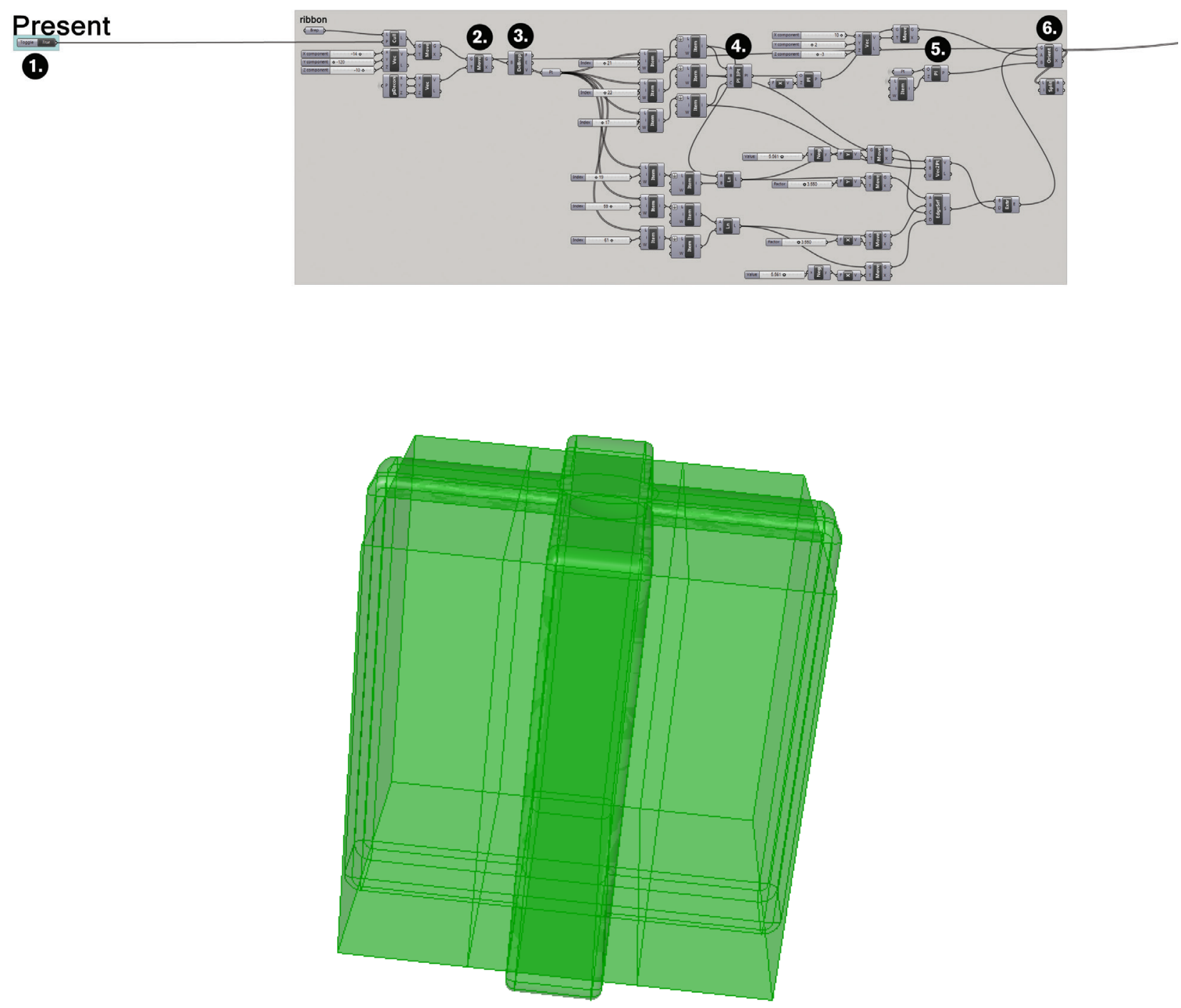
This following definition is used to define the legs of the dinosaur.

1. Controls the size of each component.

2. Turns the points into a curve

3. Pipes a circle along the curve.

4. Mirrors the first leg.

5. Creates a ball for ball and socket joints, with the socks at the correct scale from the end of the leg.

6. Mirrors this to the other leg.

7. Creates a union of the ball and the leg together.

8. Defines the socks in Grasshopper, which are modelled in CAD.

\section{LEGS}
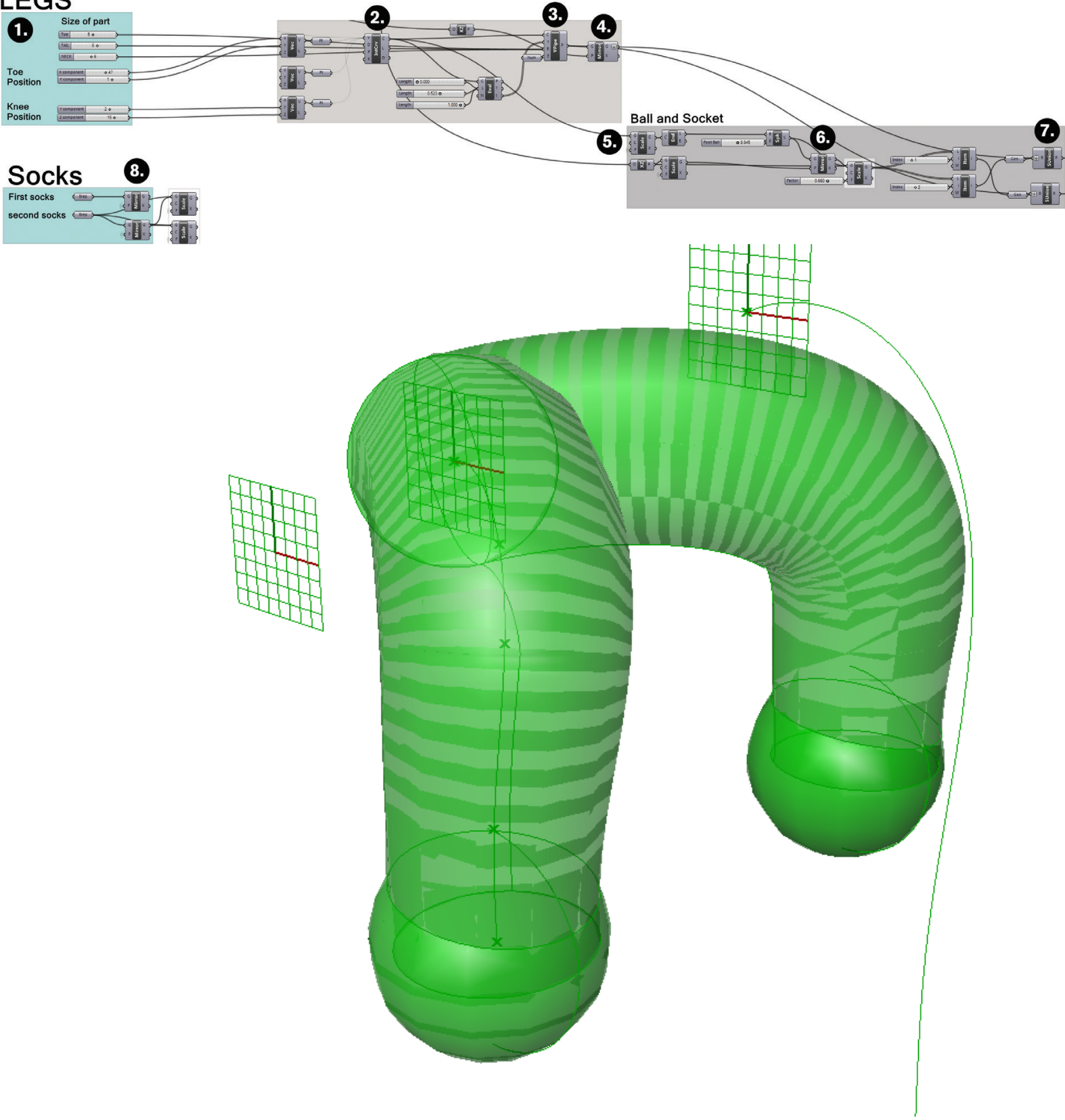
This following definition is used to define the scales of the dinosaur.

1. Is used to define the shape of the scales.

2. Breaks the surface of the dinosaur into boxes, controlled with sliders.

3. The scale form is then morphed into each.

4. Splits off the scales from around parts of the model where not desired e.g., the face

5. and 6. Creates a duplicate of this with scales on the tail only to create a gradient of the scale size.

7. Modifies the scales to fit the body proportions.
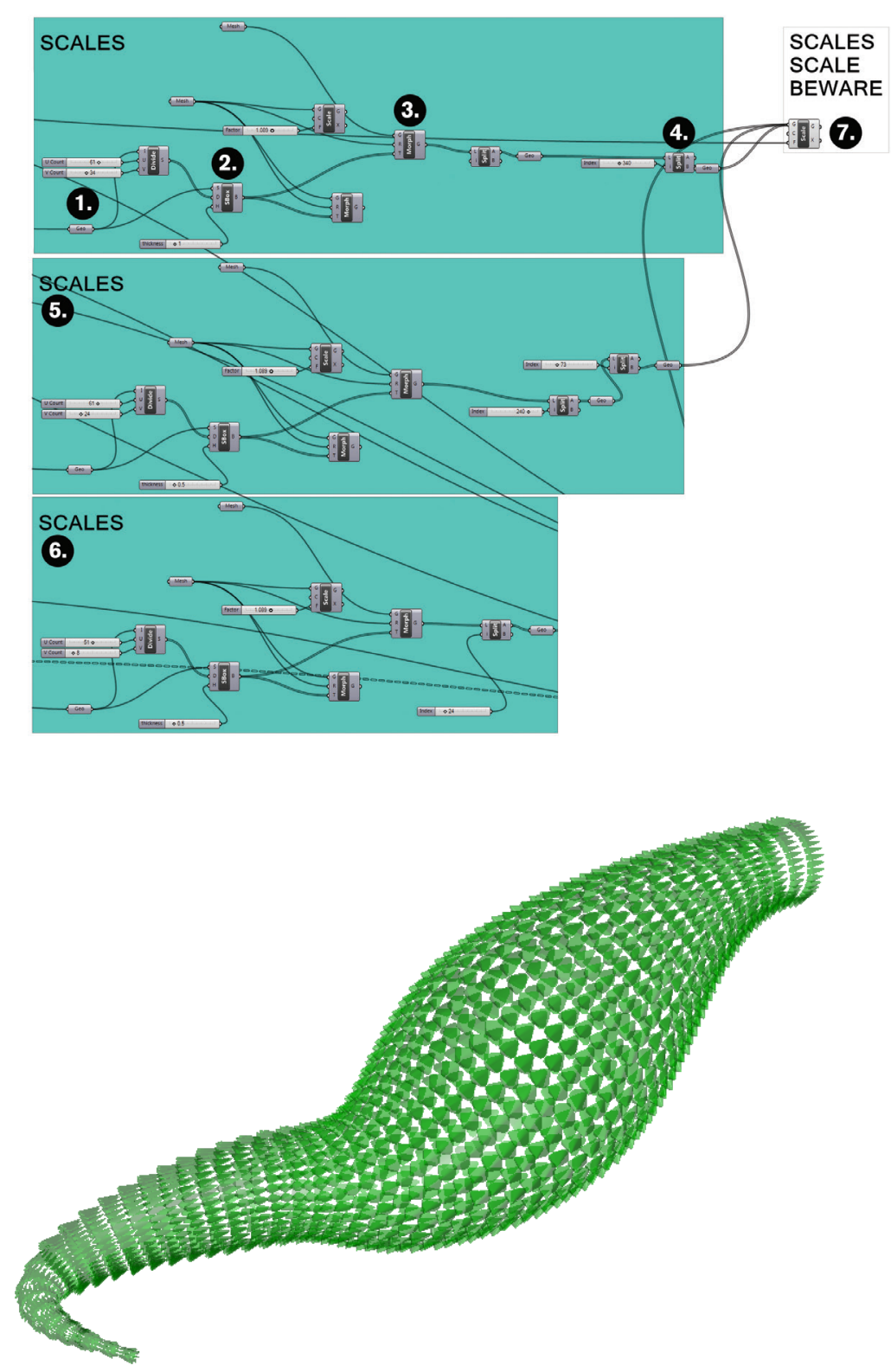

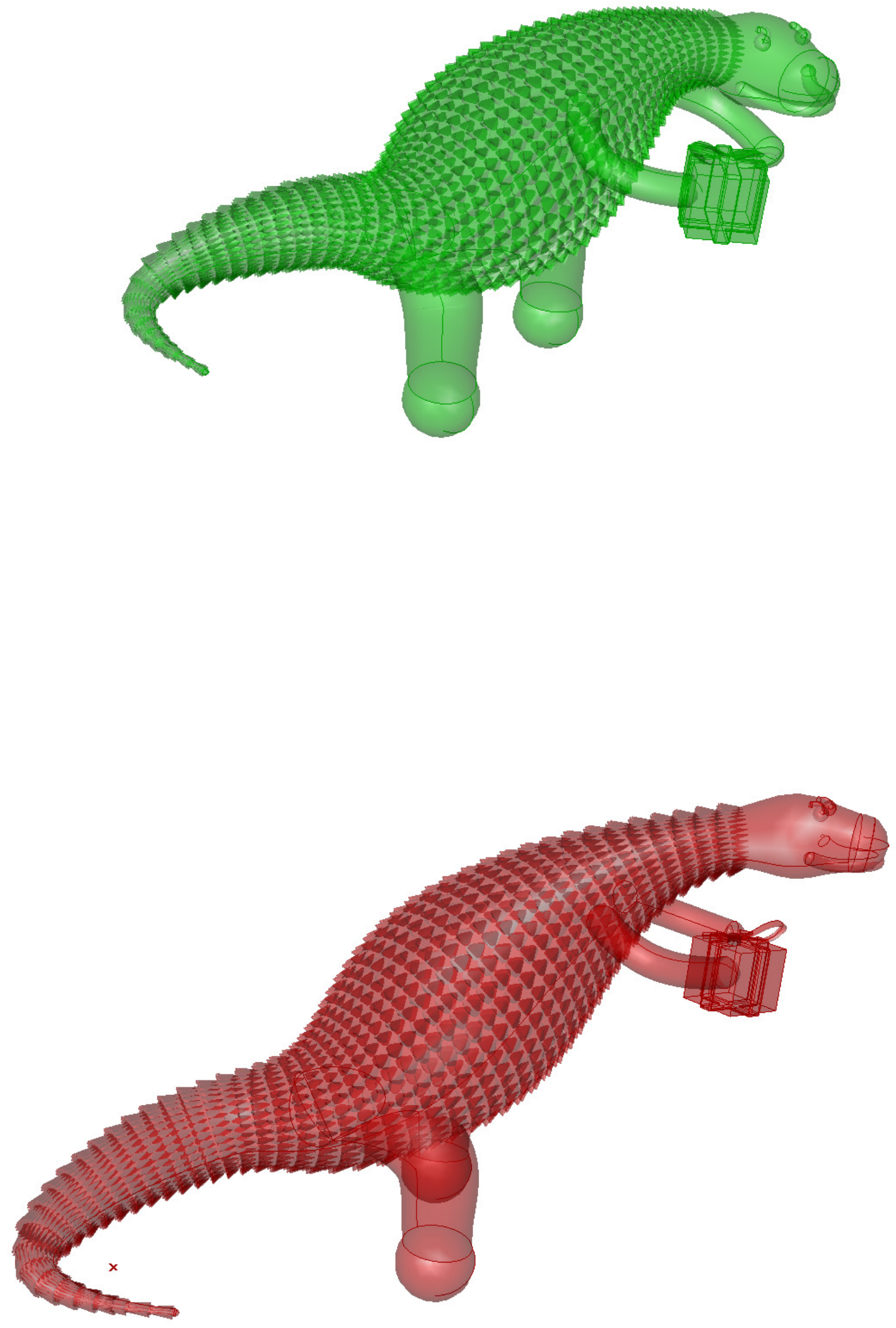


\section{Scenario 1}

In this scenario FDM 3D prints of the dinosaur were used as a blank canvas for children to hand paint as they saw fit. Different sizes of prints were used to find the best size. Also a number of socks were printed to assess the best fit and suitability for painting.

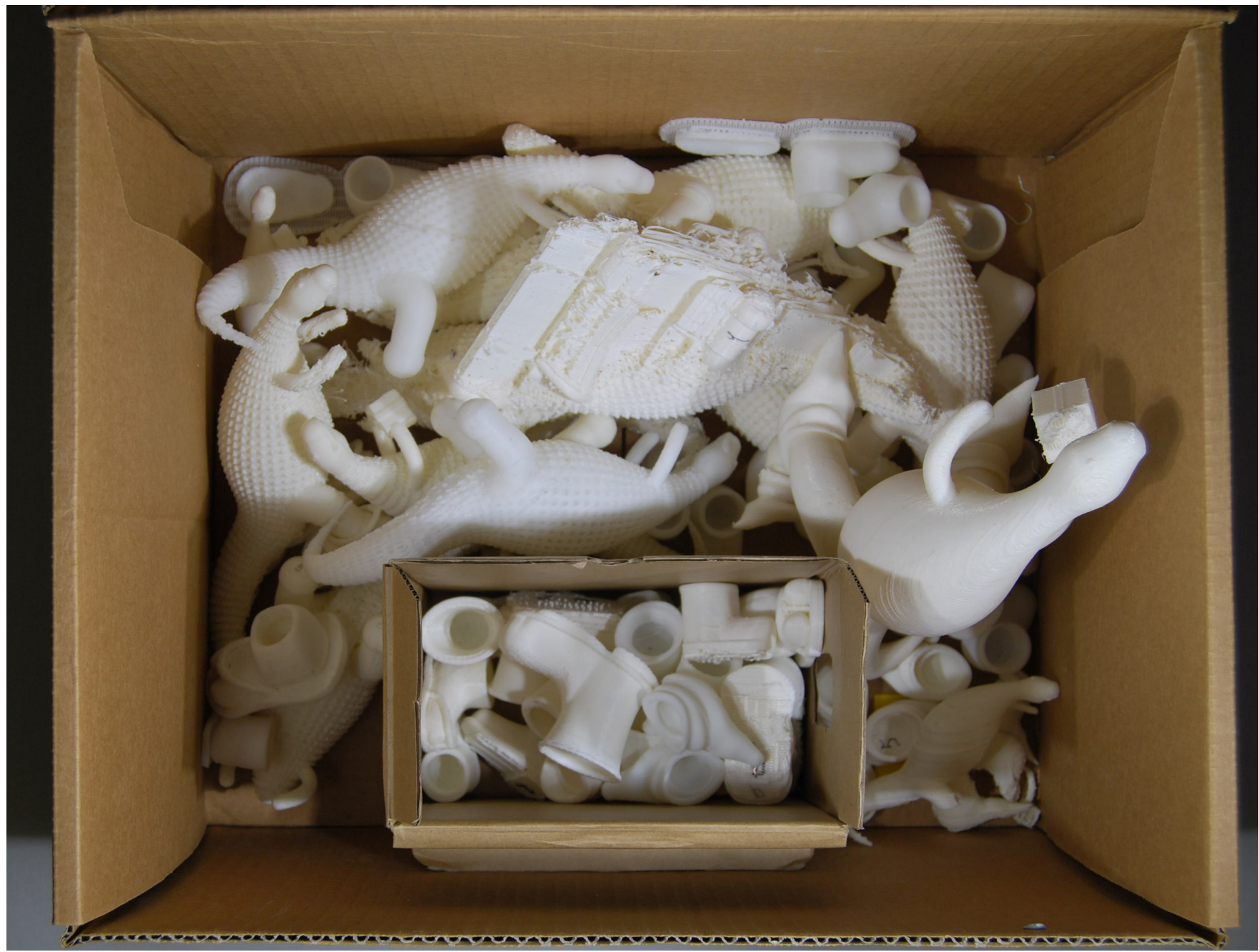




\section{Scenario 2}

Scenario 2 called for speculation of what shoes the dinosaur could be wearing now that he had tight-fitting socks. It was decided that gumboots, dress shoes, and socks and jandals would be used to demonstrate a variety of situations. These models were made in Rhino.

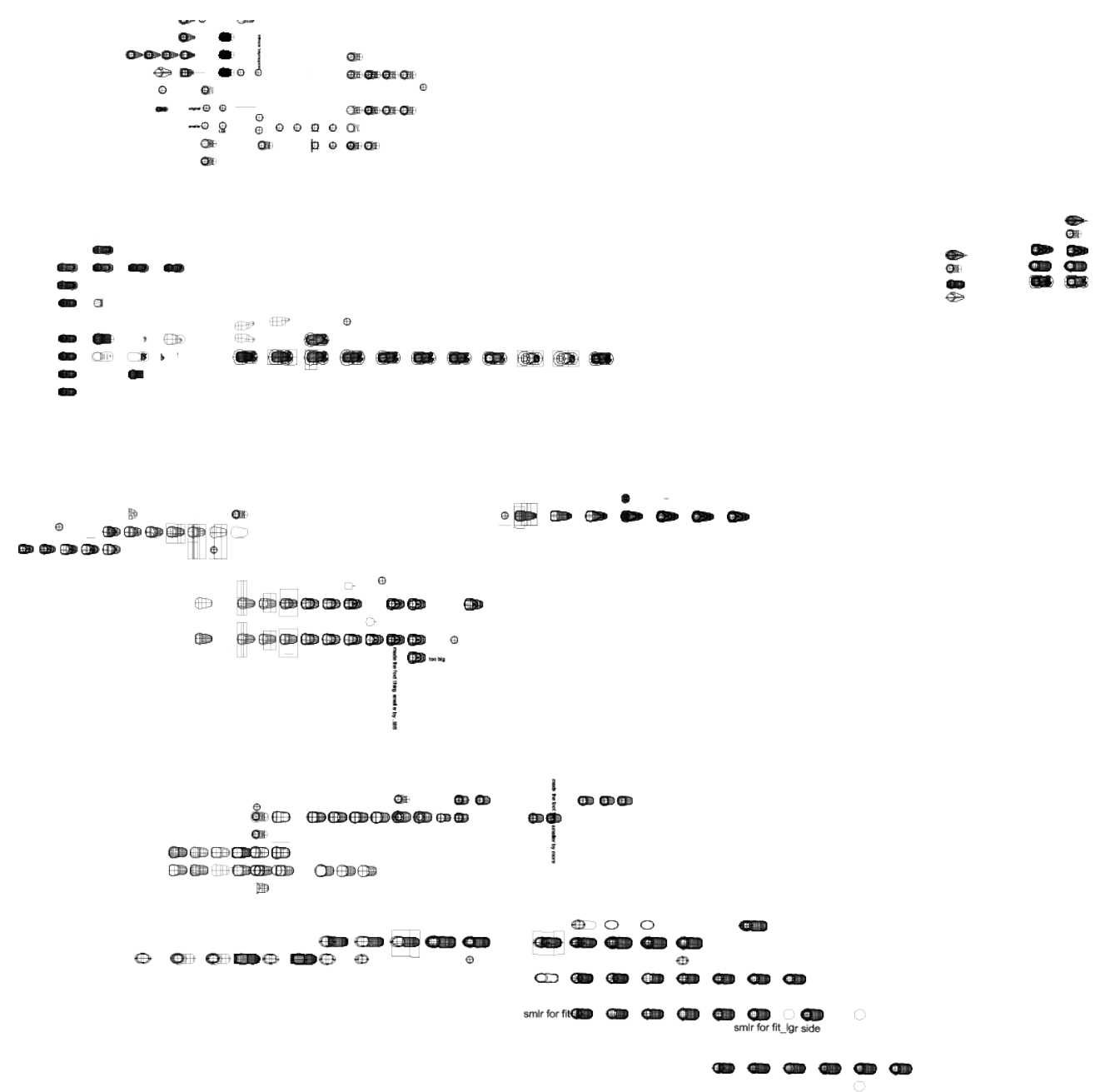




\section{Socks and Jandals.}

Following the image left to right you can see how the sock and jandal was made. A networked surface was used to make the sock and one toe then a modified and mirrored version of this was used to make the second toe. A networked surface is a Rhino function that uses curves to define the shape of a surface created in one action.

From this the jandal form was created using an extruded surface and pipes to create the toe holds. The top of the sock was removed and the ball joint booleaned out of the form. Some small adjustments to the form and bottom of the jandal were then made to complete the form.
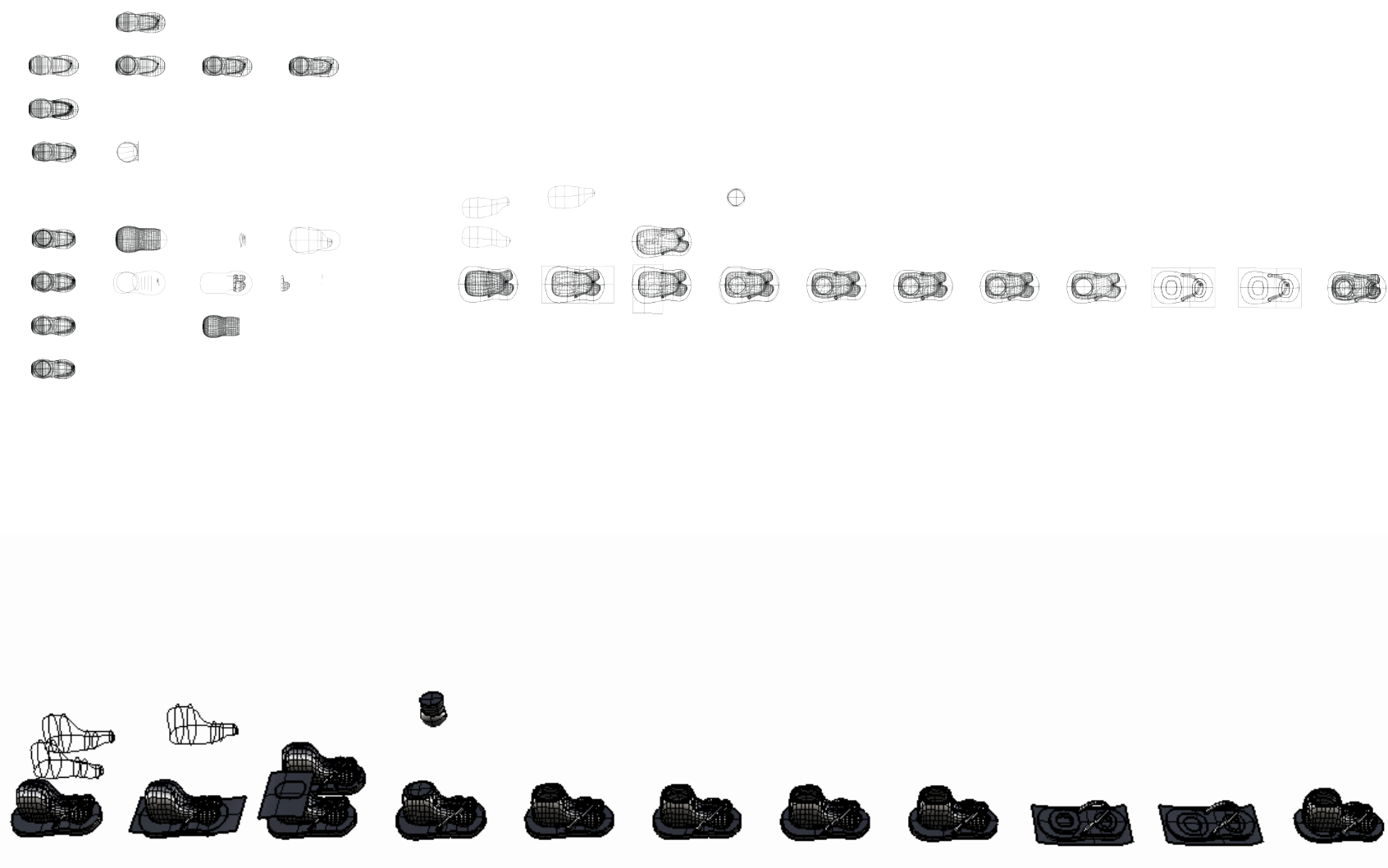


\section{Gumboots.}

The gumboots have had a few iterations to find the best size that would fit onto the dinosaur without reaching too high up the leg. The process to create the gumboots is shown left to right below. First, a loft from a series of ovals were used to create the back half of the boot. This was combined with a networked surface that created the front of the boot. A lofted section between the bottom profile of the overall form was used to create the heel of the boot, with a pipe around this to make it more realistic. Once these parts were created and combined a boolean subtraction was used to form the socket for the ball, and the gumboot model is complete.
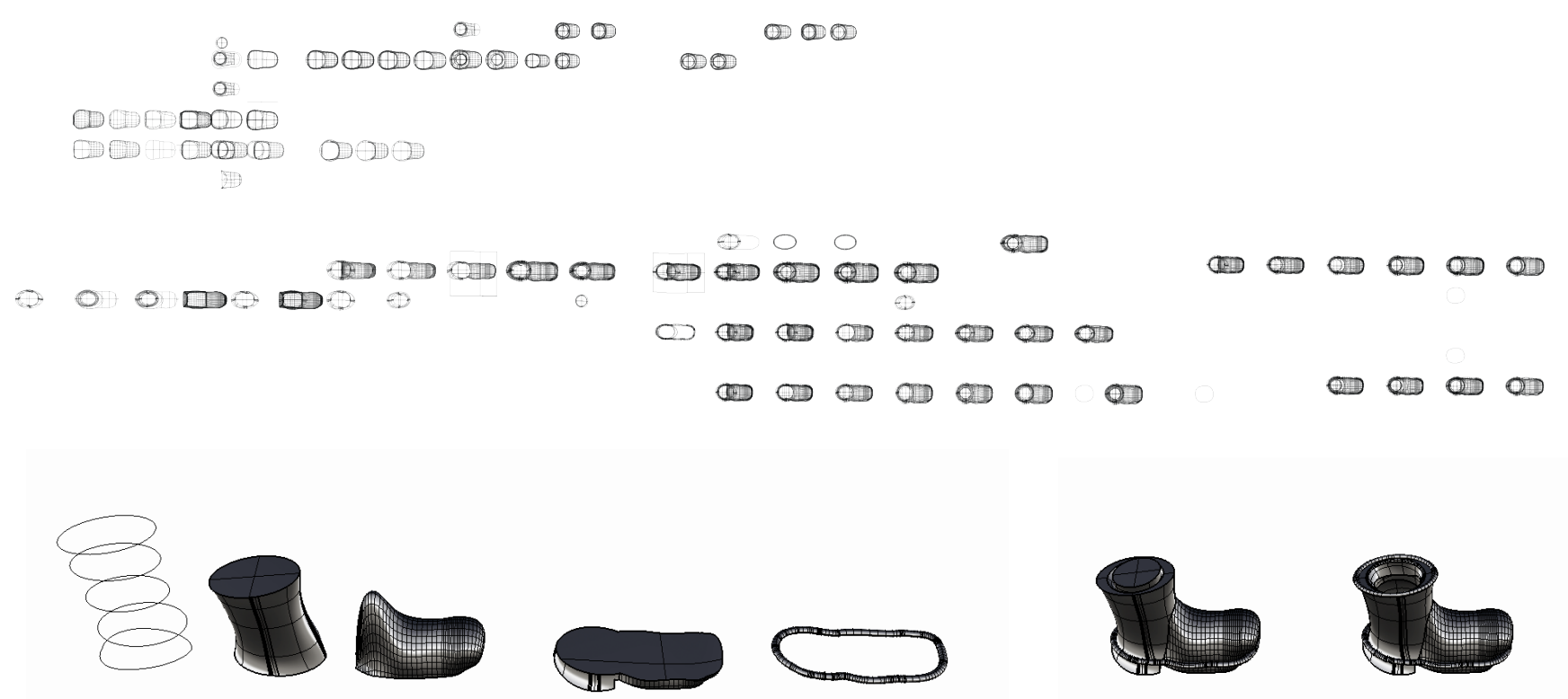
Dress shoes.

The dress shoes were created in a similar way to the front of the gumboots, with a networked surface from curves. The top was then cut off it and a section of the bottom cut out to make the heel and scaled up slightly. A curve was projected onto the middle of the shoe to form an area for decorative holes, as seen on a Brogue shoes. These holes were generated by creating an array of circles on a curve. These circles were then cut out and filleted. Another curve was projected onto the front to generate a pipe for further decoration. Finally, the socket was boolean subtracted away from the form.
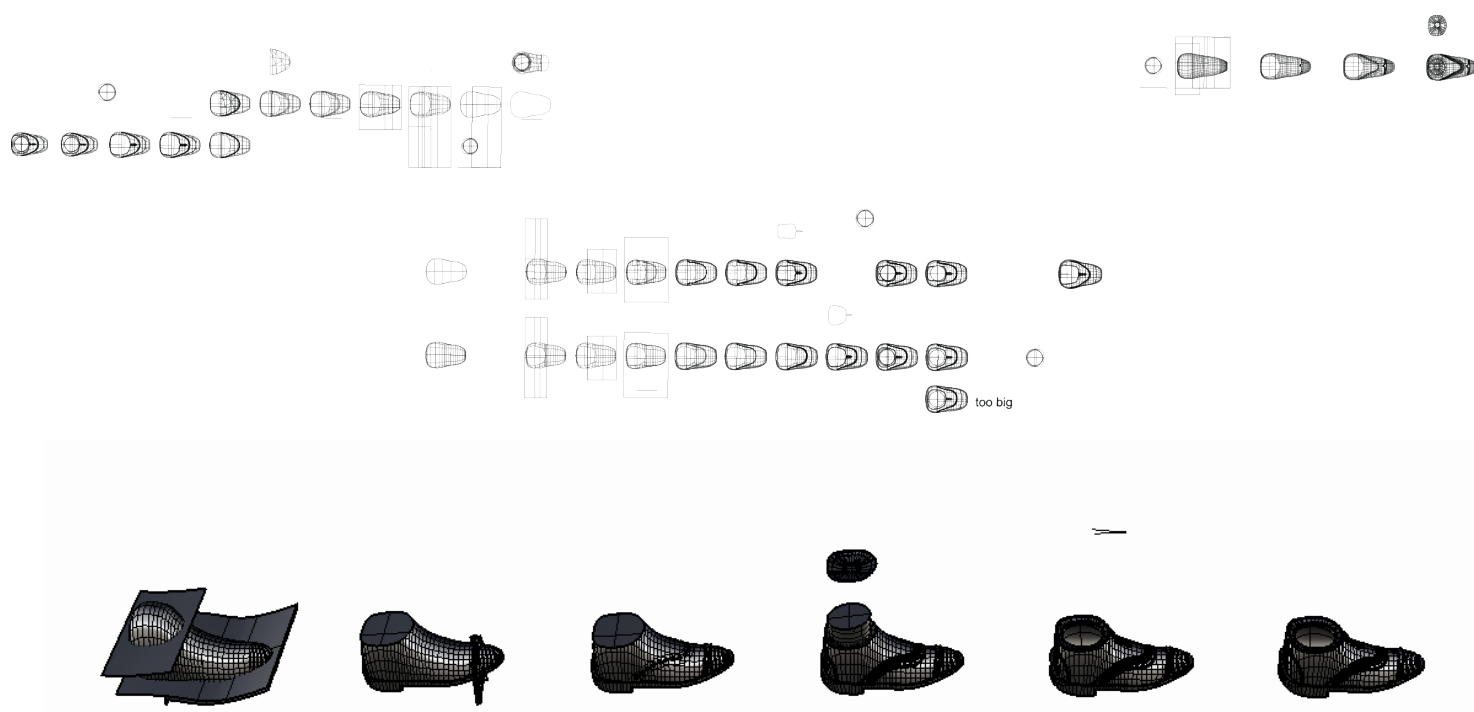

$\infty \infty$ 


\section{$3 D$ print preparation.}

Once created, these shoes had to be prepared for colour Connex 3D printing. The colour Connex 3D printer is a polyjet 3D printer that uses precisely placed drops of liquid hardened by UV light to build up the form layer by layer. This printer was chosen for its accuracy and ability to produce multiple colours and hardnesses.

To prepare the files a colours had to be chosen for the prints; shown below is a selection of renders to find a suitable colour.

Once the desired colours were chosen each part of the model needed to be exported as a separate stereolithography (STL) file for each colour/ material and sent to the printer.Socks and Jandles.

Following the image left to right you can see how the Sock and Jandle was made. A networked surface was used to make the sock and one toe and a modified mirrored version of this used to make the second toe. A networked surface is a Rhino function that uses curves to define the shape of a surface created in one action.
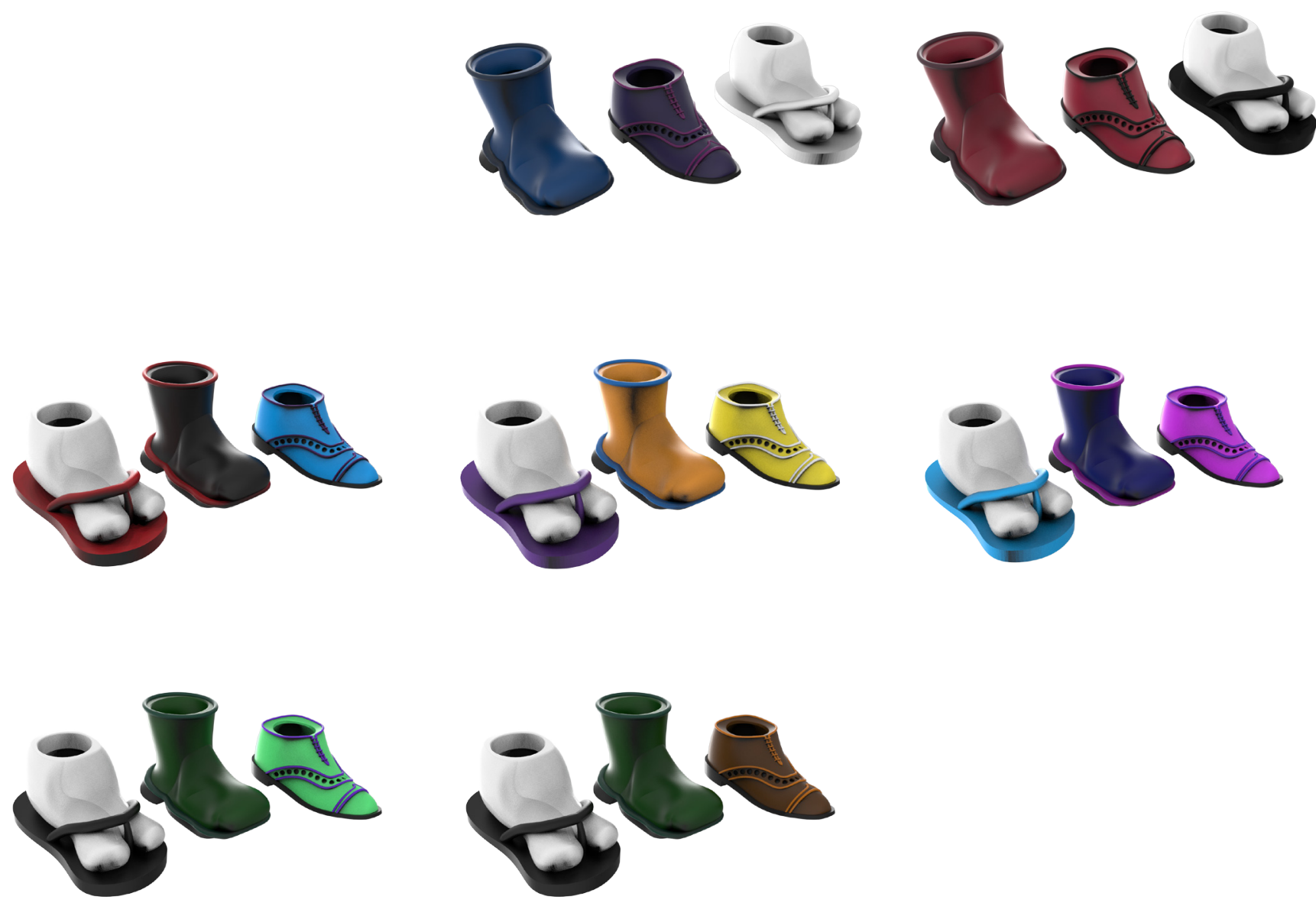


\section{Scenario 3}

Creating a fat dinosaur as part of the narrative extension was done parametrically through adding to the Grasshopper definition. The highlighted blue section below indicates the part of the definition that was added to create a hollow fat dinosaur.

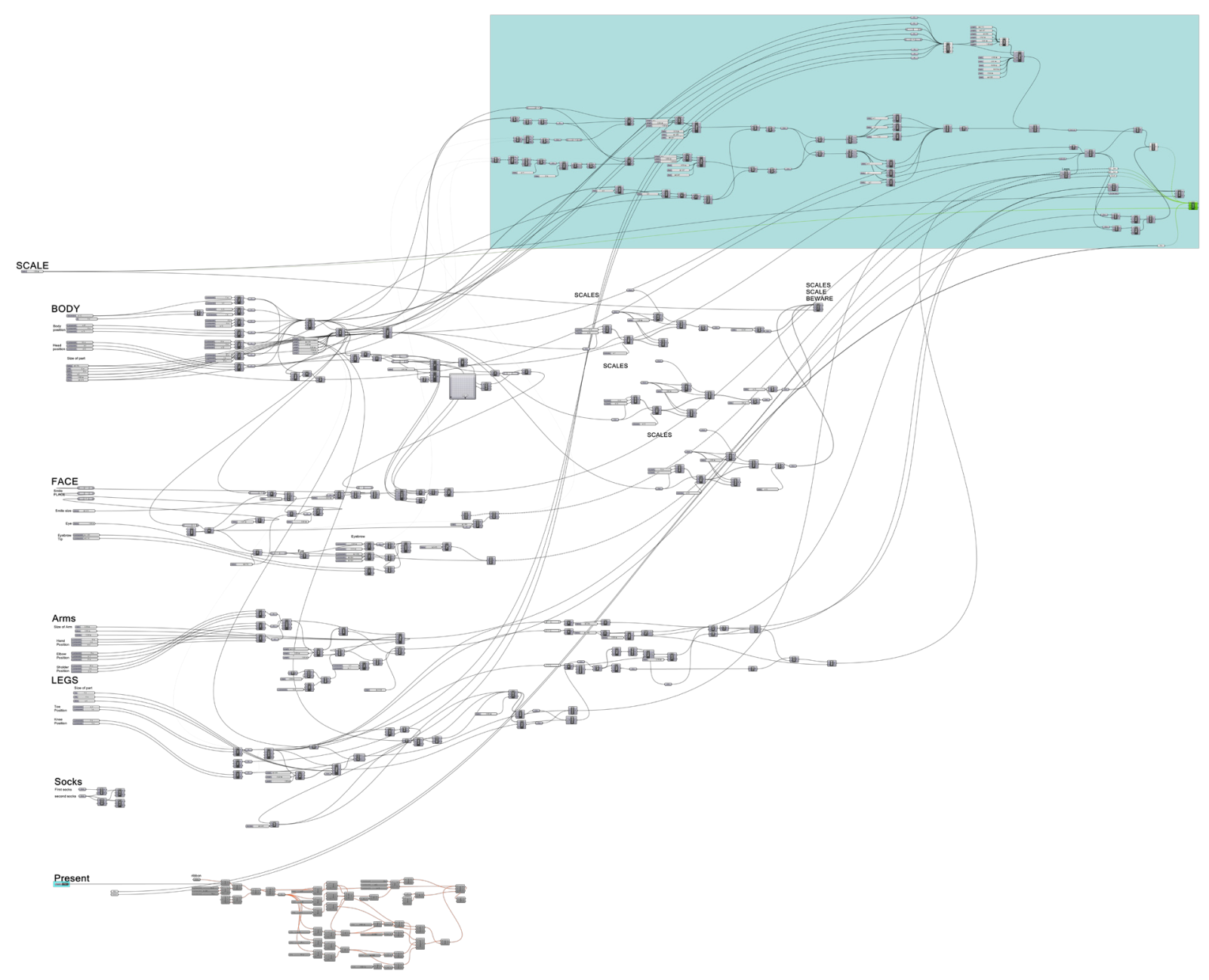


Below is the definition that was added to create the hollow.

1. Imports the enlarged dinosaur from the rest of the definition and defines a split point for head and eye hollow.

2. Creates pipes that connect to the eyes.

3. Splits these with each other and begins the union.

4. Unions these together into one geometry.

5. Takes variables from the original dinosaur and creates a pipe around them for the body hollow.

6. Unions the body and eye hollow together.

7. Creates a union with the rest of the model.

\section{5.}
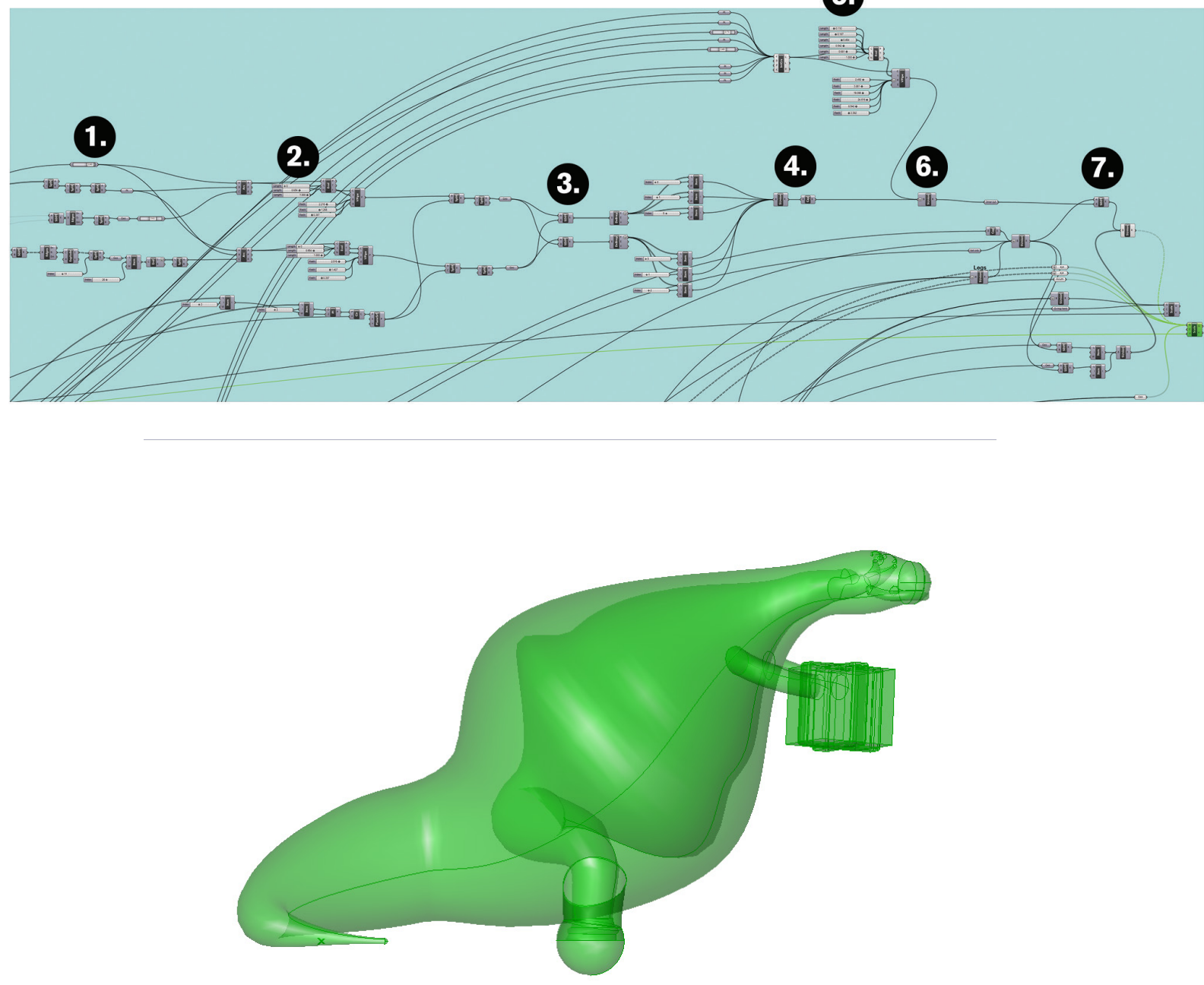


\section{Scenario 4}

The final scenario called for the dinosaur to be texture mapped with the colour from the image Jan Farr coloured in. This texturing was created in 3DS Max.

First the model had to be imported into 3DS and the surface of it unwrapped into flat sections. For this to happen the scales of the dinosaur had to be removed as they were too complex.

Once unwrapped the texture was mapped onto the unwrapped surface in photoshop and applied back onto the model in 3DS to create the final output.

The final colour model was printed in full colour Projet sandstone.
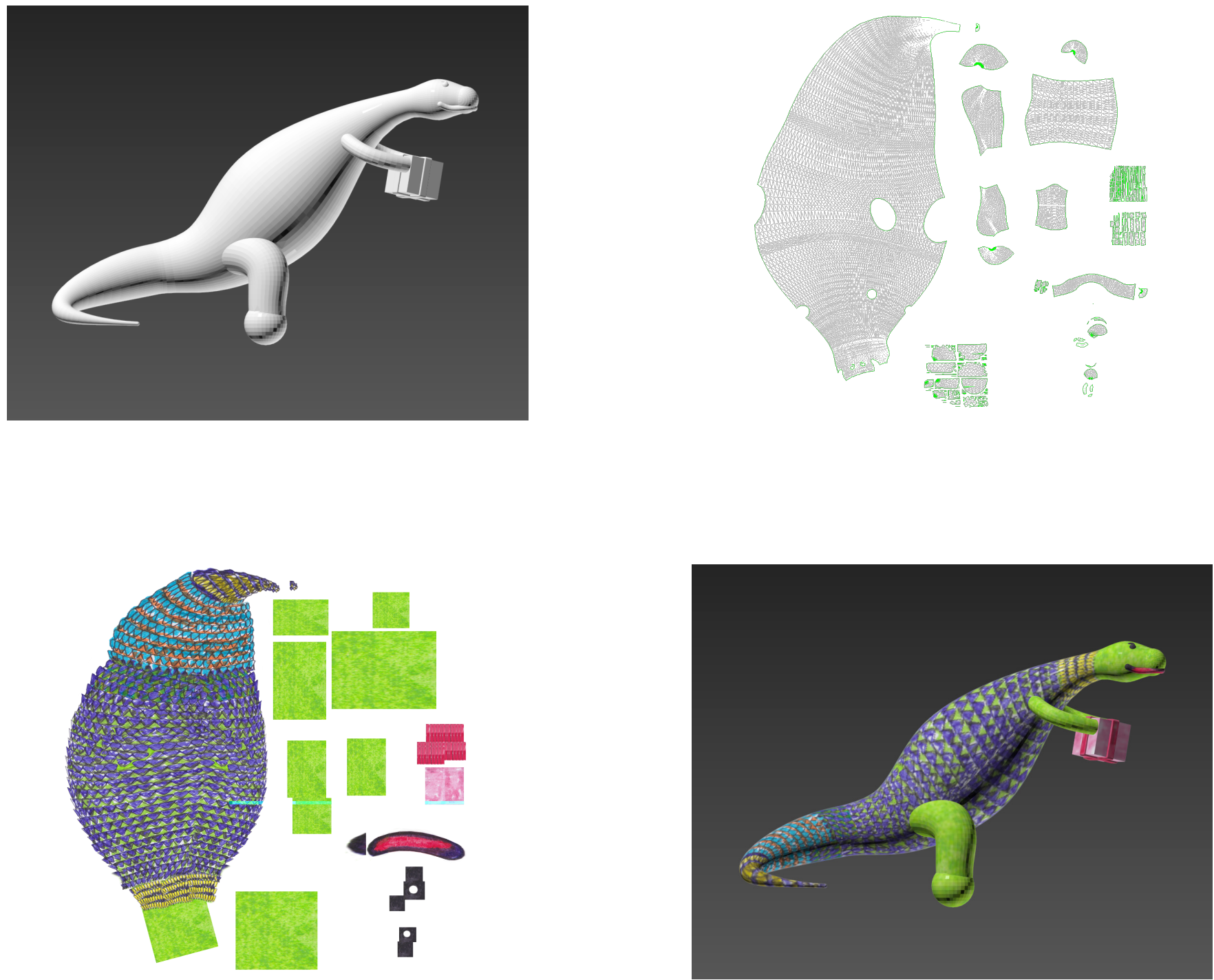


\section{Cases \\ Appendix (b)}

Radio Frequency IDentification (RFID) 1993.

Radio Frequency IDenti cation(RFID) has been around a long time and was originally used for digital ticketing and has been used for that ever since. The development of the technology created a new idea of quick and easy payments in a more secure way. With a simple one way interaction that frees the user of cash, but lacks important two way interactions. Current uses of the technology are able to gather data about these interactions and give feedback to the user, developing closer to a smart object.

\section{QR Codes}

The Quick Response (QR) codes have been in use since 1994, they are a type of barcode that can be used to encode data onto and use image scanning to read them. They are often used for product tracking or identi cation. Programs are used to encode the data you choose into a $\mathrm{QR}$ code that can be read later by a reader. More commonly now they are being used in advertising, exhibitions and in some cases payment systems.

QR codes are a good way of quickly giving users access to additional information not displayed. As a smart object they only allow one way interaction, although having the ability to link to more responsive content. Having the ability to program QR codes has kept them in use to this day because of the exibility they offer.

\section{MiME: Glow Tags (2001)}

MiME tags or Multiple Intimate Media Environment tag was an experimental research project conducted by Philips Design, Xerox Research Centre Europe, and Nottingham University. It aimed to integrate personal memories into physical media. It created this augmentation using small physical objects that can be attached onto physical media. The tags allow the user to link text, photos, times, 
dates, places, audio, or video to physical media. MiME used wireless technology and RFID to create these links to media. The tags activate when the linked media is mentioned on the user's other digital devices, reminding the user of the associated memory.

These tags begin to give a new way of storytelling and augmentation with the ubiquitous digital devices we have. The ability for tags to selfactivate allows a different interaction to simply viewing the memories on the device. This experimental and creative application gives a unique take on autonomous technology and the role it could play in our world - using such a simple technology to create a smart object.

Gaia (University Of Illinois, 2004)

Gaia developed at University Of Illinois at Urbana-Champaign, gives the ability to physically touch to interact with an operating system, allowing multiple users and devices to interact at once. This creates one of the first devices to incorporate plasma panels, HDTV, webcams, Tablet PCs, IR beacons, bluetooth, wireless ethernet, fingerprint and Iris scanners, smart phones and location technology to create a smart learning environment.

The use of such large amounts of technology allows multiple users but not a feedback loop to create a system that creates it's own data. Gaia does showcase the ability of larger augmented environments to create possible new learning environment tools.

Cence Me (A. T. Campbel 2008)

CenceMe using the ipod touch to collating and uploading of sensed data about the user. The application use the accelerometer to determine activity of user along with microphone data. You can share and curate this data on the social network, creating a people centric view of smart objects and data collected from them. This is one of example of off the shelf products adapted to share and pair with other social networks using inbuilt activity data. The ability to utalise this often automatically generated data to the users advantage is what CenceMe begins to show. 
Walky (Elena Nazzi 2009)

Example of smart objects being used in walker's, allowing tracking and communication of activities to a community. Made in march 2009 initially, facilitating seniors walking. The community is where this becomes interesting as it makes mundane activities noticeable. User exploration included. For everyday use and everyday interaction.

$$
\text { Nike + (Nike, 2009) }
$$

Nike + are a commercial running shoe that uses sensors attached to the shoe(in the soul or heal) to track the activities of users. This data can be analysed by the user to meet fitness goals or even shared on social media. This is a good example of simple connected technologies used to give the user more information about themselves. Nike + does create a one way transfer of information generated by the user to the app which may be improved in future products.

Wolfwalk (AR) iphone app (2010)

Wolfwalk is a mobile app from North Carolina State University Library (NCSU) that gives a walking historic photographic tour of the university campus, using over 1000 historic photos and 100 locations (Wust, 2010). This walking tour uses geolocation to access historical photos in the locations they were taken; this positions the photos in the physical world, allowing users instantly to view locations as they were and what they have become. Layering these physical and digital worlds together in a visually relatable way builds a context of what came before and adds to the experience of learning about the history of the campus. The app provides textual information about the photo, providing further context. The app has a simple content delivery system that could have been improved to create more concrete links between location and historical images. The linking of this historical information and the location is successful in creating engagement with the history of the campus; however, it lacks feedback into the system to build new narratives from users into the history. 


\section{Valle Giulia (Sorin Voicu, 2010)}

Sorin Voicu's thesis project Valle Giulia poses the question how might augmented reality affect the way we learn. Visually demonstrating some conceptual ways that augmented reality could affect the way we learn. The project's conceptual nature forces us to question the extent that augmented reality could improve the learning experience. Consider the impact the internet has on information access today and the possibility of having that access immediately in your sight with the blink of an eye. 2013)

Wolf Walk (North Carolina State University Library,

Wolfwalk is a mobile application from North Carolina State University Library (NCSU) that gives a walking historic photographic tour of the university campus, using over 1000 historic photos. This combination of physical and digital though a walking tour allows users to view locations as they were and what they have become, this gives a larger impact as they viewer is at each physical location to view the photo. The layering of these physical and digital worlds together in a visually relatable way builds a context of what came before and adds to the experience.

\section{Google Glass (Google, 2013)}

Google glass is google's augmented reality device that has taken the often imagined augmented reality and created head mounted optical display unit. Glass gives the ability to use voice commands to google things, along with being able to answer calls, connect to mobile devices and record video. The creation of this device is a step in the direction of augmenting the human experience. With technology at the time this was a large leap forward which may have alienated some people causing the lackluster sales.

MemPhone (Bin Guo, 2013)

MemPhone uses mobile phones to allowing linking of memories 
to objects using computer vision and object tagging. This can be used to associate human experience with physical objects creating a further memory link. This technology develops that of meme tags and combines it with the ubiquity of mobile phones to create an easily accessible memory links. The control that the user has over tagging and image creation shows the limited ability of this application to become a smart object and does not incorporate any added memory reminders to further the memory recollection. However MemPhone does showcase the abilities of mobile platforms to conduct this kind of collection and tagging.

\section{Self assembling robots. M.I.T. (2013)}

M-Blocks from Massachusetts Institute of Technology (MIT) are self assembling cubes able to autonomously transform into any programmed cube form (Hardesty, 2013). To move they use a spinning motor inside to generate angular momentum that can propel them around; in essence they walk up each other and form the desired shape (Hardesty, 2013).

M-Blocks embody the name smart object, with the ability to carry out movement on their own to form a programmed shape. With the engineered approach to the creation of form from simple cubes, one can begin to imagine the possibilities when the forms around us become programmable down to the pixel. With the implementation of a simple application to program the forms these robots would become the latest toy of every engineer.

\section{Tangible Geographical Interface (Wiberg, Hafssteinsson \&. Jonasson, 2013)}

Digital Heritage Expo of 2013 exhibited the Tangible Geographical Interface displaying geographical information in the form of a large 3D screen-based map (Wiberg et al. 2013). This map could be interacted with through a puck that acted as a spatial navigation tool: by rotating the puck, users viewed changes in the terrain over time as well as different information layers. 
The map is a great way to show how users can explore virtual spaces by physically interacting with objects. Its simple use of a tactile puck to navigate gives the user control over how the narrative of landscape unfolds. With basic sensing technology to create this interaction the 3D map becomes more user-friendly and navigable.

\section{Fitbit (2014)}

Fitbit is a biodata tracking device, a user can track many aspects of their life activity on it and easily synchronize this with an application to gain insights to their daily bio data or track fitness. The application also allows you to set goals for a day, your progress towards that goal will be displayed in LED form on the device motivating you to complete it. This product adds a gameification aspect to the tracking of bio data such as gaining badges as you progress. However with the multiple levels feedback this device shows more qualities of a smart object than most wearable technology.

\section{Tweeting Seat. (Chris McNichol, 2014)}

The TweetingSeat is an interactive bench that logs its use by photographing itself and its surroundings each time a user sits on it and uploads the pictures to Twitter. This creates an interesting interaction with each user as they may visit the Twitter feed and interact with the seat in an online environment as well as physical. Using wireless and sensor technology to achieve this the TweetingSeat generates its own data achieving smart object status.

\section{Context Toolkit (Arnab Sinha, Paul Couderc, 2014)}

Context Toolkit utilises computer vision and to create a database of items that can be checked for using the camera. This begins to show further linking of physical and digital areas, this is becoming more common. The ability to generate data from the photo recognition gives some feedback to the user but further information tagging would need to be involved to create full smart object interactions. 
Virtex (CHNT - Vienna, 2014)

Virtex an abbreviation of VIRTual EXhibition, is a 3D printed smart replica of a marble statue with sensors and buttons embedded into it. The smart replica links to digital information about the model and when triggered tells stories and supplies more information about the marble statue. This simple linking of information allows the viewer to become more engaged in the exhibition and discover information in a different way. The form of augmentation here allows for a one way interaction between the viewer and information displayed, yet still gives a tactile tangible interaction the viewer would not have otherwise had.

Smart Farming (Farming sensors in cows, 2014.) "Precision livestock farming technologies bring the possibility of closely monitoring the behavior, liveweight and other parameters of individual animals in free-ranging systems." S.M. Rutter (2014). The technology employed by farmers is increasing rapidly, with smart farming they can monitor livestock, vegetation, water, health and soon administering medicine. All this from the comfort of the of ce using smart sensors feeding back to a central system. Creating a smart system that can feedback to itself and learn from instructions.

\section{Google Nest (Google, 2015)}

Google Nest a smart home thermostat, that can save you money. Nest builds up data from your thermostat usage and can begin to control autonomously. This creation and automation of heating shows a smart object implemented in everyday life can assist in your environmental impact.

\section{Eye (Dyson, 2015)}

Dyson 360 eye a robot vacuum cleaner, uses computer vision and room scanning to build up a map of the room and sets the cleaning path. Another smart object that allows you to forget about it and let it automate the vacuuming process. 


\section{E-Call (Europe, 2015)}

Road accidents killed 25,700 people in the European Union (EU) last year (ANE. 2015), an outstanding reason to install E-Call. E-Call is a machine to machine communication for cars, using impact sensors to tell if a car has had an accident and calling the emergency services using an onboard mobile chip. Additionally to this an E-Call button for the driver to press is installed. This automation has been predicted to drastically reduce the response time for accidents. E-Call is one further automation that is helping to make driving safer and reduce road toll.

\section{Unfold (Unfold, Kirschner3D and Penny Webb, 2015)} Physical measuring of things to generate digital measurements. Unfold create a augmented 3D modeling devices, these devices gives the ability to input physical measurements straight into the software. This level of augmentation gives a new freedom to the user to easily craft items of perfect $t$. Being able to take measurements makes this smart augmentation an element of its own data generation but is not truly generating its own data that is feeding back to the $3 \mathrm{D}$ modeling software. However this level of digital and physical augmentation will become more common with new technologies in augmented reality.

\section{WiFi Washing Machine (Samsung, 2015)}

Samsung have created a washing machine connected to the internet using WiFi, this allows the washing machine to be controlled via a smartphone. This creates an connected smart object that builds memory, allows assessment of weights of washing and saves power. This does also begin to ask about the point of adding wifi connectivity to a washing machine and whether it is beneficial.

\section{Smart Ring (Logbar, 2015)}

A smart ring that people would actually want to wear, is the marketing tag for this smart ring. Aimed towards women as a fashion piece and reminder, allows info to be sent to the ring to notify you about 
incoming calls and texts. Another practical reminder of the blurring of the digital and physical divide. With a device such and this wearable you can see the building of technologies together to create a device that gives physical feedback from digital interactions.

\section{Apple Watch (Apple, 2015)}

The Apple Watch is Apple's debut into the wearable market, pairing with the iPhone to create a succinct relationship. Taking the functionality the the Fitbit offers and combining with the ability to respond to noti cations instantly creates a smart watch. Simply tracking and responding to noti cations however does not make this wearable hit the smart object criteria as it still only allows further functionality from the smart phone.

\section{Sony (Lutero, 2016)}

SONY has created an AR system that brings the Alice in Wonderland book to life through an immersive interactive story book (Lutero, 2016) showcasing one way that AR technology is being implemented to extend storytelling. This demonstration uses object tracking and projection mapping to bring the book to life. The interaction occurs on a table under a projector that maps the objects placed under it with animations and interactive content. To interact with the story the user can place objects onto the table and the book begins to spills out onto the table (Lutero, 2016). 
